2019-06-25

\title{
Atomic spectrometry update: review of advances in elemental speciation
}

Clough, $\mathrm{R}$

http://hdl.handle.net/10026.1/14711

10.1039/c9ja90028d

Journal of Analytical Atomic Spectrometry

Royal Society of Chemistry

All content in PEARL is protected by copyright law. Author manuscripts are made available in accordance with publisher policies. Please cite only the published version using the details provided on the item record or document. In the absence of an open licence (e.g. Creative Commons), permissions for further reuse of content should be sought from the publisher or author. 
Atomic Spectrometry Update: review of advances in elemental speciation

Robert Clough, Chris F. Harrington, Steve J. Hill, Yolanda Madrid and Julian F. Tyson

Abstract

This is the $11^{\text {th }}$ Atomic Spectrometry Update (ASU) to focus on advances in elemental speciation and covers a period of approximately 12 months from December 2017. This ASU review deals with all aspects of the analytical atomic spectrometry speciation methods developed for: the determination of oxidation states; organometallic compounds; coordination compounds; metal and heteroatomcontaining biomolecules, including metalloproteins, proteins, peptides and amino acids; and the use of metal-tagging to facilitate detection via atomic spectrometry. The review does not cover fractionation, which is sometimes termed operationally defined speciation. As with all ASU reviews the focus of the research reviewed includes those methods that incorporate atomic spectrometry as the measurement technique. However, because speciation analysis is inherently focused on the relationship between the metal(loid) atom and the organic moiety it is bound to or incorporated within, atomic spectrometry alone cannot be the sole analytical approach of interest. Therefore, molecular detection techniques are also included where they have provided a complementary approach to speciation analysis. As in previous years, As speciation continues to dominate the current literature with a significant number of publications concerning $\mathrm{Hg}$ and Se speciation and 'biomolecules', in which category a number of papers covered in the Se section could also belong. The number of elements covered in these updates also continues to rise with the speciation analysis of over 20 elements reported this year.

\section{Contents}

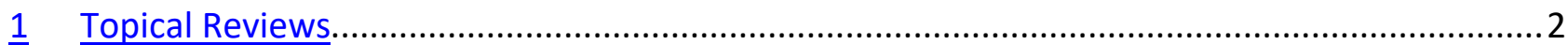

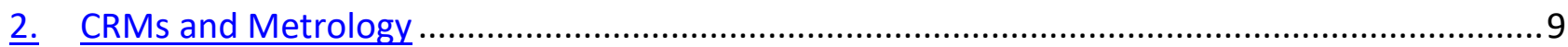

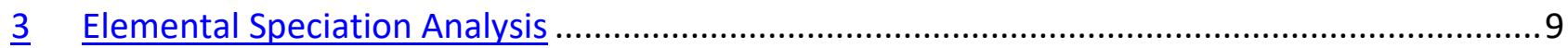

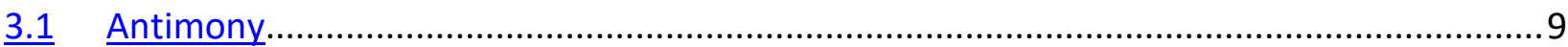

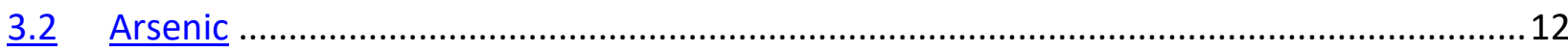

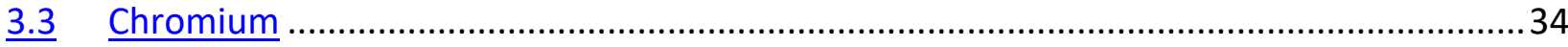

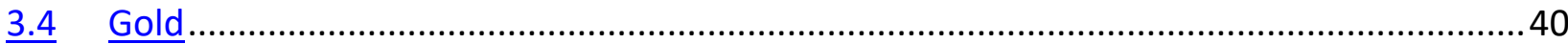

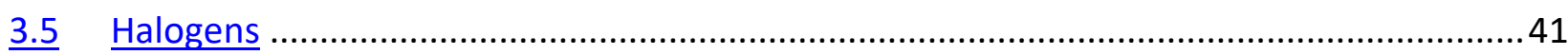

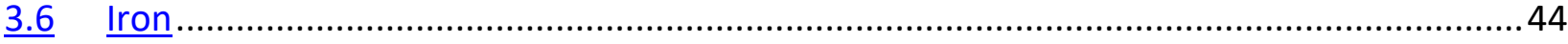

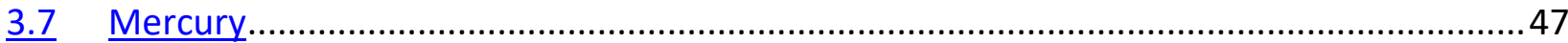

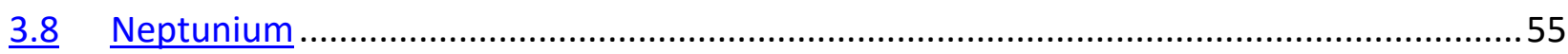

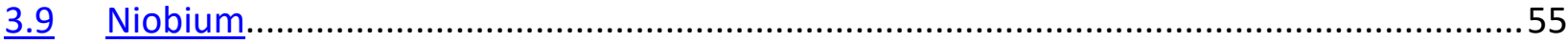

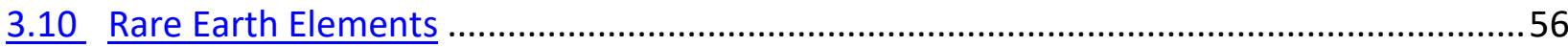

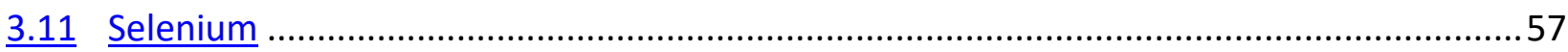

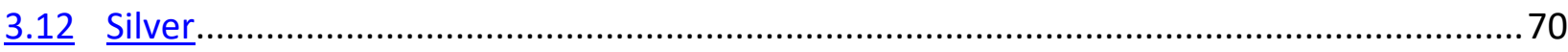

Page 1 of 96 


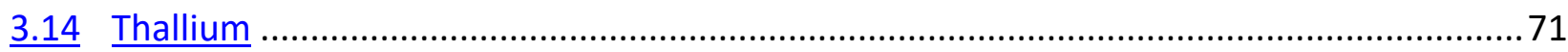

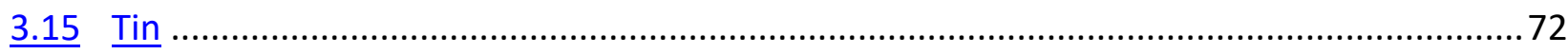

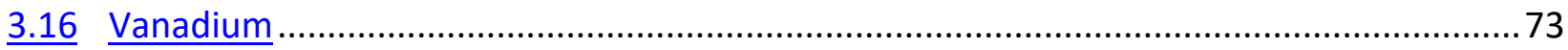

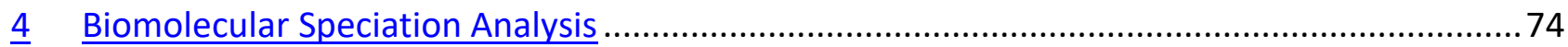

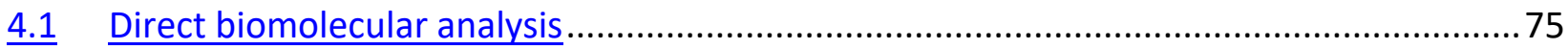

4.2 Tagging methods for macromolecular analysis .......................................................... 76

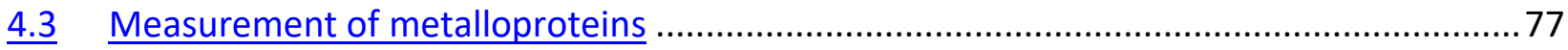

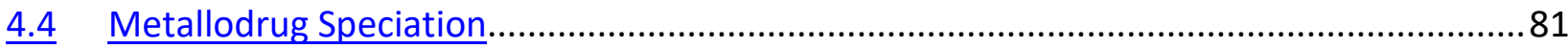

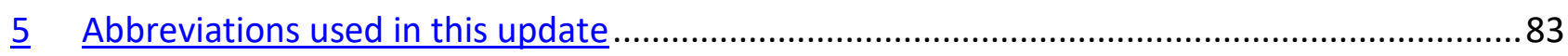

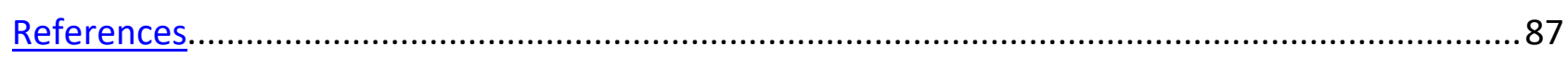

\section{$1 \quad$ Topical Reviews}

This latest update adds to that from last year ${ }^{1}$ and complements the five other annual Atomic Spectrometry Updates ${ }^{2,3,4,5,6}$. The interest highlighted in the 2018 elemental speciation ASU on the measurement of metal species in biological systems has continued with the publication of a book entitled 'Metallomics: The Science of Biometals,' volume 1055 in the series Advances in Experimental Medicine and Biology ${ }^{7}$. The book contains several chapters concerned with elemental speciation, as well a general survey of the field ${ }^{8}$ and reviews of topics that are not concerned with the analytical methodology, such as neurodegenerative and mental diseases ${ }^{9}$, or that do not involve elemental speciation by atomic spectrometry techniques, such as bioimaging ${ }^{10}$ and the application of nuclear techniques ${ }^{11}$. The remaining chapters are primarily concerned either with the provision of speciation information to support metallomic studies in particular areas or with analytical methods and instrumental techniques. In the former category are a chapter ${ }^{12}$ covering applications of chemical speciation to human health risk, food and human diet, drugs, forensics, nanoscience, and geological metallomics (188 references). Sample preparation and some strategies for maintaining the integrity of the metallomics information is also discussed. Another chapter ${ }^{13}$ (127 references) deals with plants exposed to $\mathrm{As}, \mathrm{Hg}, \mathrm{S}$ and $\mathrm{Se}$ in which the reviewers highlight the importance of S chemistry, as the three other elements interact with S-rich proteins during the processes of uptake, bio-accumulation and translocation. A comprehensive coverage of the entire process (soils to plant roots, to vacuoles, to shoots, leaves and grains) is given together with a 
description of methods based on HPLC coupled with both/either ICP-MS and ES-MS. A shorter chapter (38 references) deals with metallomics in fish ${ }^{14}$. In the category analytical methods is a broader view of environmental metallomics ${ }^{15}$ (118 references) that stresses the importance of analytical methods incorporating MS, such as elemental ICP-MS and molecular Q-TOF-MS, generally coupled with multidimensional chromatography, and LA-ICP-MS. Several examples of applications are discussed including a study of the exposure of mice to toxic metals, metal imaging, and metabolic alterations caused by the over-or down-expression of metallobiomolecules. The power of MS when combined with stable isotopic tracers ${ }^{16}$ is the subject of a further chapter (56 refs). The preparation of isotopically enriched metalloproteins and the determination of Se biological pathways utilising isotope dilution analysis are discussed to illustrate the application of the analytical methodology. In the final chapter, "new frontiers", the possibilities for the analysis of single cells are the main topic (76 references) ${ }^{17}$. The reviewers point out that single cells, which are the basic units of life, cannot be studied by classical bioanalytical methods because these only provide information that is averaged over a number of cells. They discuss a number of possible instrumental techniques including single-cell ICP-MS, mass cytometry, LA-ICP-MS, synchrotron XRF microscopy (SXRF), and nanoSIMS. The extremely low detection capabilities needed are still a considerable challenge.

Several reviews feature the central role of ICP-MS, particularly when combined with LC separations. Bishop et al. provide a tutorial introduction to and review of (90 references) recent developments for a range of chromatographic separation techniques with on-line elemental detection by ICP-MS for the speciation of metalloproteins, heteroatom-containing molecules and other compounds tagged with exogenous metals ${ }^{18}$. The reviewers discuss the challenges of sample preparation for situations in which the relevant metal-protein bonds are likely to be disrupted by the reagents employed, such as the SDS of gel electrophoresis, and point out that reagents and gels may contain high concentrations of metals that could substitute for the target element in a non-endogenous manner. The chronic problems of lack of suitable standards and CRMs are mentioned and the major limitation of reliance on retention-time matching for identification are discussed. They point out that in a complex biological system, with many analytes containing the same elements incorporated into proteins with distinct roles, the risk of mis-identification is high, and so molecular MS (running in parallel) is needed for positive protein identification. The reviewers consider that for metalloprotein concentrations to be used as clinical biomarkers, full method validation, including laboratory round-robin studies with CRMs, is needed. Advances in instrumentation are also 
highlighted, including nebulisers compatible with the low flow rates typical of many proteomic separations and the increased sensitivity that derives from better vacuum systems, mass analyser designs and improved detectors. It is predicted that ICP-QQQ-MS will emerge as a viable alternative for the determination of difficult analytes that previously required expensive HR-ICP-MS and that TOF instruments will be increasingly used. Klenscar et al. have reviewed (149 references) the quantitative metabolite profiling of non-metal drugs ${ }^{19}$, pointing out that only a very small fraction of pharmaceuticals feature a metal-containing API molecule. The first part of the review is a tutorial introduction to the interfacing of LC separations with plasma source MS which includes a detailed discussion of the problem of compound-dependent responses due to gradient elution. The second part of the review deals with the determination of APIs that contain an ICP-MS-quantifiable element, including (listed in order of occurrence) $\mathrm{S}, \mathrm{Cl}, \mathrm{F}, \mathrm{P}, \mathrm{Br}$ and I. This part contains a detailed discussion of the role of collision and reaction cells in overcoming various isobaric interferences and two useful summary tables. The third part of the review deals with possible derivatisation reactions that have been employed for the determination of drug molecules that do not contain an element quantifiable by ICP-MS. This section is further subdivided by functional group (hydroxyl, carboxyl, thiol, and amino). The reviewers note that the application of HPLC-ICP-MS is still far from routine in the pharmaceutical industry, which they consider to be due, in part, to the lack of quantification procedures that allows for validation in accordance with Good Manufacturing Practice. They conclude that further fundamental studies are needed as well as methods to further extend the applicability of the technique in pharmaceutical R\&D. They also consider that the introduction of tandem ICP-MS/MS has revolutionised the determination of the most important hetero-elements $(\mathrm{S}, \mathrm{Cl}, \mathrm{P})$ but that further work is needed, especially for the determination of $\mathrm{Cl}$. They also point to the considerable desirability of being able to quantify $F$ (which is one of the top 5 hetero-elements present in APIs), suggesting that negative ion monitoring or the use of helium plasmas be evaluated. The determination of $\mathrm{F}$ is also discussed by Feldmann et $\mathrm{al}^{20}$ in a tutorial review (49 references) of the 'future trends for targeted and non-targeted element speciation analysis.' They also point to the desirability of negative ion monitoring and reference their own work in which the species $\mathrm{BaF}^{+}$was generated and monitored. By 'targeted speciation analysis,' they mean the determination of one specific compound, such as inorganic arsenic in rice, an analytical challenge they consider will be increasingly met by simpler and cheaper procedures that do not involve ICP-MS, or even HPLC. By 'non-targeted speciation' they mean the determination of all forms of a particular element in a sample. The problems of compound-dependent responses are discussed and the value of ICP-MS in 
discovering previously unknown species is pointed out for the case of organothioarsenicals and new classes of arsenolipids. The reviewers consider that there is still considerable potential to be exploited for the determination of $\mathrm{Br}$ compounds in various samples of marine origin and of $\mathrm{Cl}$ compounds in biological and environmental samples. They conclude that in some areas, developments are driven not by need but by instrumental capabilities, citing as an example the fact that although numerous articles about arsenic speciation exist, they are still published on a weekly basis without driving the field of arsenic speciation forward. They consider that there is a real need to understand ligand-metal interactions, especially for essential elements for which method development is difficult because of the species are not stable outside of the cell. They note the considerable interest by environmental scientists in the development of non-targeted methods for fluorinated compounds.

Several reviews of the use of X-ray spectrometry for elemental speciation have appeared. Anagnostopoulos $^{21}$ draws on results obtained with high resolution XRF spectrometers (59 references) to show the possibilities of extracting information about chemical speciation from the $\mathrm{K}$ X-ray emission spectra of $\mathrm{Al}, \mathrm{C}, \mathrm{Cr}, \mathrm{Mn}, \mathrm{P}, \mathrm{Si}$ and Ti, obtained with a lab-based instrument. A twoway approach involved first selecting the appropriate transitions for the element that exhibit maximum sensitivity to the chemical environment, typically the transitions involving outer electrons that participate in chemical bonding. The second stage involved maximising energy resolution and ensuring adequate detection efficiency, by selecting suitable crystal analysers and beam optics. The author concludes that enhanced energy resolution, improved detection efficiency, and smaller beam spots could expand the capabilities of the lab-based X-ray emission spectrometry. Although increased resolution usually means decreased detection efficiency, advances in X-ray tube characteristics, crystal analysers and position-sensitive detectors may allow both experimental requirements to be achieved. As smaller X-ray beam spots can be obtained with either smaller slits or X-ray capillaries, irradiation with ionising micro-beams in conjunction with high resolution measurement could provide elemental and chemical spectroscopic analysis, combined with scanning microscopy, in laboratory scale instruments. Beccia et al. have reviewed (71 references) the application of SR-XAS techniques for speciation studies of the marine radiochemistry ${ }^{22}$ of the following elements: $\mathrm{Am}, \mathrm{Cs}, \mathrm{I}, \mathrm{Np}, \mathrm{Pu}$, and $\mathrm{U}$. The introduction is a highly readable account of the occurrence of these elements in the marine environment that includes a brief history of nuclear weapons testing. The reviewers also include a discussion of the role of thermodynamic models for predicting speciation but point out that seawater is a complex matrix of very high ionic strength, 
combined with high carbonate concentrations, high $\mathrm{pH}$ with particles, organic ligands and microorganisms. The reviewers conclude with a lengthy section highlighting further developments that are needed to deal with the very dilute samples that are typically encountered. They discuss developments such as increasing the photon flux (as high brilliance synchrotrons come on line), collection over a larger solid angle, using a crystal analyser spectrometer and freezing the sample, which although helping with sample stability was not thought to be a good idea, because of changes in speciation produced by the water-ice phase change. Finally, they suggest that the use of other detection systems, such as those making use of superconducting transition-edge sensors, could be beneficial. Developments in nuclear forensic analysis have also been reviewed ${ }^{23}$ with particular reference to the information available from scanning transmission X-ray microscopy measurements made at the Molecular Environmental Science Beamline 11.0.2 of the Advanced Light Source at Lawrence Berkeley National Laboratory. This technique has a spatial resolution of $25 \mathrm{~nm}$ or finer, which makes it possible to study microgram quantities, producing information that is complementary to that provided by techniques, such as the elemental distributions provided by SEM and energy dispersive X-ray spectroscopy EDS, and the isotopic information available from nano-SIMS. In addition, the soft X-rays access both the actinide $\mathrm{N}_{4,5}$-edges and the K-edges of light atoms, particularly $\mathrm{C}, \mathrm{N}, \mathrm{O}$, and $\mathrm{F}$, which are often more sensitive than the actinoid metal edges to variations in oxidation state and bonding. Results from several studies demonstrated the ability to identify the distribution of the species present in heterogeneous uranium-bearing materials. The authors conclude that additional scanning transmission X-ray microscopy studies are still needed, especially of heavier actinide elements.

Although the primary focus of a review of AFS (142 references) is the potential and progress towards miniaturised instrumentation, as showed particularly by researchers in China since 2000, a substantial number of the articles cited describe a speciation analysis ${ }^{24}$. In addition, much of the work cited involves methods in which HG is used as the sample introduction procedure, and so (as HG is inherently selective for certain species) all the methods could be considered as contributions to elemental speciation analysis. Much of the review is devoted to developments in different instrumental components (light source, atomiser, detector) as well as in methods of sample introduction, which in addition to vapour generation by chemical means, includes LA and ETV. The coupling of separation systems is also briefly reviewed, and the possibilities of CE are highlighted. In terms of miniaturisation and portable instrumentation, the reviewers concede that progress lags behind that of XRF spectrometry and of LIBS, though the appearance some commercial mercury 
analysers based on AFS is noted.

A review (71 references) of the applications of nanomaterials in the speciation analysis of $\mathrm{As}, \mathrm{Cr}, \mathrm{Hg}$, and $\mathrm{Se}^{25}$, although dated 2018, appears to cover much the same material as an earlier review ${ }^{26}$, highlighted in the 2017 Speciation ASU. The review contains no citations dated 2018 or 2017 and only 5 dated 2016 . However, the review contains a short section ( 8 references) on methods involving molecular spectrometric techniques that includes both fluorescence and surface enhanced Raman spectrometry for the determination of $\mathrm{As}, \mathrm{Cr}$ and $\mathrm{Hg}$ species. The reviewers conclude that more work is needed on the development of nanomaterial-based methods for the analysis of biological materials and of procedures capable of monitoring in vivo changes in chemical form.

In a broad ranging review (131 references) of the determination of $G d$-and Tc-based contrast agents in medicine and the environment, Clases et al. cover aspects of the synthesis and applications of these chemicals as well as the chemical measurement challenges ${ }^{27}$. Most of the analytical methods reviewed are for the total element, but there are a small number of speciation methods, mostly for Gd compounds, which are used in high doses (up to $50 \mathrm{mg}$ per $\mathrm{kg}$ of patient body weight). As the compounds excreted are eventually introduced into the water cycle, there is a considerable input to this from areas with high population densities and advanced medical facilities (estimated to be over $1000 \mathrm{~kg}$ per year in Germany). Many speciation methods are based on separation by HILIC with detection by ICP-MS. For Tc, the methods for environmental samples are mostly based on beta counting and ICP-MS, but in nuclear medicine, gamma-counting is most often used, though the reviewers suggest that HPLC-ICP-MS will play a role in the future, particularly if instruments featuring triple quadrupole or TOF analysers are available. Such instruments will also drive the development of improved procedures for Gd speciation, especially for applications in studies of the pathogenesis of conditions such a nephrogenic systemic fibrosis, a disease related to Gd deposition in renal dysfunction patients.

In a review (73 references) of recent (past 10 years) trends in the element speciation analysis of crude oils and heavy petroleum fractions, the focus is on the determination of $\mathrm{S}$ and of some firstrow transition elements, notable $\mathrm{Ni}$ and $\mathrm{V}^{28}$. The reviewers identify the key advances to be the optimisation of ICP-SF-MS for trace elements in organic matrices, and developments allowing the long-term continuous introduction of organic solvents without plasma perturbation. They also highlight the use of LA as a means of interfacing TLC separations with ICP-MS detection and the need, in many cases, for 2D chromatographic separations, such as SEC combined with normal-phase HPLC. About one-third of the review is devoted to speciation analysis by HR-FT-MS for which Page 7 of 96 
atmospheric pressure photoionisation was identified as a significant advance. To discriminate a metal-containing species ion, a resolving power above one million and a mass accuracy of $0.05 \mathrm{ppm}$ are needed. Currently these can only be obtained by an ICR instrument; however, the reviewers propose that the splitting of HPLC eluent between ICP-MS, to identify metal elution, and Orbitrap MS, to detect the molecular metal-containing isotopic pattern, may be applicable to speciation studies. They conclude that comparisons of both systems for the same samples are urgently needed. In a tutorial review (231 references) of analysis at the nanoscale by ICP-MS, the reviewers point out that metal-based NPs are analytes for which the quantitative information needed can be mass, molarity, or number concentration, and for which the qualitative information required could include both chemical information (composition of the core and coating) and physical information (size, shape and agglomeration state) ${ }^{29}$. When ions are released, various elemental species may be formed and speciation analysis is also needed. Following the introduction there is a section on sample preparation that is largely devoid of references to previous work, and then a long section entitled "stand alone ICP-MS" that cites some 30 previous publications and discusses the similarities between slurry sampling and NP sampling. Single-particle (sp) ICP-MS is the subject of an even longer section (over 50 references), and is recommended reading as an excellent starting point for anyone wishing to implement this mode of analysis. As the reviewers state, a feature of sp-ICP-MS is that any commercial instrument can be used, as no instrument modification is needed apart from the software for data evaluation although this can also be undertaken in a suitable spreadsheet. The final section is devoted to the combination of various separation techniques with ICP-MS, including field flow fractionation, hydrodynamic chromatography, HPLC and CE. This section also includes LA for the study of the distributions in the surface layers of a solid material. The sections include, where relevant, selected examples of applications of the various methods to NP use or exposure in consumer products, food, medicine and the environment. Quality assurance aspects are dealt with in the next section and the review concludes with a useful summary chart and some future perspectives. The reviewers consider that applications of stable isotopes will increase; they list some desirable future directions for instrument capabilities (greater transmission, for example), and finish with the universal request of all speciation analysts: more CRMs.

On the periphery of speciation as defined for this atomic spectrometry update are various imaging techniques that have the potential to provide spatially resolved speciation information. The authors of a review (100 references) of quantitative MS imaging of molecules in biological systems, consider this technique to be 'a rapidly growing field poised to transform MS imaging into an analytical 
technique that will enable accurate measurement of chemical gradients of hundreds of molecules in biological samples. ${ }^{30}$. The reviewers conclude that there is still some way to go in terms of the further development and validation needed to ensure accuracy, robust operation, and applicability to a broad range of compounds.

Reviews of the speciation analysis of individual elements are discussed in the relevant element subsections of Section 3.

\section{CRMs and Metrology}

A new CRM, IAEA-456 which is a marine sediment certified for trace elements and MeHg and available in $15 \mathrm{~g}$ lots, has been reported on this year ${ }^{31}$. The material was collected from the intertidal zone during low tide in Ducos beach (Noumea, New Caledonia). After drying, grinding and sieving to collect the $<125 \mu \mathrm{m}$ fraction the material was distributed to 17 laboratories of which nine reported values for the MeHg content. Acidic extraction with dichloromethane, followed by back extraction into an aqueous phase was the most commonly applied procedure, distillation was used by two laboratories whilst one laboratory used a UAE nitric acid leach. Aqueous phase ethylation of the extracted $\mathrm{MeHg}$ was used by eight laboratories with propylation being the other derivatisation method. In all cases GC was used to separate the derivatised $\mathrm{Hg}$ species and was coupled with either pyr-AFS or ICP-MS. Two laboratories used an IDA approach with conventional external calibration being used by the other participants. All of the methods used are referenced in the paper, which also covers the homogeneity and stability studies undertaken on the sediment. The certified mass fraction of $\mathrm{MeHg}$ is $0.125 \mu \mathrm{gg}^{-1}$ (as $\mathrm{Hg}$ ) which is $0.16 \%$ of the total $\mathrm{Hg}$ content. The mass fractions of $\mathrm{Al}, \mathrm{As}, \mathrm{Cd}, \mathrm{Co}, \mathrm{Cr}, \mathrm{Cu}, \mathrm{Fe}, \mathrm{Mn}, \mathrm{Ni}, \mathrm{Pb}, \mathrm{V}$ and $\mathrm{Zn}$ were also certified.

\section{Elemental Speciation Analysis}

\subsection{Antimony}

A useful overview of seven things to consider when determining Sb in environmental samples has been published by Maher et al. ${ }^{32}$. In terms of sample treatment, total $\mathrm{Sb}$ concentration measurements in waters require digestion with $\mathrm{HNO}_{3}-\mathrm{HCl}$ to release $\mathrm{Sb}$ from particulate material and may require a preconcentration step to remove Sb from saline matrices or to obtain the required sensitivity. Plant analyses require the use of $\mathrm{HNO}_{3}-\mathrm{HBF}_{4}$ or $\mathrm{HNO}_{3}-\mathrm{HF}$ while sediments require the use of $\mathrm{HNO}_{3}-\mathrm{HCl}$ to solubilise $\mathrm{Sb}$ and prevent adsorption to silicates. The choice of methods should also be fit for purpose and various options are discussed. Volatile Sb species can be Page 9 of 96 
measured successfully using SPME-GC-MS, waters via HG-ICP-MS and sediment extracts using HPLCICP-MS. Extraction of Sb from sediments and plants presents a challenge; however, the use of citrate is adequate for extraction of $\mathrm{Sb}$ from sediments predominately containing $\mathrm{Sb}$ associated with FeMn oxyhydroxide phases. The authors report that they have been unable to successfully quantify organic $\mathrm{Sb}$ species in plants because of the oxidation of $\mathrm{Sb}^{111}$ to $\mathrm{Sb}^{\vee}$ and the formation of artefact $\mathrm{Sb}$ species. For the analysis of solid samples, XAS should be considered as it has been shown to discriminate between $\mathrm{Sb}^{\mathrm{III}}$ and $\mathrm{Sb}^{\vee}$ as well as $\mathrm{Sb}$ minerals, oxides and adsorbed $\mathrm{Sb}$ species.

A method for Sb speciation by hydride trapping on nanoparticles packed in a needle trap device with ETAAS detection has been reported ${ }^{33}$. Oxidised multiwall carbon nanotubes were combined with $\mathrm{TiO}_{2}$ nanoparticles to obtain hybrid nanoparticles. A miniaturised $\mathrm{FI}$ system was used with a headspace vial for HG and the hybrid nanoparticles introduced into a needle trap device as a sorbent for Sb hydride preconcentration using gas phase trapping. The synergistic effect of hybrid nanoparticles improved $\mathrm{Sb}$ adsorption when compared to oxidised multiwall carbon nanotubes alone with quantitative preconcentration of the analyte in 1 minute. After optimisation using a BoxBehnken design, the optimal response was achieved using $0.5 \% \mathrm{NaBH}_{4}, 1.5 \mathrm{~mol} \mathrm{~L}^{-1} \mathrm{HCl}$ and a $40 \mu \mathrm{L}$ elution volume. A retention efficiency of $>99 \%$ was achieved with a preconcentration factor of 100 . The LOD and LOQ were 0.4 and $1.2 \mathrm{ng} \mathrm{L}^{-1}$ respectively with an RSD of 7.9\% $(n=10)$ with an analysis time of 14 minutes per sample. The technique was successfully applied to the analysis of river water samples and a total Sb CRM (QC Metal LL) with standard addition.

As in previous years, most terrestrial environmental studies involving Sb speciation have focused on specific geographical regions. Studies on the total levels and speciation of Sb in both waters (well, reservoir and wastewater) and sediments from the world's largest Sb mining area at Xikuangshan in China have been reported ${ }^{34}$. The study, which used HPLC-HG-AFS as the analytical technique, revealed $\mathrm{Sb}^{\mathrm{V}}$ as the predominant form with the geochemistry controlled by oxidation and adsorption/combination with environmental matrices, mainly $\mathrm{Fe} / \mathrm{Al}$ hydroxide. The study highlighted improvements in contamination levels in the area (previously up to $29.4 \mathrm{mg} \mathrm{L}^{-1}$ in water samples) following restoration measures and less mining/smelting activities, although tailings heaps remain a potential source of Sb. Antimony exposure threats to human health have also been reported from a study based on the Hunan region of China ${ }^{35}$. Elevated Sb concentrations exceeding reference levels, measured by HPLC-AFS, were detected in drinking water ( $70 \%$ of $n=83$ total samples), foods $(80 \%, n=188)$, urine $(95 \%, n=63)$, saliva $(44 \%, n=48)$, hair $(80 \%, n=51)$ and nails $(83 \%, \mathrm{n}=47)$. Drinking water contributed $85-100 \%$ of the average daily dose $\left(11.7 \mu \mathrm{g} \mathrm{kg}^{-1}\right.$ 
bodyweight day-1) at levels thirty times higher than the oral reference dose $\left(0.4 \mu \mathrm{gg}^{-1}\right.$ bodyweight day $^{-1}$ ) as recommended by USEPA. A positive correlation was found between the average daily dose and $\mathrm{Sb}$ content in hair $(p=0.02)$, but not in urine $(p=0.051)$, saliva $(p=0.52)$ or nails $(p=0.85)$, suggesting that hair is the best non-invasive biomarker. Analyses using $\mu \mathrm{XRF}$ indicated that $\mathrm{Sb}$ is distributed in discrete spots in hair and nails, and that the Sb distribution is correlated with other metals. Methylated Sb species were predominant in urine (46-100\%) and saliva (74-100\%) in collected samples, implying that the human metabolic system adopts methylation as an effective pathway to detoxify and excrete $\mathrm{Sb}$.

Although the toxicity of $\mathrm{Sb}$ to humans is well documented, the underlying mechanism of its accumulation in red blood cells is not so clear. Wu et al. ${ }^{36}$ have reported on the processes and mechanism of $\mathrm{Sb}$ sequestered by red blood cells and its metabolic conjugation with $\mathrm{Hb}$ in rats using a series of in vitro and in vivo studies. These include the binding affinity of Sb compounds with rat $\mathrm{Hb}$ and red blood cells, acute exposure of $\mathrm{Sb}$ potassium tartrate, and subchronic oral exposure of $\mathrm{Sb}$ potassium tartrate, potassium pyroantimonate and Sb trioxide. The Sb was determined by ICP-MS. The in vitro study indicated that the parent form of Sb exhibited notable affinity with red blood cells, while having negligible affinity with $\mathrm{Hb}$. However, after acute exposure to $\mathrm{Sb}$ potassium tartrate over $93 \%$ of $\mathrm{Sb}$ in rat blood was integrated into $\mathrm{Hb}$. The $\mathrm{Sb}$ retained in liver homogenate supernatants was substantially integrated into $\mathrm{Hb}$, which indicated liver metabolism played a potential role influencing its ultimate partitioning in blood. The subchronic exposure study also demonstrated that most of $\mathrm{Sb}$ metabolites were integrated into $\mathrm{Hb}$, regardless of which $\mathrm{Sb}$ compounds administered. Further nano-HPLC-MS-MS analysis suggested that a dimethylated Sb species in pentavalent state $\left[\mathrm{Sb}\left(\mathrm{CH}_{3}\right)_{2} \mathrm{O}_{2} \mathrm{H}\right]$ was a major $\mathrm{Sb}$ group, conjugated with $\mathrm{Hb}$ at $\mathrm{Cys} 104$ and Cys 111 especially, in a chain of rat $\mathrm{Hb}$ but this conjugation Hb's oxygen binding capability. As the deposit sites for both the parent forms and the metabolite, Sb re-released to circulation system due to red blood cells and $\mathrm{Hb}$ degradation could have high substantial toxicological effects on its potential sites of action.

In a more unusual application, XANES spectroscopy has been used to investigate Sb species in corroded bullet cases and soils in shooting fields of the North and East region of Cordoba, Argentina ${ }^{37}$. Samples consisted of dust taken from physically deformed and strongly corroded metallic bullets retained in soil samples. The results showed that the main species found in all samples were $\mathrm{Sb}^{\vee}, \mathrm{Sb}_{2} \mathrm{O}_{5}$, and metallic $\mathrm{Sb}, \mathrm{Sb}^{\prime \prime \prime}$ was not observed. Table 1 shows other applications of $\mathrm{Sb}$ speciation presented in the literature during the time period covered by this ASU. 


\subsection{Arsenic}

This year, several reviews on As speciation have been published. The analytical methodologies for As speciation in macroalgae have been the subject of a critical review by Reis and Duarte ${ }^{38}$. The review considered analytical methodologies, including ICP-MS, FI-HG-AAS, HG-AFS and some less common techniques such as CE-ES-TOF-MS. The review also considers sampling, sample extraction and sample processing and discusses relevant speciation studies performed by various authors since 2007, highlighting the methodologies and respective figures of merit for determining all As species in macroalgae. The need to develop appropriate CRMs in order to assist in the validation of analytical methodologies for As speciation in macroalgae is also covered. Recent trends in microextraction techniques used in the determination of As species have also been reviewed ${ }^{39}$. Modern analytical procedures mainly include usage of microextraction techniques which tend to reduce solvent consumption, e.g. LPME, or employ solvent free methods, e.g. SPME. Both these areas are reviewed together with a limited number of papers were devoted to the use of deep eutectic solvents or surfactants. Other reviews have been more focused in terms of application. The occurrence and remediation of aromatic organoarsenic compounds, which are common feed additives in the poultry industry, has received attention once again ${ }^{40}$. The authors also identified knowledge gaps and research needs, including the elucidation of the environmental fate of aromatic organoarsenic compounds, metabolic pathways, the impact of metabolic modification on toxicity, and advanced analytical methods that allows for monitoring, identification or removal of the degradation products. Recent analytical advances in the speciation of phenyl arsenicals have also been reviewed by Liu et al. ${ }^{41}$. The authors cover instrumentation, the characterisation of phenylarsenical metabolites to better understand the fate of phenylarsenicals and the potential risk of human exposure, and the binding of trivalent phenylarsenicals to proteins facilitated by the development of analytical techniques for the capture and identification of As-binding proteins. Thiolated As compounds where the sulphur analogous substructures of oxo- As species as the $\operatorname{arsinoyl}(A s=0)$ is substituted by an arsinothioyl $(A s=S)$ group have been reviewed by Herath et al. ${ }^{42}$. This review attempts to provide a critical overview of the formation mechanisms of thioarsenicals, their chemistry, speciation and analytical methodologies in order to provide a rational assessment of what is new, what is current, what needs to be considered in future research. Thioarsenic compounds play a vital role in determining the biogeochemistry of As in sulfidic environments under reducing conditions and they are widely immobilised by naturally occurring processes such as the adsorption on Fe oxyhydroxides and precipitation on Fe sulfide minerals. Accurate measurement of 
thioarsenic species is a challenging task due to their instability with respect to $\mathrm{pH}$, temperature, redox potential, and concentrations of $\mathrm{Fe}, \mathrm{O}_{2}$ and $\mathrm{S}$. Dimethylmonothioarsinic acid is the most cytotoxic As metabolite having similar toxicological effects as DMA in human and animal tissues. The formation and chemical analysis of thioarsenicals in soil and sediments is still largely unknown. The synthesis of standards for As speciation studies is not often addressed. Dimethylated thioarsenicals such as DMMTA ${ }^{\vee}$ and DMDTA ${ }^{\vee}$, which are produced by the metabolic pathway of $\mathrm{DMA}^{\vee}$ thiolation, have been synthesised by Lee et $a{ }^{43}$. The paper discusses the synthesis, purification, and confirmation of the compounds and also considers the preparation of chemical reagents, filtration methods, and storage. A novel approach has also been developed for quantitatively converting alkylated As to As acid $\left(\mathrm{H}_{3} \mathrm{AsO}_{4}\right)^{44}$. The approach was used in the development of a new series of organic As reference materials, NIST SRMs 3030, 3031, 3033 and 3034, for MMA, DMA, AB and AC, respectively, at NIST. To assess the effectiveness of the conversion TMAO was used as a model alkylated As compound due to its structural stability and difficulty to convert to As acid. The only reagent capable of quantitative conversion of the alkylated As compound to $\mathrm{As}^{\mathrm{V}}$, using microwave assistance, was $\mathrm{HCl}$. The minimum concentration of $\mathrm{HCl}$ required for quantitative conversion under the experimental conditions used was $4.4 \mathrm{~mol} \mathrm{~L}^{-1}$, which was 3 $\mathrm{mL}$ of concentrated $\mathrm{HCl}$ in $8 \mathrm{~mL}$ of solution. This is the first report of $\mathrm{HCl}$ affecting the quantitative conversion of alkylated As to As acid. After converting to As acid, the mass fraction of As in the alkylated $A s^{\vee}$ compounds was quantified using ICP-OES with an expanded uncertainty $\leq 2.4 \%$. These ICP-OES results were in good agreement with INAA, a technique that is not susceptible to interferences from elemental speciation.

There are been several reports of new or modified techniques for As speciation. Nanolitre flow rate HPLC offers low of solvent and sample consumption, and, when coupled to ICP-MS, offers a good choice for As speciation when sample volume is limited. A systematic investigation on coupling nanolitre HPLC to ICP-MS has been reported by Cheng et al. ${ }^{45}$. The mobile phase was delivered by flow splitting using a conventional high-pressure pump with reuse of mobile phase not sent to the column. The dead volume was minimised to $60 \mathrm{~nL}$ for a sheath less interface based on a previously developed nano-nebuliser. Capillary columns for HPLC were found to be sensitive to sample loading volume and a difference found in the optimal mobile phases for $\mathrm{nL}$ and conventional HPLC. Baseline separation of $A s^{\prime \prime \prime}, A s^{\vee}, D M A$ and MMA was achieved within 11 min on a $15 \mathrm{~cm} \mathrm{C} \mathrm{C}_{18}$ capillary column and within $12 \mathrm{~min}$ on a $25 \mathrm{~cm}$ strong anion exchange column. The LOD values obtained were 0.9$1.8 \mu \mathrm{g} \mathrm{L}^{-1}$ with precision variable in the range of $1.6-4.2 \%$. A good agreement between determined 
and certified values of a CRM, human urine (GBW 09115) validated method accuracy with recoveries of $87-102 \%$. A sp-ICP-MS method has been utilised for analysis of the physical forms of As in cigarette smoke condensates ${ }^{46}$, although no particulate As was observed. Solvent extraction experiments followed by HPLC-ICP-MS showed that water-soluble As species predominated, with $A s^{\prime \prime \prime}, A s^{v}, D M A$ and MMA being detected. There were large differences in levels of As between the commercial brands used in the study, although $\mathrm{As}^{\vee}$ was the main species in all cases. Alternative methods to HPLC-ICP-MS for As speciation have been evaluated by Gilmartin and Gingrich ${ }^{47}$. The publication considered the determination of $A s^{\prime \prime \prime}$ and $A s^{V}$ in ground water utilising LC instrumentation to speciate and determine the iAs compounds using UV or MS via selected ion recording or multiple reaction detection. The LOQ values for the techniques described were $454 \mu \mathrm{g}$ $\mathrm{L}^{-1}\left(A s^{\prime \prime \prime}\right)$ and $562 \mu \mathrm{g} \mathrm{L}^{-1}\left(A s^{\vee}\right)$ for UV detection, $45.4 \mu \mathrm{g} \mathrm{L}^{-1}\left(A s^{\prime \prime \prime}\right)$ and $56.2 \mu \mathrm{g} \mathrm{L}^{-1}\left(A s^{\vee}\right)$ for selected ion recording detection, and $4.54 \mu \mathrm{g} \mathrm{L}^{-1}\left(\mathrm{As}^{\prime \prime \prime}\right)$ and $5.62 \mu \mathrm{g} \mathrm{L}^{-1}\left(\mathrm{As}^{\mathrm{V}}\right)$ for multiple reaction detection. An alternative approach for As speciation has been described by Pena-Pereira et al. ${ }^{48}$ who developed a method utilising an in situ arsine generator to transfer volatile As species into a headspace device where it reacts with silver nitrate on what the authors call a 'paper-based analytical device'. The chemical reaction between the detection area and the analyte derivative results in the formation of a coloured product which can be detected by scanning the detection zone. Data treatment follows using an image processing and analysis program. The detection and injection zones were defined on the paper substrate by formation of hydrophobic barriers, thus enabling the formation of the volatile derivative without affecting the chemical stability of the device. The experimental parameters influencing the analytical performance, i.e. colour mode detection, composition of the paper-based sensor, HG and mass transfer conditions, were also evaluated. Under optimal conditions, the proposed method offered a LOD and LOQ 1.1 and $3.6 \mathrm{ng} \mathrm{mL}^{-1}$, respectively. Thus, the LOD of the method was much lower than the maximum contaminant levels set by both the WHO and the US EPA for As in drinking water, which is better than some commercially available As test kits. The RSD was 7.1\% ( $n=8)$. The method was validated against the CRM ERM (R)-CA615 groundwater and successfully applied to the determination of $A s^{\prime \prime \prime}, \mathrm{As}^{\mathrm{V}}$ and total iAs in a number of water samples. The feasibility of HG from arsenosugars (dimethylarsinoylribosides) in batch and flow injection modes has been studied by Marschner et al. ${ }^{49}$. The efficiency of HG was greater in a $\mathrm{H}_{2} \mathrm{SO}_{4}$ medium than in $\mathrm{HCl}$, and greater in batch mode than in the $\mathrm{FI}$ mode. To increase the efficiency in the $\mathrm{FI}$ mode a new generator with two inlets of $\mathrm{NaBH}_{4}$ solution was designed and this was interfaced between an HPLC column and an AFS detector. The arsenosugars studied yielded HG 
efficiencies in the range $13-30 \%$ most probably due to a complicated mechanism of HG. While the mechanism included a formation of two structures of the analyte-borane-complexes, only one of them can lead to a formation of volatile arsanes (dimethylarsane, methylarsane, and arsane were identified). The use of a functionalised miniaturised membrane for ultratrace iAs speciation has been reported by Lukojko et al. ${ }^{50}$. The membranes, $5 \mathrm{~mm}$ diameter and $4.4 \mathrm{mg}$ weight, were prepared by the synthesis of an amorphous silica coating on cellulose fibres followed by modification with (3mercaptopropyl)-trimethoxysilane. Batch adsorption experiments showed that membranes were highly selective toward As ${ }^{\prime \prime \prime}$ in the presence of heavy metals and anions that usually exist in natural water. The As ${ }^{\prime \prime \prime}$ could be quantitatively adsorbed at $\mathrm{pH} 1$ from $50 \mathrm{~mL}$ of sample within 60 min using the membrane with maximum adsorption capacity of $60 \mathrm{mg} \mathrm{g}^{-1}$. After adsorption, the As ${ }^{\text {III }}$ retained onto the membrane was directly measured by EDXRF, avoiding an elution step. An enrichment factor of 972 was achieved with a LOD of $0.045 \mathrm{ng} \mathrm{mL}^{-1}$. The incorporation of active nanomaterials into printing resins used with a stereolithographic 3D printer has been employed to fabricate a demountable mini-column for the selective extraction of iAs and Se species from high-salt-content samples ${ }^{51}$. Titanium dioxide nanoparticles were used with detection by ICP-MS. After optimisation, the automated system offered LOD values of 0.004-0.033 $\mu \mathrm{g} \mathrm{L}^{-1}$ for As and 0.061-0.128 $\mu \mathrm{g} \mathrm{L} \mathrm{L}^{-1}$ for Se. The reliability was confirmed through analyses of the NIST SRM $1643 f$ (fresh water), NRCC SLEW-3 (estuarine water), CASS-4 (near shore water), and NIST 2670a (human urine), as well as spike analyses of samples of collected water samples and human urine.

Several authors have addressed potential errors in the measurement of As species. The accuracy of determining total As using ICP-MS and As speciation by AEC-ICP-MS has been increased by using Se as an internal standard ${ }^{52}$. For AEC, Se was used in the form of a trimethylselenonium cation, which did not interact with the stationary phase and could be added directly to the mobile phase as the selenite. Selenium was able to correct non-spectral interferences, caused by carbon or sodium build up on the sampler and skimmer cones, up to concentrations of $3000 \mathrm{mg} \mathrm{L}^{-1} \mathrm{C}$ and $35 \mathrm{mg} \mathrm{L}^{-1} \mathrm{Na}$, respectively, in the case of total As determination, and up to $3000 \mathrm{mg} \mathrm{L}^{-1} \mathrm{C}_{\text {and }} 3450 \mathrm{mg} \mathrm{L}^{-1} \mathrm{Na}$ in the case of speciation analysis. The use of Se as an internal standard was tested for the analysis of $A B$ in the CRM DORM-2 (NRCC, dogfish muscle). The results were in good accordance with certified values regardless of $\mathrm{NaCl}$ spikes. In addition, the results of total As determination in canned fish using a Se internal standard were not affected by residual $\mathrm{C}$ in an imperfectly decomposed sample. The potential for As speciation changes in methanol-water solvent mixtures have been investigated ${ }^{53}$. Optimised conditions using a mobile phase of $30 \mathrm{mmol} \mathrm{L}^{-1}\left(\mathrm{NH}_{4}\right)_{2} \mathrm{CO}_{3}$ at a pH of 9.3 
were used for the AEC-ICP-MS determination of $A B, A C, A s^{\prime \prime \prime}, A s^{V}, D M A$ and MMA. The results indicated that the peak area measured for As"II and DMA increased significantly with increasing methanol contents, indicating a compound dependent response. Further tests with a $25 \%$ methanol solvent mixture showed a minimal effect on the As speciation.

Arsenic speciation has been applied to some less usual sample types this year. Methylated As species have been determined in a 4-m deep core from a free-floating peat island ${ }^{54}$. A total of 57 peat samples were collected and analysed for total As and AB, DMA, MMA and TMAO by HPLC-ICP-MS. Aqueous trifluoroacetic acid was used as extractant, resulting in an average extraction efficiency of almost $80 \%$. The total As concentration throughout the profile ranged between 0.2 and $9.8 \mathrm{mg} \mathrm{kg}^{-}$ 1. Organic As species (DMA + MMA + TMAO + AB) accounted, on average, for $28 \pm 10 \%$ of the total As (range: $6-51 \%$ ), and for $37 \pm 13 \%$ of the extracted As (range: 7-64\%). The relative abundance of organoarsenicals generally followed the order DMA > TMAO similar to MMA > AB. A positive correlation ( $p<0.001$ ) was found among all organic As compounds, whereas their concentrations were negatively correlated with total sulphur content. The submerged zone (bottom $300 \mathrm{~cm}$ ) showed average and maximum concentrations of organoarsenic compounds that were almost twice those found in the top $100 \mathrm{~cm}$. This study demonstrated that significant proportions of methylated As species occur even in peat samples characterised by low total As. A comparison of As speciation in freshwater and saltwater samples (water, suspended particles, zooplankton, sediments, and porewater) from the from the Youngsan River Estuary in Korea has been reported ${ }^{55}$. Six As species, $A s^{\prime \prime \prime}, A s^{\vee}, M M A, D M A, A B$, and AC, were separated and measured using HPLC-ICP-MS equipped with an anion exchange column. Samples were sonicated for $30 \mathrm{~min}$ and then placed on a mechanical water bath shaker for $4 \mathrm{~h}\left(60^{\circ} \mathrm{C}, 120 \mathrm{rpm}\right)$, centrifuged for $15 \mathrm{~min}$ at $3000 \mathrm{rpm}$ and the supernatants finally filtered through $0.22-\mathrm{mm}$ syringe filters and stored frozen. Concentrations of As in water samples of the inner region (mean $=1.5 \mu \mathrm{g} \mathrm{As} \mathrm{L}^{-1}$ ) were significantly lower than in those of the outer

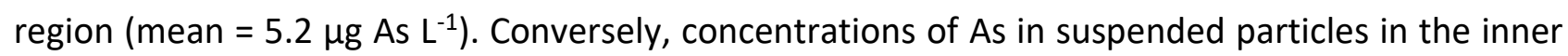

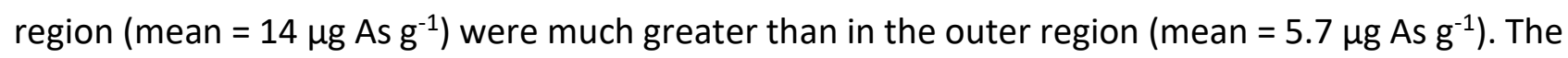
field-based distribution coefficient $\left(K_{d}\right)$ for As depended strongly on salinity; relatively larger $K_{d}$ values were found for freshwater compared with saltwater. The major form of As in all water and particle samples in both inner and outer regions was found to be $A s^{\vee}$. The As concentrations in zooplankton were shown to be particle-concentration dependent, suggesting that dietary exposure plays a substantial role in the bioaccumulation of As. The $A s^{\vee}$ and $A s^{\prime \prime \prime}$ species were the most dominant forms found in zooplankton. Partitioning behaviour of As between porewater and 
sediments was similar to that in water particle distributions. A method based on ion-pair RP-ICP-MS has been developed for As speciation in extracts from tree moss ${ }^{56}$. Using optimised conditions, six known As species were identified ( $A s^{\prime \prime \prime}, A s^{V}, D M A, T M A O, T M A$ and $A B$ ) with detection limits in the range $0.04-0.07 \mathrm{ng} \mathrm{mL}^{-1}$. Three unknown As species were also recorded, one of which was a kind of arsenosugar (2,3-dihydroxypropyl-5-deoxy-5(dimethylarsenoso)furanoside, as identified by ESqTOF-MS. Silver nanoparticles (AgNPs) are being widely used in drinking water disinfection due to their excellent bactericidal performance. Guo et $a l .{ }^{57}$ have used HPLC-ICP-MS to investigate the effects of environmental parameters such as $\mathrm{pH}$, natural organic matter, cation ions (e.g., $\mathrm{Ca}^{2+}$ ), and the intrinsic properties of the silver nanoparticles such as size and coatings, on the conversion of $A s^{I I I}$ and $A s^{V}$ in aqueous solution. It was found that the silver nanoparticles showed no physical adsorption of $A s^{\prime \prime \prime}$, whilst significant catalytic oxidation of $\mathrm{As}^{\mathrm{III}}$ into $\mathrm{As}^{\mathrm{V}}$ occurred. Most of the

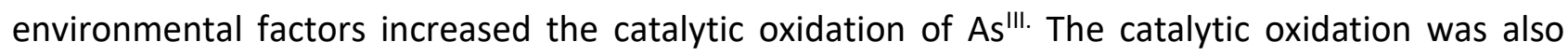
confirmed in environmental waters. The authors conclude that silver nanoparticles could play a dual function in both sterilisation and detoxification of $A s^{\prime \prime \prime}$, which offers a novel way to effectively treat As contamination.

Studies on As in contaminated soils and flora and fauna at mine sites remain popular. The As characteristics in the terrestrial environment in the vicinity of a former As mine at Shimen in China has been reported ${ }^{58}$. Multiple sample types, including soils, plants, litter and soil invertebrates were collected. The total As concentrations in the soils, earthworms, litter and the above ground portions of grass from the contaminated area followed the decreasing order of 83-2224 mg kg-1, 31-430 mg $\mathrm{kg}^{-1}, 1-62 \mathrm{mg} \mathrm{kg}^{-1}$ and 2-23 $\mathrm{mg} \mathrm{kg}^{-1}$, respectively. Analysis by XANES revealed that the predominant form of As in the soils was $A s^{\vee}$, while no $A s^{\prime \prime \prime}$ was detected. In the grass and litter of the native plant community, $A s^{\prime \prime \prime}$ and $A s^{\vee}$ were the main species, while minor amounts of DMA, MMA, AC, and an unknown As species were also detected using HPLC-ICP-MS. The As speciation and As concentrations varied with the plant species, and very high As levels (197-584 mg kg-1) and proportions of inorganic As (>99\%) were found in two As-hyperaccumulating ferns, Pteris vittata and Pteris cretica. The major As species extracted from earthworms were inorganic, with proportions of $51-53 \% \mathrm{As}^{\prime \prime \prime}$ and $38-48 \% \mathrm{As}^{\mathrm{V}}$. The only organic species present in the earthworm samples was $A B$, although at low proportions ( $<9 \%)$. The internal bioconversion of other As species was hypothesised to contribute greatly to the formation and accumulation of $A B$ in earthworms, although the direct external absorption of organic As from soils might be another potential source. Arsenic concentrations and distributions in contaminated soils and mine tailings have been studied 
by combining X-ray-based techniques (WDXRF, $\mu X R F$, and XRD), field emission SEM, and a sequential extraction procedure coupled to TXRF analysis ${ }^{59}$. Samples were collected from the Crocette gold mine in the Monte Rosa mining district, Piedmont, Italy. The As concentration, measured with WDXRF, ranged from 145 to $40,200 \mathrm{mg} \mathrm{kg}^{-1}$. Analysis by XRD showed the presence of jarosite and the absence of any As-bearing mineral, suggesting a high weathering grade and strong oxidative conditions. However, small domains of Fe arsenate were identified by combining $\mu$ XRF with field emission SEM-EDX. Sequential extraction results revealed that As was mainly associated to amorphous Fe oxides/hydroxides or hydroxysulfates (50-80\%) and the combination of XRD and field emission SEM-EDX suggested that this phase could be attributed to schwertmannite. On the basis of the results, the authors suggest that the As is scarcely mobile, even if a consistent As fraction (1$3 \mathrm{~g} \mathrm{As} \mathrm{kg}^{-1}$ of soil) is still potentially mobilised. The As distribution and speciation in the bauxitic Fe$\mathrm{Ni}$-laterite ore deposit of the Patitira mine, in Greece which contains assemblages of unusual Asbearing goethite-type phases in samples with significant organic matter, has been reported ${ }^{60}$. The bulk material was initially characterised by ICP-MS and SEM-EDS, and then the distribution and speciation of As studied using SR techniques. The SR $\mu$ XRF elemental maps and the As K-edge $\mu$ XAFS spectra revealed that $\mathrm{As}$ is exclusively correlated to $\mathrm{Fe}$, occurring as $\mathrm{As}^{\mathrm{V}}$ in the form $\mathrm{AsO}_{4}{ }^{3-}$. However, the $A s^{\vee}$ anions, considered as sorbed species on goethite-type phases, exhibit a molecular scale disordered structural environment, resembling locally to the configuration of such anions in natural hydrated $\mathrm{Ni}$ arsenates (annabergite) rather than to natural hydrated ferric arsenates (scorodite). The local environment of As in sulphide minerals has also been studied ${ }^{61}$. The As-Fe-S system presents various oxidation states and local structures which were studied using resonant inelastic X-ray scattering (RIXS), high-energy fluorescence detection (HERFD-XANES), and first-principles Xray absorption near-edge structure (XANES) calculations, highlighting the interest of going beyond the usual fingerprint analysis of standard experimental XANES spectra. The position of maximum fluorescence on the RIXS plane provided a fingerprint of the As local environment. Spectra from HERFD-XANES were found to significantly improve the spectral resolution and to reduce the signal background at the As K-edge, but have to be interpreted carefully as they present different shifts in energy compared to their standard XANES counterparts. First-principles As K-edge XANES calculations were performed for reference compounds with As oxidation states ranging from -I to +III (arsenopyrite (FeAsS), lollingite (FeAs2), realgar (AsS) and orpiment (As2S3)). Comparison with experimental spectra showed that the oxidation state of As could be retrieved from the position of the inflection point of the edge. Calculations from the XANES spectra were also carried out for As 
incorporated as an impurity in pyrite either at the $\mathrm{S}$ tetrahedral or Fe octahedral sites, allowing the authors to draw conclusions on the oxidation state of As in this mineral. Sulfur isotope analysis by IC-MC-ICP-MS has also provided insight into the fractionation of thioarsenates during abiotic oxidation ${ }^{62}$. Standard precipitation procedures for separation of sulfide and sulfate were applied to monothioarsenate solutions. The monothioarsenate was found to co-precipitate together with sulfide thus potentially impeding correct sulfide isotope analysis. To overcome the limitations associated with this procedure, a method was developed based on separating sulfur species by ICMC-ICP-MS. Fractionation between monothioarsenate and sulfate of up to - 6.1 was found during monothioarsenate oxidation. In contrast oxidation of tetrathioarsenate via tri- and di- to monothioarsenate did not result in fractionation. However, the released sulfide became increasingly enriched in $\mathrm{S}^{34}$ due to oxidation to sulfate. The process was found to introduce an additional enrichment, of up to 9.1, to monothioarsenate through intermolecular isotope exchange between As-bound sulfur and sulfide in solution. The results provide information for the interpretation of isotope fractionation patterns in sulfidic environments.

Continuing on the topic of mine sites Coal and ash samples (bottom ash and electrostatic precipitator ash) in four particle size ranges from $\mathrm{PM}<1-\mathrm{PM}>10$ have been used to study the distribution and speciation of As in the coal ${ }^{63}$. Two species, As ${ }^{\prime \prime \prime}$ and $A s^{\vee}$, were determined by HPLC-ICP-MS and the morphological structure and chemical components of the surface characterised SEM and XRF respectively. The results revealed that the coal used in the study was low-sulfur and low chlorine bituminous coal with $3.85 \mathrm{mg} \mathrm{kg}^{-1}$ As. Arsenic is prone to enrich in electrostatic precipitator ash and dissipate in bottom ash. The total As content in the electrostatic precipitator ash was 11 times of that in the bottom ash $\left(1.637 \mathrm{mg} \mathrm{kg}^{-1}\right)$. When the fly ash particle diameter decreased, the concentration of total As increased from $9.6 \mathrm{mg} \mathrm{kg}^{-1}$ to $20 \mathrm{mg} \mathrm{kg}^{-1}$, and the corresponding relative enrichment index increases from 0.68 to 1.42 . The main As specie in coal-fired fly ash is $A s^{\vee}$, which was $90-98 \%$ of the total As. The As concentrations and speciation in wild birds on an abandoned As mine in China has been studied by Yang et al. ${ }^{64}$. In the study, four passerine bird species (tree sparrow, Passer montanus, light-vented bulbul Pycnonotus sinensis, Garrulax canorus, Leucodioptron canorus, and magpie Pica pica, were collected. The highest recorded As concentrations were $4.95 \mathrm{mg} \mathrm{kg}^{-1}$ and $51.7 \mathrm{mg} \mathrm{kg}^{-1}$ in muscles and feathers, respectively. Detection by HPLC-ICP-MS revealed six As species, $A s^{\prime \prime \prime}, A s^{v}, D M A, M M A, A B$ and $A C$, with the former three species as the dominant (>92\%) As species. Further analysis of the bird samples using XANES revealed the existence of As ${ }^{\prime \prime \prime}$-tris-glutathione ( $\left.A s^{\prime \prime \prime}-\mathrm{GSH}\right)$. which can be regarded as equivalent to 
the non-extractable and unidentified As form in the HPLC-ICP-MS data. Both methods revealed similar patterns of As species in the birds from the As mine, with muscles containing mainly iAs and DMA and feathers containing mainly iAs.

Following the trend in previous years, food remains a popular matrix for As speciation studies and As in rice and rice products has again received considerable attention. With the establishment by CODEX of a $200 \mathrm{ng} \mathrm{g}^{-1}$ limit of iAs in polished rice grain, more analyses of iAs will be necessary to ensure compliance in regulatory and trade applications, to assess quality control in commercial rice production, and to conduct research involving iAs in rice crops. Although analytical methods using HPLC-ICP-MS have been demonstrated for full speciation of As, this relatively expensive and timeconsuming approach may be considered excessive when regulations are based only on iAs. Chaney et $a l .{ }^{65}$ have addressed this issue and reported on an inter-laboratory validation of a streamlined method to measure iAs in powdered rice grain. The method is based on a heated extraction with $0.28 \mathrm{~mol} \mathrm{~L}^{-1} \mathrm{HNO}_{3}$ followed by $\mathrm{HG}$ under control of acidity and other simple conditions. Analysis of iAs is then conducted using FI-HG and ICP-OES or other suitable detectors. A key innovation compared with previous methods was to increase the acidity of the reagent solution with $4 \mathrm{~mol} \mathrm{~L}^{-1}$ $\mathrm{HCl}$ (prior to reduction of $A s^{\mathrm{V}}$ to $\left.A s^{\prime \prime \prime}\right)$, which minimised interferences from DMA. An inter-laboratory method validation was conducted among 12 laboratories worldwide based on the analysis of six shared blind duplicates and a NIST SRM involving different types of rice and iAs levels. Also, four laboratories used the standard HPLC-ICP-MS method to analyse the samples. The results between the methods were not significantly different, and the Horwitz ratio averaged 0.52 for the new method, which met official method validation criteria. A non-chromatographic method for speciation analysis of four target As species in rice samples has been presented ${ }^{66}$. The HG conditions and sample pre-treatment were optimised for the determination of $A s^{\prime \prime \prime}, A s^{\vee}, M_{M} A^{\vee}$ and $D M A^{\vee}$. For optimum results, $\mathrm{HCl} /$ sodium citrate buffer (1.6 mol L-1 sodium citrate; $\mathrm{pH} \mathrm{4.8)}$ was used for the carrier solution and $0.06 \mathrm{~mol} \mathrm{~L}^{-1}$ citric acid for sample acidification. The concentrations of the four As species were determined by HG-AFS using a series of linear independent equations corresponding to four different sample pre-treatment procedures. The LOD values for the method were $0.21,0.52,0.65$ and $0.9 \mu \mathrm{kg}^{-1}$ for $\mathrm{As}^{\prime \prime \prime}, \mathrm{As}^{\vee}, \mathrm{MMA}^{\vee}$ and $\mathrm{DMA}^{\vee}$ respectively. Extraction efficiencies (96-104\%) and recoveries of As species in rice (95-100\%) were good. Interconversion among the four As species in the extract did not occur. The accumulation of As in rice grains depends greatly on the redox chemistry in the rice rhizosphere such that any intentional or accidental introduction of strong oxidising or reducing agents, such as metallic engineered nanoparticles into 
the plant soil ecosystem, can change As speciation and plant uptake. Wang et al. ${ }^{67}$ have investigated the mutual effects of two, $\mathrm{CeO}_{2}$ and $\mathrm{ZnO}$, commonly encountered metallic engineered nanoparticles and two iAs species on their uptake and accumulation in rice seedlings in a hydroponic system. The size and shape of these two nanoparticles were determined by TEM and the As species determined by IC-ICP-MS. Rice seedlings were exposed to different combinations of $1 \mathrm{mg} \mathrm{L}^{-1}$ of $A s^{\prime \prime \prime}$ or $A s^{\vee}$ and $100 \mathrm{mg} \mathrm{L}^{-1}$ of $\mathrm{CeO}_{2}$ and $\mathrm{ZnO}$ nanoparticles for 6 days about 40 days after germination. The $\mathrm{ZnO}$ nanoparticles significantly reduced the accumulation of $A s^{\prime \prime \prime}$ in rice roots by 88 and $97 \%$ and in rice shoots by 71 and $77 \%$ when the initial As was supplied as $A s^{\prime \prime \prime}$ and $A s^{V}$, respectively. The ZnO nanoparticles also reduced $A s^{\vee}$ in rice roots by 68 and $52 \%$ when the $A s$ was provided as $A s^{\prime \prime \prime}$ and $A s^{\vee}$, respectively. However, the $A s^{\vee}$ in rice shoots was unaffected by $\mathrm{ZnO}$ nanoparticles regardless of the initial oxidation state of As. Neither the total As nor the individual species of As in rice tissues was significantly changed by $\mathrm{CeO}_{2}$ nanoparticles. The co-presence of $\mathrm{As}^{\prime \prime \prime}$ and $\mathrm{As}^{\mathrm{V}}$ increased $\mathrm{Ce}$ in rice shoots by 6.5 and 2.3 times but did not affect plant uptake of $\mathrm{Zn}$. The results confirmed the active interactions between metallic engineered nanoparticles and coexisting inorganic As species, and the extent of their interactions depends on the properties of metallic engineered nanoparticles as well as the initial oxidation state of As. A simultaneous speciation analysis for the risk assessment of $\mathrm{As}, \mathrm{Cr}$, and Se in food has been reported based on cooked and uncooked rice samples (long-grain basmati, organic white and brown rice $)^{68}$. The rice $(0.2-0.25 \mathrm{~g}$ ) was rolled in pre-treated quartz wool and packed into a PTFE tube $(8 \mathrm{~cm}$ long, $3 / 15 \mathrm{in.}$ od, $1 / 8 \mathrm{in}$. id), with a quartz wool plug at each end to prevent the escape of particles. A mini-column containing only quartz wool was also used as a blank. These tubes, which were kept at $37^{\circ} \mathrm{C}$, were used sequentially with mini-columns containing artificial saliva, gastric juice, and intestinal juice while continuously monitoring potentially toxic elements (As, $\mathrm{Cr}$, and Se) by ICP-MS. Using gradient elution with three $\mathrm{HNO}_{3}$ mobile phases ( $\mathrm{pH} 3.3$, 1.1 , and 0.1 with mobile phases $A$ and $B$ also containing $1 \%$ methanol), four As species ( $A s^{\prime \prime \prime}, A s^{V}$, MMA, and DMA, two $\mathrm{Cr}$ species $\left(\mathrm{Cr}^{\mathrm{III}}\right.$ and $\left.\mathrm{Cr}^{\mathrm{VI}}\right)$, and two Se species ( $\mathrm{Se}^{\mathrm{IV}}$ and $\left.\mathrm{Se}^{\mathrm{VI}}\right)$ were separated within $12 \mathrm{~min}$. Arsenic speciation in rice and rice-based products consumed by toddlers in Switzerland has been studied by Guillod-Magnin et al. ${ }^{69}$. An IC-ICP-MS method was developed to separate four As anions: $A s^{\prime \prime \prime}, A s^{\vee}, M^{\prime} A^{\vee}$ and $D M A^{\vee}$. Sample preparation was done in mild acidic conditions to ensure species preservation. The predominant As species found in rice and rice-based products, except for rice drinks, was As'"I, comprising $60-80 \%$ of the total As content, followed by $D_{M A} A^{\vee}$ and $A s^{\vee}$ with $M_{M} A^{\vee}$ found only at low levels (<3\%). A NIST rice flour, SRM 1568b, was also used for quality control. Rice products $(\mathrm{N}=105)$ intended for toddlers, including special products 
destined for infants and toddlers, such as dry form baby foods ( $\mathrm{N}=12)$ or ready-to-use formulas $(\mathrm{N}=9)$, were also investigated. The study found that toddlers with a high consumption of rice based cereals and rice drinks are at risk of high iAs exposure, for which a potential health risk cannot be excluded.

Continuing on the theme of As speciation in rice arsenic concentrations and speciation in Australian grown and imported rice and commercial rice products has been studied by Maher et al. ${ }^{70}$. Six varieties of Australian-grown rice $(n=130)$, imported rice $(n=53)$ and rice products $(n=56)$ from supermarkets were digested using a microwave oven procedure and then analysed using HPLC-ICPMS. The total As, iAs and DMA concentrations in the Australian rice ranged from 16 to $630 \mu \mathrm{g} \mathrm{As} \mathrm{kg-}$

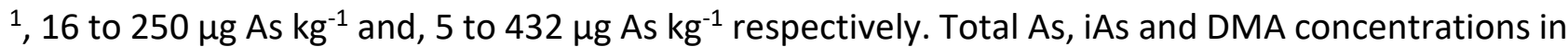
imported rice ranged between 31 and $376 \mu \mathrm{g} \mathrm{As} \mathrm{kg}{ }^{-1}, 17$ and $198 \mu \mathrm{g} \mathrm{As} \mathrm{kg}{ }^{-1}$ and, 5 and $327 \mu \mathrm{g} \mathrm{As} \mathrm{kg}$ ${ }^{1}$ respectively. Few samples exceeded the guidelines for iAs in polished rice. In rice products, total As, iAs and DMA concentrations ranged between 21 and $480 \mu \mathrm{g} \mathrm{As} \mathrm{kg}{ }^{-1}, 20$ and $255 \mu \mathrm{g} \mathrm{As} \mathrm{kg}{ }^{-1}$ and, 5 and $340 \mu \mathrm{g} \mathrm{As} \mathrm{kg}^{-1}$ respectively. Sixteen samples exceeded the $\mu \mathrm{g}$ As $\mathrm{kg}^{-1}$ maximum for iAs concentration in rice foods for infants and young children and the authors suggest that ingestion of multiple serves of some rice products poses a potential risk. Two certified rice reference materials (NIST1568a and NMIJ 7503a) were used for quality assurance purposes. A similar study has been conducted in Korea by Lee et al. ${ }^{71}$. A total of 485 domestic rice (polished rice, $n=368$; husked rice, $n=117$ ) samples. The determination of As species was conducted by HPLC-ICP-MS. The major As species detected was $A s^{\prime \prime \prime}$ whilst $A s^{v}, D M A$, and MMA occurred at a lower level in both types of rice. In polished rice, iAs represented $43-91 \%$ of the total As and in husked rice, iAs ranged from $55 \%$ to 91\% of the total As. The iAs level of both polished and husked rice samples were below the current maximum limit of the Chinese and German standard of $0.2 \mathrm{mg} \mathrm{kg}^{-1}$ for iAs in milled rice. Average dietary exposure to iAs from polished rice consumption was calculated as $0.17 \pm 0.21 \mathrm{\mu g} \mathrm{kg}^{-1} \mathrm{bw}$ day $^{-1}$ which was $8.1 \%$ of the Provisional Tolerable Weekly Intake. Following a previous study in six villages of Pakistan where As concentrations above the WHO safe limit of $10 \mu \mathrm{g} \mathrm{L}^{-1}$ were found in $89 \%$ of ground water sources, Rasheed et $a . .^{72}$ have assessed the exposure and health risks from common food stuffs. Using HPLC-ICP-DRC-MS, iAs concentrations were found to be $93 \pm 42 \mu \mathrm{gg}^{-1}$, $79 \pm 76 \mu \mathrm{gg}^{-1}$, and $116 \pm 52 \mu \mathrm{g} \mathrm{kg}^{-1}$ for raw rice, cooked rice and wheat respectively. The mean total As concentrations were $47 \pm 30.72 \mu \mathrm{g} \mathrm{kg}^{-1}, 72 \pm 75 \mu \mathrm{g} \mathrm{kg}^{-1}, 105 \pm 62 \mu \mathrm{g} \mathrm{kg}^{-1}$. Wheat was therefore demonstrated to be a significant source of As exposure with DMA the main organic species and MMA only found at trace levels. Total daily intake of iAs exceeded the provisional 
tolerable daily intake of $2.1 \mathrm{\mu g} \mathrm{kg}^{-1} \mathrm{day}^{-1}$ body weight in $74 \%$ of study participants due to concurrent intake from water (94\%), wheat (5\%) and raw rice (1\%). A significant association between total As in cooked rice and cooking water resulted in total As intake $43 \%$ higher in cooked rice compared to raw rice. The study suggested that As intake from food, particularly from wheat consumption, holds particular significance where iAs is relatively low in water. Chronic health risks were found to be significantly higher from wheat intake than rice, whilst the risk in terms of acute effects was below the USEPA's limit of 1.0. Children were at significantly higher health risk than adults due to iAs exposure from rice and/or wheat. The dietary exposure of participants to total As was attributable to staple food intake with ground water iAs $<10 \mu \mathrm{g} \mathrm{L}^{-1}$, however the preliminary advisory level (200 $\mu \mathrm{g} \mathrm{kg}^{-1}$ ) was achievable with rice consumption of $<=200 \mathrm{~g}$ day $^{-1}$ and compliance with $<=10 \mu \mathrm{g} \mathrm{L}^{-1}$ iAs in drinking water. Although the daily iAs intake from food was lower than total water intake, the potential health risk from exposure to As and its species still existed and requires exposure control measures. The hydrogeochemical behaviour of As in the aquifers of Punjab, Pakistan has also been reported $^{73}$. A total of 123 groundwater wells from five different areas of Punjab, Pakistan were evaluated for both total As and As species. Results by IC-ICP-MS revealed that $75 \%$ of the groundwater wells exceeded the WHO limit $\left(10 \mu \mathrm{g} \mathrm{L}^{-1}\right)$ and $41 \%$ were above the Pakistan-EPA limit

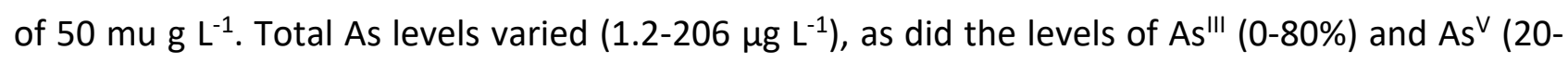
100\%). The mean As content $\left(5.2 \mu \mathrm{g} \mathrm{L}^{-1}\right)$ of shallow wells at 9-40 m depth did not exceed the WHO safe limit, representing a safe aquifer zone for pumping of groundwater compared to deeper wells at 41-90 m (51 $\left.\mathrm{g} \mathrm{L}^{-1}\right)$ and $>90 \mathrm{~m}\left(23 \mu \mathrm{g} \mathrm{L}^{-1}\right)$ depths. The aqueous chemistry was dominated by Na$\mathrm{SO}_{4}, \mathrm{Na}-\mathrm{Ca}-\mathrm{SO}_{4}, \mathrm{Na}-\mathrm{Mg}-\mathrm{SO}_{4}$ type saline water. Principal component analysis grouped As concentration with well depth, $\mathrm{pH}$, salinity, $\mathrm{Fe}$ and $\mathrm{CO}_{3}$, indicating that these hydrogeochemical factors could have potential role in controlling As release/sequestration into the aquifers of study area. Geochemical modelling showed a positive saturation indice only for the Fe oxide-phases, indicating Fe oxides as the major carrier of As.

Another popular area of study relating to food is As in fish and seafood products. A method employing enzyme-assisted extraction and LC-ICP-MS for the simultaneous determination of eleven As species in fish has been developed by Zhao et al. ${ }^{74}$. Following optimisation of different extraction solutions, enzymes and $\mathrm{pH}, 40 \mathrm{mg}$ protease with $0.75 \mathrm{~mL} 0.5 \%$ hydrochloric acid $(\mathrm{v} / \mathrm{v})$ gave the best results. An ammonium carbonate solution mobile phase at $20{ }^{\circ} \mathrm{C}$ with an AG7 anion-exchange chromatographic column and gradient elution separated all species in 17 minutes. The LOD values for each species were in the range of $0.11-0.59 \mu \mathrm{g} \mathrm{kg}^{-1}$, and repeatability values for spiked fish 
samples in the range of $1.1 \%-7.6 \%$. Recoveries were $91 \%-106 \%$. The developed method was used to analyse 39 fish samples (both marine and freshwater) with AsB being the major As specie present $\left(3.25-20,400 \mu \mathrm{g} \mathrm{kg}^{-1}\right)$. Only trace amount of iAs species were detected. Arsenic speciation in fish and shellfish species bought from local fishermen operating in the North Sea and Port Acu (Brazil) coastal areas has been studied ${ }^{75}$. Total As was assessed by ICP-OES (Brazil) and ICP-MS (North Sea) after microwave digestion. The As speciation was assessed by LC-ICP-MS (Brazil) and HG-AFS (North Sea). Several fish species had average total As concentrations above $1 \mu \mathrm{g} \mathrm{g}^{-1}$ wet weight (ww), but the highest concentrations were found in the less spotted dogfish, lemon sole and whelks from the North Sea, with 50, 49 and $50 \mu \mathrm{g} \mathrm{g}^{-1}(\mathrm{ww})$ respectively. The iAs fractions were highest in scallops (almost $10 \%$ ) but rarely exceeded $2 \%$ in all other species. Liver samples were only analysed in ray, dogfish and catfish and their iAs fractions were between 2 and 4 times higher than in muscle. For a consumption of $150 \mathrm{~g}$ of seafood, only 3 samples exceeded the provisional total daily intake limit of $2 \mathrm{~g} \mathrm{~kg}^{-1}$ body weight, however, cancer risks remain. The characterisation of As in dried baby shrimp (Acetes sp.) using synchrotron-based SR-XRF and LC-ICP-MS-MS has been studied as part of an independent field study of human exposure to toxic metals/metalloids among the ethnic Chinese community located in Upstate New York ${ }^{76}$. The dried baby shrimp were analysed in a home environment using a portable XRF instrument based on monochromatic excitation. The shrimp were typically between 10-20 mm in size and are consumed whole, without separating the tail from the head. Elevated levels of As were detected ranging between 5-30 $\mu \mathrm{g} \mathrm{g}^{-1}$. Shrimp samples were also analysed by SR-XRF elemental mapping using a 384-pixel Maia detector system. The Maia detector provided high resolution trace element images for $\mathrm{As}, \mathrm{Br}$ and $\mathrm{Ca}$ (among others) and showed localised accumulation of As within the shrimp's cephalothorax (head), and various abdominal segments. Arsenic quantification by SR-XRF was performed using a lobster hepatopancreas CRM (NRCC TORT-2), with results in good agreement with both portable XRF and ICP-MS. Additional As characterisation using XANES with the Maia XRF detector identified $A B$ and/or $A C$ as the possible $A s$ species present. Further As speciation analysis by LC-ICP-MS-MS confirmed that the majority of As $(>95 \%)$ is present as the largely non-toxic $A B$ species with trace amounts of $A C$, methylated As and iAs species detected. The quantification of labile and stable non-polar arsenolipids in commercial fish meals and edible seaweed samples has been reported by Petursdottir et al. ${ }^{77}$. The authors found that when using sequential extraction, there is a significant difference in the concentration of As in each fraction depending on the order of the extraction solvents. Extracting non-polar arsenolipids using $\mathrm{MeOH} / \mathrm{DCM}$ before water extraction resulted in the extraction of $A B$ and possibly other 
cytosolic As species. Using water first may, however, significantly transform labile non-polar arsenolipids, and the labile part of the hexane fraction ranged from 71 to $93 \%$ for three fish meal types and nearly all non-polar arsenolipids (93\%) in the blue whiting non-polar fraction were not stable through a water extraction. The non-polar arsenolipid fraction was found to be minor for Dulse (red seaweed, Palmaria palmata). In 27 samples of herring and blue whiting fish meal, the As was mainly present in the water phase: $71 \%\left(2.8 \pm 0.8 \mathrm{mg} \mathrm{kg}^{-1}\right)$ and $93 \%\left(17.2 \pm 1.9 \mathrm{mg} \mathrm{kg}^{-1}\right)$ for herring and blue whiting, respectively. The polar arsenolipids in the $\mathrm{MeOH} / \mathrm{DCM}$ fraction accounted for $15 \%$ and $5 \%$ (0.5-1.2 $\left.\mathrm{mg} \mathrm{kg}^{-1} \mathrm{As}\right)$ for both herring and blue whiting, respectively. Speciation analysis of arsenolipids was also undertaken for herring meal, capelin meal and Dulse using simultaneous HPLC-ICP-MS/ES-MS for quantification and identification. Among the known arsenohydrocarbons, arseno fatty acids and arsenosugarphospholipids, a novel AsFA374 was identified in Dulse by As detection via simultaneous protonated mass, accurate mass as well as MSMS fragmentation. Additionally, recently reported non-polar arsenolipid groups, As containing phosphatidylcholines and arseno fatty alcohols, were reconfirmed to occur in marine samples. A method for the determination of iAs in seaweed without chromatography using HG-ICP-MS has been reported by the same group ${ }^{78}$. Using an extraction of $2 \% \mathrm{HNO}_{3}$ and $3 \% \mathrm{H}_{2} \mathrm{O}_{2}$ prior to $\mathrm{HG}-\mathrm{ICP}$ MS the method was reported to out perform the most commonly used method of HPLC-ICP-MS and compare well with HPLC-HG-ICP-MS for the determination of iAs in the seaweed samples. Linear regression showed reasonable linearity $\left(R^{2}\right.$ of 0.82$)$, with a slope slightly higher than $1(1.15 \pm 0.09)$ and intercept $0.03 \pm 0.01$ when comparing the concentrations of iAs determined with the two methods. Hence there was a minor overestimation of iAs with HG compared to the HPLC-HG, however, the method was well suited for use as a quick screening method. The iAs concentration was below $1 \%$ of total As concentration in 40 brown macroalgae samples (Focus vesiculosus, Ascophyllum nodosum, Saccharina latissima), irrespective of using HG-ICP-MS or HPLC-HG-ICP-MS. A method for As speciation in shark, shrimp, squid, oyster and scallop using LC-ICP-MS-MS has been proposed by Schmidt et al. ${ }^{79}$. Suitable sensitivity and selectivity were obtained using $10 \mathrm{mmol} \mathrm{L}^{-1}$ $\left(\mathrm{NH}_{4}\right)_{2} \mathrm{HPO}_{4}$ diluted in $1 \%$ methanol $(\mathrm{pH} 8.65)$ as mobile phase. Recoveries from 90 to $104 \%$ for $A B$, $A s^{\prime \prime \prime}, D M A, M M A$ and $A s^{\vee}$ were obtained for all samples. The CRM DORM-3 fish protein was also analysed and the sum of As species was in agreement with the total As concentration. The LOQ for $A B, A s^{\prime \prime \prime}, D M A, M M A$ and $A s^{\vee}$ were 6, 30, 6, 12 and $26 \mathrm{ng} \mathrm{g}^{-1}$, respectively. A higher concentration of $A B$ was found in all seafood, while As ${ }^{\prime \prime \prime}$ and DMA were found only in oyster. Arsenate was found in squid and scallops, and MMA was below the LOQ in all samples. 
Studies looking at fungi have identified several As compounds not previously recorded. Arsenic speciation has been reported for the first time in nine collections of Elaphomyces spp. (deer truffles) from the Czech Republic ${ }^{80}$. Using HPLC-ICP-MS the authors found total As concentrations ranging from 12 to $42 \mathrm{mg} \mathrm{kg}^{-1}$ dry mass in samples of $E$. asperulus and from 120 to $660 \mathrm{mg} \mathrm{kg}^{-1}$ dry mass in E. granulatus and E. muricatus. These concentrations are remarkably high for terrestrial organisms and demonstrate the As-accumulating ability of these fungi. The dominant As species in all samples was MMA which accounted for more than $30 \%$ of the extractable As, whilst $A B, D M A$, and iAs were also present, but only at trace concentrations. Trimethylarsine oxide was also found in all samples (0.32-28\% of the extractable arsenic), and in all but two samples significant amounts of the highly toxic trivalent As compound methylarsonous acid (0.08-0.73\% of the extractable arsenic) was found. This is the first report of the occurrence of trimethylarsine oxide and methylarsonous acid at significant concentrations in a terrestrial organism. The same group have also reported on the As speciation in macrofungi of the Ramaria genus again utilising HPLC-ICP-MS ${ }^{81}$. Besides As species that are already known for macrofungi, such as $A b$ and $A C$, two compounds that were only known from marine samples, trimethylarsoniopropanate and dimethylarsinoylacetate were found for the first time in a terrestrial sample. An unknown arsenical was also isolated and identified as homoarsenocholine. The authors suggest that this could be a key intermediate for further elucidation of the biotransformation mechanism. A method utilising UAE and AEC-ICP-MS for simultaneously determining six As species in Shiitake (Lentinus edodes) mushrooms has been reported $^{82}$. All six As species were separated within $15 \mathrm{~min}$ using $0.3 \mathrm{M}$ acetic acid as the extraction solvent and 25 mmol L-1 $\mathrm{NH}_{4} \mathrm{H}_{2} \mathrm{PO}_{4}$ as the mobile phase. Under optimised conditions, the LOD values were in the range of $0.31-0.59 \mu \mathrm{g} \mathrm{kg}^{-1}$, with recoveries between $94-102 \%$. When applied to the fresh Shiitake mushrooms and processed products, the iAs ranged from 0.204 to $0.500 \mathrm{mg} \mathrm{kg}^{-1}$, with half of the samples $>0.400 \mathrm{mg} \mathrm{kg}^{-1}$ and therefore close to the maximum level allowed by China $(0.5 \mathrm{mg}$ $\mathrm{kg}^{-1}$ ). The influence of microwave blanching on the As speciation in Lentinus edodes has also been reported $^{83}$. Using HPLC-ICP-MS the bioaccessibility of As species in raw L.edodes and microwave blanched $L$. edodes were determined following a simulated gastrointestinal digestion. The $\mathrm{As}^{\mathrm{V}}, \mathrm{As}^{\prime \prime \prime}$, $M M A, D M A, A B$, and $A C$ did not undergo decomposition and transformation in the study. The total As in the $L$. edodes samples ranged from $0.138 \pm 0.004-0.235 \pm 0.014 \mathrm{mg} \mathrm{kg}^{-1}$. During the various microwave blanching treatments, $3.38-43.3 \%$ of the As was released from samples into the blanching water. The oxidation of As'll and demethylation of DMA and MMA were observed in L.edodes during digestion, increasing the likelihood of As toxicity in the liver. The health risk from 
As in L edodes was found to decrease after microwave blanching with the available As following microwave blanching of $L$. edodes samples $(83.8 \pm 0.91 \%)$ being lower than that in raw L.edodes samples (88.3 $\pm 0.80 \%)$. Ophiocordyceps sinensis or caterpillar fungus as it is sometime known, has been utilised in China and adjacent countries for thousands of years as a functional food to promote health and treat diverse chronic diseases. In recent years, adulterants have been noted in the processed products of wild $O$. sinensis. Guo et al..$^{84}$ have reported novel As markers to discriminate between wild and cultivated cordyceps. The total As and As species in cultivated 0 . sinensis, Cordyceps militaris, and other edible fungi were determined by ICP-MS and HPLC-ICP-MS. The results suggest that distribution of five known As species ( $A s^{\prime \prime \prime}, A s^{\vee}, M_{M} A^{\vee}, D M A^{v}$, and $A B$ ) together with an unknown As compound, believed to an arsenosugar, can act as sensitive markers to discriminate between the types of fungus and prove of value in providence testing.

Measuring As in urine provides important information for clinical and epidemiological studies. While many researchers have studied ways to improve sample storage and understand why As species undergo species interconversion, few have investigated inline dilution as a solution for As speciation sample stability. This has been addressed by Quarles et $a{ }^{.85}$ who have developed an inline dilution method to eliminate species interconversion for LC-ICP-MS based applications. Using AB, DMA, MMA, $A s^{\prime \prime \prime}$, and $A s^{V}$ standards, inline dilution calibrations from a single stock standards were shown to have good linearity and resulted in LOD values in the single digit $\mathrm{ng} \mathrm{L}^{-1}$ range. Inline dilutions of 30,50 , and 100 fold resulted in $0.1 \mathrm{~s}$ to $1.1 \mathrm{~s}$ variation in retention time. Manual sample preparation resulted in poor recovery (61\%) for As ${ }^{\prime \prime \prime}$ over a $24 \mathrm{~h}$ time period, which was a direct result of $A s^{\prime \prime \prime}$ converting to $A s^{\vee}$. Inline dilution of urine spiked with $A s^{\prime \prime \prime}$ resulted in good recovery (101\%) and reduced the species interconversion of $A s^{\prime \prime \prime}$ to $A s^{\vee}$ to around $1 \%$. The accuracy using the CRM NIST SRM 2669 (As in frozen urine) was found to be within reported values for the five As species tested for in this method. Preliminary studies of urinary As concentration and As methylation capacity effects on neurodevelopment in very low birth weight preterm children under 24 months of corrected age have been reported in a study from Taiwan ${ }^{86}$. The objective of the study was to systematically investigate relationships of urinary As concentrations, the As methylation capability, and toenail As concentrations on cognitive, language, and motor development such children. Participants $(n=60)$ in the study were recruited from October 2010 to April 2013. Urine and toenail samples were collected for evaluation to assess As exposure. The Bayley scales of infant development were used to evaluate neurodevelopment at 2 years of corrected age. Concentrations of As species in urine and the As concentration in toenails were, respectively, analysed using HPLC- 
HG-AAS and ICP-MS. The mean concentration of total As was $28.6 \mu \mathrm{g} \mathrm{g}^{-1}$ creatinine, and iAs was 1.01 $\mu \mathrm{g} \mathrm{g}^{-1}$ in urine. The urine contained an average of 3\% iAs, 2\% MMA, and 95\% DMA. The mean concentration of As in toenails was $225 \mathrm{ng} \mathrm{g}^{-1}$ Children with a longer gestational age (>= 28 weeks) and higher DMA \% levels appeared to have the highest unadjusted cognitive and fine motor scores. The results suggested that gestational age was associated with neurodevelopment in very low birth weight preterm children. Five As species ( $A s^{\prime \prime \prime}, A s^{\vee}, M M A, D M A$ and $A B$ ) have been identified in urine and serum samples from subjects in Vietnam ${ }^{87}$. A gradient elution with ammonium carbonate, $\mathrm{Na}_{2}$ EDTA, and methanol at pH 9.0 was used with HPLC-ICP-MS utilising a Hamilton PRP-X100 strong anion-exchange column. The urine and serum samples were treated by dilution in solvent and protein precipitation by trichloroacetic acid, respectively. The extraction efficiency was greater than 91\% for urine matrix, and recoveries from spiked samples were in the range of $94-139 \%$ for the As species in human serum. The LOD and LOQ were found to be 0.3-1.5 and 1.0-5.0 ng mL respectively. The major species of $A$ s in the urine and serum samples were $A B$ and DMA. $A$ study to assess the effects of polymorphic variants of gutathione-S-transferase (GST) and metallothioneins (MTs) on profiles of urinary As species has been reported by Gonzalez-Martinez et al. ${ }^{88}$. Drinking groundwater from Margarita and San Fernando, Colombia were analysed and the lifetime average daily dose of As was determined. Specific surveys collected demographic information and other exposure factors. In addition, GSTT1-null, GSTM1-null, GSTP1-rs1695 and MT-2A-rs28366003 genetic polymorphisms were evaluated, either by direct PCR or PCR-RFLP. Urinary speciated As concentrations were determined by HPLC-HG-AFS for the species As ${ }^{\prime \prime \prime}, A s^{v}$, MMA, DMA, and total urinary As. Primary methylation index (PMI) and secondary methylation index (SMI) were also calculated as indicators of the metabolic capacity. Polymorphisms effects were tested using multivariate analysis, adjusted by potential confounders. The As concentrations in groundwater were on average $34.6 \pm 24.7 \mu \mathrm{g} \mathrm{L}^{-1}$ greater than the WHO guideline for As $\left(10 \mu \mathrm{L} \mathrm{L}^{-1}\right)$. There was a correlation between As concentrations in groundwater and total urinary As $(r=0.59 ; p=0.000)$. Urinary iAs was associated with GSTP1, LADD, GSTP1*Age, GSTP1*alcohol consumption $\left(r^{2}=0.43\right.$; likelihood-ratio test, $p=0.000)$. The PMI was associated with $\operatorname{sex}\left(r^{2}=0.20\right.$; likelihood-ratio test, $p=$ 0.007). GSTPI ( $A G+G G$ ) homozygotes/heterozygotes could increase urinary iAs decrease the PMI ratio in people exposed to low and high As from drinking groundwater. Therefore, the explanatory models indicated that some covariates could influence the effects of the polymorphisms on these exposure biomarkers to As.

Arsenic in hair and nails has been widely used to assess chronic exposure of humans to Page 28 of 96 
environmental As, although not acute exposure to sub-lethal doses of As as typically used in therapeutics. In a study by Chen et al. ${ }^{89}$, hair, fingernail and toenail samples were collected from nine acute promyelocytic leukemia (APL) patients who had been administered intravenously a daily dose of $10 \mathrm{mg}$ arsenic trioxide (7.5 $\mathrm{mg}$ arsenic) for up to 54 days. The samples were analysed for As species using HPLC-ICP-MS. The predominant form among water-extractable arsenicals was As ${ }^{\text {III }}$ whilst $\mathrm{DMA}^{\mathrm{V}}, \mathrm{MMA}^{\mathrm{V}}$, MMA"I, monomethylmonothioarsonic acid (MMMTAV), and dimethylmonothioarsinic acid (DMMTA ${ }^{\vee}$ ) were also detected in both hair and nail samples. This is the first report of the detection of $\mathrm{MMA}^{\mathrm{III}}$ and $\mathrm{MMMTA}^{\mathrm{V}}$ as metabolites of arsenic in hair and nails of APL patients.

The clinical field continues to report the results of work involving As speciation although the analytical details are often minimalist in nature. Further work has been published this year on Asgene interactions from the Strong Heart Family Study, this time focusing on As-gene interactions influencing pancreatic beta-cell activity ${ }^{90}$. Forty two variants with associations with either beta-cell function (31 variants) or As metabolism (11 variants) were selected. Beta-cell function was calculated as homeostatic model - beta corrected for insulin resistance (cHOMA-B) by regressing homeostatic model - insulin resistance (HOMA-IR) on HOMA-B and adding mean HOMA-B. The As exposure was dichotomised at the median of the sum of creatinine-corrected inorganic and organic As species measured by HPLC-ICP-MS. Additive GxE models for cHOMA-B were adjusted for age and ancestry, and accounted for family relationships. Models were stratified by centre (Arizona, Oklahoma, North Dakota and South Dakota) and meta-analysed. The two interactions between higher vs. lower As and SNPs for CHOMA-B that were nominally significant at $\mathrm{P}<0.05$ were with rs10738708 (SNP overall effect - 3.91, $P=0.56$; interaction effect with As $-31.14, P=0.02$ ) and rs4607517 (SNP overall effect $+16.61, P=0.03$; interaction effect with arsenic $+27.02, P=0.03$ ). The corresponding genes GCK and TUSC1 suggest oxidative stress and apoptosis as possible mechanisms for arsenic impacts on beta-cell function. No interactions were Bonferroni-significant $(1.16 \times 10(-3))$. The findings were suggestive of oligogenic moderation of As impacts on pancreatic beta-cell endocrine function, but were not Bonferroni-significant. A comparison of As methylation capacity and polymorphisms of As methylation genes between bladder cancer and upper tract urothelial carcinoma has been reported in two very similar papers by the same group ${ }^{91},{ }^{92}$. It is known that As exposure is an environmental risk factor for urothelial carcinoma, although the risk of urothelial carcinoma differs from that of bladder cancer. The study aimed to evaluate the association between As methylation capacity and upper tract urothelial carcinoma and/or bladder 
cancer, separately, and additionally evaluate the association between polymorphisms of the As metabolism-related genes AS3MT, GSTOs, and PNP against bladder cancer and/or upper tract urothelial carcinoma, separately. The authors conducted a hospital-based study and collected 216 BC and 212 upper tract urothelial carcinoma cases, and 813 healthy controls, over a four-year period (2007 - 2011). Urinary As profiles were measured using HPLC-HG-AAS. The polymorphisms of AS3MT, GSTO, and PNP were identified using the Sequenom MasSARRAY platform with iPLEX Gold chemistry. It was found that inefficient As methylation capacity was associated with bladder cancer in a significant dose-response relationship, but that high urinary total As concentration was related only to the risk of upper tract urothelial carcinoma, also in a significant dose-response manner. Those with a total urinary As level of $>30.28 \mu \mathrm{g} \mathrm{L}^{-1}$ compared to $\leq 9.78 \mu \mathrm{g} \mathrm{L}^{-1}$, had a odds ratio and 95\% confidence interval of upper tract urothelial carcinoma, of 4.80 (2.22-10.39). The polymorphisms of AS3MT rs11191438, AS3MT rs10748835, and AS3MT rs1046778 were related to the risk of bladder cancer and upper tract urothelial carcinoma, while the polymorphisms of AS3MT rs3740393, AS3MT rs11191453, and AS3MT rs11191454 were associated with As methylation capacity. The AS3MT gene polymorphisms and As methylation capacity appear to independently affect the risk of bladder cancer and upper tract urothelial carcinoma. Exposure to iAs has been associated with lower circulating levels of insulin-like growth factor 1 (IGF1) and impaired growth in children of pre-school age. A study by Gliga et al. ${ }^{93}$ has assessed the potential impact of exposure to As on IGF1 and insulin-like growth factor-binding protein 3 (IGFBP3) as well as DNA methylation changes in 9-year-old children. To this end, 9 year old children from a longitudinal mother-child cohort in rural Bangladesh $(n=551)$ were selected for the study. Prenatal and concurrent exposure to As was assessed via concentrations in maternal urine at gestational week 8 and in child urine, measured by HPLC-HG-ICP-MS. Plasma IGF1 and IGFBP3 concentrations were quantified with immunoassays. Methylation of DNA was also measured in blood mononuclear cells at 9 years in a sub-sample ( $\mathrm{n}=113$ ) using Infinium HumanMethylation450K beadchips. In multivariable-adjusted linear regression models, prenatal As (natural log-transformed), but not children's concurrent urinary As, was positively associated with IGFBP3 concentrations (beta $=76,95 \% \mathrm{Cl} 19,133$ ). As concentrations were not associated with IGF1. DNA methylation analysis revealed CpGs associated with both prenatal As and IGFBP3. Mediation analysis suggested that methylation of 12 CpG sites for all children was mediator of effect for the association between prenatal As and IGFBP3. The authors also found differentially methylated regions, generally hypermethylated, that were associated with both prenatal As and IGFBP3. Overall, the study revealed that prenatal exposure to 
As was positively associated with IGFBP3 concentrations in children at 9 years, independent of IGF1, and this association may, at least in part, be epigenetically mediated. Also focusing on rural Bangladesh, As ${ }^{\text {III }}$ methyltransferase (AS3MT) polymorphisms and As methylation in children has been reported ${ }^{94}$. The children's As exposure (9-years; $n=424$ ) was assessed as the sum of urinary concentration of iAs and metabolites MMA and DMA using HPLC-HG-ICP-MS. The As methylation efficiency was assessed by the individual metabolite fractions (\%). AS3MT polymorphisms (rs7085104, rs3740400, rs3740393 and rs1046778) were genotyped using TaqMan SNP genotyping assays. The study found higher \%iAs and \%MMA, and lower \%DMA in urine, among rs1046778 TT carriers (median $8.8 \%, 9.6 \%$ and $81.1 \%$ for iAs, MMA and DMA, respectively), compared to CC carriers (median $7.0 \%, 8.3 \%$ and $84.9 \%$ ). These associations were significant in multivariableadjusted linear regression models: B-coefficients for TT vs CC were 1.26, 1.33 and - 2.59 for iAs, MMA and DMA, respectively. Effect estimates were slightly stronger when restricting the analyses to children with urinary $A s \geq 58 \mu \mathrm{g} \mathrm{L}^{-1}$ (reducing the impact of ingested DMA). Estimates in girls were slightly stronger than in boys, although there were no significant differences between boys and girls. No clear associations were found for the other AS3MT polymorphisms. The AS3MT variation therefore seemed to influence As methylation efficiency in children to a lesser extent than in adults. Cell cycle-dependent uptake and cytotoxicity of As based drugs (ATO and ZIO-101) in single leukemia cells (NB4 and HL60) has been studied using a double thymidine block combined with time-resolved ICP-MS ${ }^{95}$. It was shown that cells absorb maximal amounts of both ATO and ZIO-101 in G2/M phase and minimum in S phase, and such variation is less apparent for ZIO-101 than ATO (NB4-G2/M:S = 2.5:1 for ATO and 1.6:1 for ZIO-101). The study also demonstrated that AQP9, an ATO transporter, is highly expressed in the GI phase (50.2-46.9\%) and minimum value was observed in the $\mathrm{S}$ phase (27.6-24.6\%); whereas xCT, a ZIO-101 transporter, is maximally expressed in the G2/M phase (74.876.1\%) and minimally expressed in the GI phases (55.4-59.8\%). Different expression levels of AQP9 and XCT only partially accounted for the observed differences in As uptake across cell cycle, indicative of the presence of other importers for both ATO and ZIO-101. The cytotoxicity of ATO and ZIO-101 on NB4 cells was also cell cycle dependent, with the highest cytotoxicity at S + G2/M phase and the lowest at $\mathrm{GI}+\mathrm{S}$ phase. Following on from previous work on the relationship between As and renal cell carcinoma, Hsueh et al. ${ }^{96}$ have reported on the relationship between adiponectin gene (ADIPOQ) polymorphisms and renal cell carcinoma and investigate whether individuals with an ADIPOQ risk genotype, obesity, and high urinary total As levels, have a modified odds ratio (OR) of renal cell carcinoma. A total of 389 patients with renal cell carcinoma and 389 age- and sex-matched 
controls were recruited over a 6 years period in Taiwan. Image-guided biopsy or surgical resection of renal tumours was performed to pathologically verify the renal cell carcinoma. Genomic DNA was used to examine the genotypes of the ADIPOQ rs182052, ADIPOQ rs2241766, ADIPOQ rs1501299, and ADIPOQ rsl 063539 SNPs by PCR-RFLP. HPLC-HG-AAS was used to measure the concentrations of urinary As species. Participants with the ADIPOQ rs182052 G/A+ A/A genotype had a significantly higher OR of renal cell carcinoma compared with those with the ADIPOQ rs182052 G/G genotype. The OR (95\% confidence interval) was 1.70 (1.23-2.36). The OR of renal cell carcinoma for the combined effect of high urinary total As levels and obesity, which was dose-dependent in individuals with the ADIPOQ rs182052 G/A +A/A genotype, was 9.33 (3.85 - 22.62). The study found a significant combined effect of obesity and the ADIPOQ rs182052 G/A + A/A genotype on the As-related risk of renal cell carcinoma in a population with low As exposure. Biomethylation metabolism studies on $A s^{\prime \prime \prime}, A^{\vee}, M^{\vee} M A^{\vee}$, and DMA ${ }^{\vee}$ in SCC-7 cells using RP- ion pair -HPLC-ICP-MS have been reported ${ }^{97}$. LOD values in the range 4-27 ng L-1 with a linear range up to four orders of magnitude were reported. The effect of exposure time, exposure concentrations and elimination time on the As species and total As in SCC-7 cells incubated by As'II were also evaluated. At low exposure concentrations $(<5 \mu \mathrm{M})$, a large proportion of intracellular As ${ }^{\text {III }}$ transformed to methylated metabolites. The final methylated metabolite $\mathrm{DMA}^{\mathrm{v}}$, could not be completely removed from the cells in the elimination process, and was considered the primary carcinogen. At higher exposure concentrations ( $>5 \mu \mathrm{M})$, most of intracellular As ${ }^{\prime \prime \prime}$ was thought to be bound to biomacromolecules rather than follow the biomethylation process, thus exhibiting a different metabolism pathway.

Table 1 shows other applications of As speciation presented in the literature during the time period covered by this ASU.

Table 1 Applications of Speciation Analysis: Arsenic and Antimony

\begin{tabular}{|c|c|c|c|c|c|c|c|}
\hline $\begin{array}{l}\text { Analyte } \\
\text { species }\end{array}$ & Technique & Matrix & $\begin{array}{l}\text { Sample } \\
\text { treatment }\end{array}$ & Separation & LOD & Validation & $\begin{array}{c}\text { Referenc } \\
\text { e }\end{array}$ \\
\hline $\begin{array}{l}\mathrm{As}^{\prime \prime \prime}, \mathrm{As}^{\mathrm{V}} \\
\mathrm{MMA}^{\mathrm{v}} \\
\mathrm{DMA}^{\mathrm{V}}\end{array}$ & $\begin{array}{l}\text { Continuous } \\
\text { flow HG- } \\
\text { AFS }\end{array}$ & Meat & $\begin{array}{l}\text { Freeze dried, } \\
\text { ground, MAE } 1 \\
\mathrm{~mol} \mathrm{~L}^{-1} \mathrm{HNO}_{3}\end{array}$ & $\begin{array}{l}\text { Selective } \mathrm{HG} \text { in } \\
\text { presence of } \mathrm{HCl} \text { and } \\
\text { L-cysteine. }\end{array}$ & $\begin{array}{l}0.013 \\
\mu g \mathrm{~L}^{-1}\end{array}$ & $\begin{array}{l}\text { Results } \\
\text { comparison with } \\
\text { other method } \\
\text { by same group }\end{array}$ & 98 \\
\hline $\begin{array}{l}\mathrm{As}^{\prime \prime \prime}, \mathrm{As}^{\mathrm{V}} \\
\mathrm{MMA}^{\mathrm{V}} \\
\mathrm{DMA}^{\mathrm{V}}\end{array}$ & $\begin{array}{l}\text { HPLC-ICP- } \\
\text { MS }\end{array}$ & $\begin{array}{l}\text { Rice (NIST } \\
\text { SRM } \\
1568 b)\end{array}$ & $\begin{array}{l}\text { Heat }\left(95^{\circ} \mathrm{C}\right) \text {, in } \\
0.28 \mathrm{~mol} \mathrm{~L}^{-1} \\
\mathrm{HNO}_{3}, \mathrm{H}_{2} \mathrm{O}_{2}\end{array}$ & $\begin{array}{l}\text { AEC, isocratic, } 20 \\
\mathrm{mmol} \mathrm{L}^{-1} \mathrm{NH}_{4} \mathrm{H}_{2} \mathrm{PO}, \\
\mathrm{pH} 6.0\end{array}$ & $\begin{array}{l}\text { Not } \\
\text { given }\end{array}$ & $\begin{array}{l}\text { NIST 1568b (rice } \\
\text { flour) }\end{array}$ & 99 \\
\hline $\begin{array}{l}\mathrm{As}^{\prime \prime \prime}, \mathrm{As}^{\mathrm{V}} \\
\mathrm{MMA}^{\mathrm{v}} \\
\mathrm{DMA}^{\mathrm{v}}\end{array}$ & $\begin{array}{l}\text { HPLC-ICP- } \\
\text { MS }\end{array}$ & $\begin{array}{l}\text { Rice and } \\
\text { fish }\end{array}$ & $\begin{array}{l}\text { UAE with 1:1 } \\
\text { MeOH: } \mathrm{H}_{2} \mathrm{O}\end{array}$ & $\begin{array}{l}\text { AEC, isocratic, } 1.0 \\
\mathrm{mmol} \mathrm{L}^{-1} \mathrm{NH}_{4} \mathrm{H}_{2} \mathrm{PO}_{4} \\
\mathrm{pH} 10.2 \text {, the } 2 \mathrm{~min}\end{array}$ & $\begin{array}{l}\text { Not } \\
\text { given }\end{array}$ & $\begin{array}{l}\text { Spike recoveries } \\
\text { (only } 55-76 \% \\
\text { for rice) }\end{array}$ & 100 \\
\hline
\end{tabular}




\begin{tabular}{|c|c|c|c|c|c|c|c|}
\hline$A B$ & & & & $\begin{array}{l}\text { salt gradient from } 1 \\
\text { to } 10 \mathrm{mmol} \mathrm{L}^{-1}\end{array}$ & & & \\
\hline $\begin{array}{l}\mathrm{As}^{\prime \prime \prime}, \mathrm{As}^{\mathrm{V}} \\
\mathrm{MMA}^{\mathrm{V}} \\
\mathrm{DMA}^{\mathrm{V}} \\
\mathrm{AB}\end{array}$ & $\begin{array}{l}\text { HPLC-ICP- } \\
\mathrm{MS}, 20 \% \mathrm{O}_{2} \\
\text { in } \mathrm{He} \\
\text { collision } \\
\text { gas, } \\
\text { measured } \\
\text { at } \mathrm{m} / \mathrm{z} 91\end{array}$ & $\begin{array}{l}\text { Seafood } \\
\text { and } \\
\text { marine } \\
\text { sediment }\end{array}$ & $\begin{array}{l}\text { Seafood: UAE } \\
\text { 1:1 MeOH: } \mathrm{H}_{2} \mathrm{O} \\
\text { Marine } \\
\text { sediment: } 0.5 \\
\text { mol L}^{-1} \mathrm{H}_{3} \mathrm{PO}_{4}+ \\
0.1 \mathrm{~mol} \mathrm{~L}^{-1} \\
\mathrm{HONH}_{2} \cdot \mathrm{HCl} \text {. }\end{array}$ & $\begin{array}{l}\text { AEC, isocratic, } 20 \\
\text { and } 50 \mathrm{mmol} \mathrm{L}^{-1} \\
\mathrm{NH}_{4} \mathrm{CO}_{3} \text { (for } \\
\text { seafood) } 20 \mathrm{mmol} \mathrm{L}^{-} \\
{ }^{1} \mathrm{NH}_{4} \mathrm{H}_{2} \mathrm{PO}_{4} \text { (pH 6.0, } \\
\text { for sediment) }\end{array}$ & $\begin{array}{l}\text { Not } \\
\text { given }\end{array}$ & $\begin{array}{l}\text { NRCC DORM 3, } \\
\text { DORM 4, PACS } \\
\text { 2, PACS } 3 \text { and } \\
\text { MESS 4, oyster } \\
\text { powder CRM } \\
\text { from KRISS, } \\
\text { Korea }\end{array}$ & 101 \\
\hline $\begin{array}{l}\text { As }^{\prime \prime \prime}, A s^{v}, \\
M^{V} A^{v}, \\
D M A^{v}, \\
A B+ \\
\text { unknow } \\
\text { n As } \\
\text { species }\end{array}$ & $\begin{array}{l}\text { HPLC-ICP- } \\
\text { MS, He } \\
\text { collision } \\
\text { gas, } \\
\text { external } \\
\text { calibration } \\
\text { with As }\end{array}$ & $\begin{array}{l}\text { Ophiocord } \\
\text { yceps } \\
\text { sinensis }\end{array}$ & $\begin{array}{l}0.15 \mathrm{~mol} \mathrm{~L}^{-1} \\
\mathrm{HNO}_{3}\left(90{ }^{\circ} \mathrm{C} 12\right. \\
\text { h) }\end{array}$ & $\begin{array}{l}\mathrm{AEC}, 5 \mathrm{mmol} \mathrm{L}^{-1} \\
\mathrm{NaCH}_{3} \mathrm{COOH}+3 \\
\mathrm{mmol} \mathrm{L}^{-1} \mathrm{KNO}_{3}+10 \\
\mathrm{mmol} \mathrm{L}^{-1} \mathrm{NaH}_{2} \mathrm{PO}_{4}+ \\
0.2 \mathrm{mmol} \mathrm{L}^{-1} \\
\mathrm{Na}_{2} \mathrm{EDTA}\end{array}$ & $\begin{array}{l}\leq 2 \\
\mu g \\
\mathrm{~kg}^{-1}\end{array}$ & $\begin{array}{l}\text { GBW10049, } \\
\text { GBW10051, } \\
\text { GBW08573, } \\
\text { GBW100358 } \\
\text { and spike } \\
\text { recovery }\end{array}$ & 102 \\
\hline $\begin{array}{l}\mathrm{As}^{\mathrm{III}}, \mathrm{As}^{\mathrm{V}} \\
\mathrm{MMA}^{\mathrm{V}} \\
\mathrm{DMA}^{\mathrm{V}} \\
\mathrm{AB}, \mathrm{AC}\end{array}$ & $\begin{array}{l}\text { HPLC-ICP- } \\
\text { MS }\end{array}$ & $\begin{array}{l}\text { Cordyceps } \\
\text { sinensis }\end{array}$ & $\begin{array}{l}\text { Heated with } \\
\text { simulated } \\
\text { gastric and } \\
\text { intestinal } \\
\text { juices. Also } 2 \% \\
\mathrm{HNO}_{3}\left(90^{\circ} \mathrm{C} 2\right. \\
\text { h) }\end{array}$ & $\begin{array}{l}\mathrm{AEC} \text {, gradient, } \\
0.1 \mathrm{mmol} \mathrm{L}^{-1} \text { and } 4 \\
\mathrm{mmol} \mathrm{L}^{-1} \mathrm{NH}_{4} \mathrm{CO}_{3}\end{array}$ & $\begin{array}{l}0.01 \\
\mu g L^{-1}\end{array}$ & $\begin{array}{l}\text { Carrot (supplier } \\
\text { not given) }\end{array}$ & 103 \\
\hline $\begin{array}{l}\mathrm{As}^{\prime \prime \prime}, \mathrm{As}^{\mathrm{V}} \\
\mathrm{MMA}^{\mathrm{V}} \\
\mathrm{DMA}^{\mathrm{V}}\end{array}$ & $\begin{array}{l}\text { HPLC-ICP- } \\
\text { MS, He } \\
\text { collision } \\
\text { gas }\end{array}$ & $\begin{array}{l}\text { Grape } \\
\text { products } \\
\text { (juice, } \\
\text { wine, } \\
\text { raisins) }\end{array}$ & $\begin{array}{l}\text { Solids } 0.15 \mathrm{~mol} \\
\mathrm{~L}^{-1} \mathrm{HNO}_{3}(100 \\
{ }^{\circ} \mathrm{C} 2 \mathrm{~h} \text { ). Wine } \\
\text { diluted 5-10 } \\
\text { fold }\end{array}$ & $\begin{array}{l}\text { RP-IP, C-18, } \\
\text { isocratic, } 10 \mathrm{mmol} \mathrm{L}^{-} \\
{ }^{1} \mathrm{C}_{4} \mathrm{H}_{9} \mathrm{NaO}_{3} \mathrm{~S}, 4 \mathrm{mmol} \\
\mathrm{L}^{-1} \mathrm{CH}_{2}(\mathrm{COOH})_{2}, 4 \\
\mathrm{mmol} \mathrm{L}^{-1} \mathrm{TMAH}, 0.05 \\
\%(\mathrm{~V} / \mathrm{V}) \mathrm{MeOH} \text { at } \mathrm{pH} \\
3.0\end{array}$ & $\begin{array}{l}\text { Not } \\
\text { given }\end{array}$ & $\begin{array}{l}\text { NIST SRMs } 2669 \\
\text { and } 3035\end{array}$ & 104 \\
\hline $\begin{array}{l}\mathrm{As}^{\prime \prime \prime}, \mathrm{As}^{\mathrm{V}} \\
\mathrm{MMA}^{\mathrm{V}} \\
\mathrm{DMA}^{\mathrm{V}}\end{array}$ & $\begin{array}{l}\text { HPLC-ICP- } \\
\text { MS, } \mathrm{H}_{2} \\
\text { collision } \\
\text { gas }\end{array}$ & Wine & $\begin{array}{l}\text { Diluted with } \\
\text { water }(1+1) \text {, } \\
\text { filtered }\end{array}$ & $\begin{array}{l}\text { AEC, gradient, } 20 \\
\mathrm{mmol} \mathrm{L}-1 \text { and } 50 \\
\mathrm{mmol} \mathrm{L}^{-1} \text { of } \mathrm{NH}_{4} \mathrm{CO}_{3} \\
(\mathrm{pH} \mathrm{9)},\end{array}$ & $\begin{array}{l}\leq 0.3 \\
\mu \mathrm{g} \mathrm{L}^{-1}\end{array}$ & $\begin{array}{l}\text { Spike recovery } \\
\text { and mass } \\
\text { balance of As } \\
\text { species vs total } \\
\text { As }\end{array}$ & 105 \\
\hline $\begin{array}{l}\text { As }^{\prime \prime \prime}, \mathrm{As}^{\mathrm{V}} \\
\mathrm{MMA}^{\mathrm{V}} \\
\mathrm{DMA}^{\mathrm{V}}, \\
\text { protein- } \\
\text { bound } \\
\text { As }\end{array}$ & $\begin{array}{l}\text { ET-AAS, } \\
\text { SEC-ICP-MS }\end{array}$ & $\begin{array}{l}\text { Extra virgin } \\
\text { olive oils }\end{array}$ & $\begin{array}{l}\text { Heating, } \\
\text { shaking with } \\
\text { 1:1 n-hexane: } \\
\text { acetone, } \\
\text { centrifuged, } \\
\text { pellet dissolved } \\
\text { in } 4: 1 \\
\mathrm{H}_{2} \mathrm{O}: \mathrm{MeOH}\end{array}$ & $\begin{array}{l}\text { SEC, isocratic, } 50 \\
\mathrm{mmol} \mathrm{L}^{-1} \\
\mathrm{NaCH}_{3} \mathrm{COOH}+5 \% \\
\mathrm{MeOH} . \mathrm{AEC} \text { : } \\
\text { isocratic, } 20 \mathrm{mmol} \mathrm{L}^{-} \\
{ }^{1} \mathrm{NH}_{4} \mathrm{H}_{2} \mathrm{PO}_{4}(\mathrm{pH} \mathrm{5.6)}\end{array}$ & $\begin{array}{l}\leq \\
0.03 \\
\mathrm{ng} \mathrm{kg}^{-} \\
1\end{array}$ & Spike recovery & 106 \\
\hline $\begin{array}{l}\mathrm{As}^{\prime \prime \prime}, \mathrm{As}^{\mathrm{V}} \\
\mathrm{MMA}^{\mathrm{V}} \\
\mathrm{DMA}^{\mathrm{V}}\end{array}$ & $\begin{array}{l}\text { HPLC-ICP- } \\
\text { MS He } \\
\text { collision } \\
\text { gas, }{ }^{89} \mathrm{Y} \\
\text { internal } \\
\text { standard }\end{array}$ & $\begin{array}{l}\text { Herbal tea } \\
\text { leaves and } \\
\text { infusions }\end{array}$ & $\begin{array}{l}\text { Leaves: } \mathrm{MAE} \\
0.05 \%(\mathrm{v} / \mathrm{v}) \\
\mathrm{HNO}_{3}(30 \mathrm{~min} \\
\left.90{ }^{\circ} \mathrm{C}\right) \text {, residue } \\
\text { reextracted } \\
\text { with } \mathrm{H}_{2} \mathrm{O} \text {, } \\
\text { Infusions: } 1.5 \\
\mathrm{~g}, 200 \mathrm{~mL} \mathrm{H}_{2} \mathrm{O} \\
\text { ( } 3 \text { min boiling) }\end{array}$ & $\begin{array}{l}\text { AEC, isocratic, } 20 \\
\mathrm{mmol} \mathrm{L}^{-1} \\
\left(\mathrm{NH}_{4}\right)_{2} \mathrm{H}_{2} \mathrm{PO}_{4}(\mathrm{pH} \\
6.0), 27^{\circ} \mathrm{C}\end{array}$ & $\begin{array}{l}\text { Leave } \\
\mathrm{s}-10 \\
\mu \mathrm{g} \\
\mathrm{kg}^{-1} \\
\text { Infusi } \\
\text { ons } \\
0.2 \\
\mu \mathrm{g} \mathrm{L}^{-1}\end{array}$ & $\begin{array}{l}\text { NIST SRM 1547, } \\
\text { ICYHJ (Poland) } \\
\text { INCT-TL-1, (tea } \\
\text { leaves), spike } \\
\text { recovery }\end{array}$ & 107 \\
\hline $\begin{array}{l}A s^{\prime \prime \prime}, A s^{v} \\
M M A^{v} \\
D M A^{V} \\
A B, A C\end{array}$ & $\begin{array}{l}\text { HPLC-ICP- } \\
\text { MS }\end{array}$ & $\begin{array}{l}\text { Bones } \\
\text { (panda and } \\
\text { pig) }\end{array}$ & $\begin{array}{l}\text { MAE with } 2 \% \\
V / V) \mathrm{HNO}_{3}(10 \\
\left.\min 95^{\circ} \mathrm{C}\right)\end{array}$ & $\begin{array}{l}\text { AEC, gradient, } \mathrm{A}: 2 \\
\mathrm{mmol} \mathrm{L}^{-1}\left(\mathrm{NH}_{4}\right)_{2} \mathrm{CO}_{3} \text {, } \\
\mathrm{B}: 100 \mathrm{mmol} \mathrm{L}^{-1} \\
\left(\mathrm{NH}_{4}\right)_{2} \mathrm{CO}_{3}, 30{ }^{\circ} \mathrm{C}\end{array}$ & $\begin{array}{l}\text { Not } \\
\text { given }\end{array}$ & Spike recovery. & 108 \\
\hline $\begin{array}{l}\mathrm{As}^{\prime \prime \prime}, \mathrm{As}^{\mathrm{V}} \\
\mathrm{MMA}^{\mathrm{V}}\end{array}$ & $\begin{array}{l}\text { HPLC-ICP- } \\
\text { MS }\end{array}$ & $\begin{array}{l}\text { River } \\
\text { water and }\end{array}$ & $\begin{array}{l}\text { Sediment: MAE } \\
0.3 \mathrm{~mol} \mathrm{~L}^{-1}\end{array}$ & $\begin{array}{l}\text { AEC, gradient } 10 \\
\mathrm{mmol} \mathrm{L}^{-1} \mathrm{NH}_{4} \mathrm{NO}_{3}, 60\end{array}$ & $\begin{array}{l}\text { Wate } \\
\mathrm{r}: \leq\end{array}$ & Spike recovery & 109 \\
\hline
\end{tabular}

Page 33 of 96 


\begin{tabular}{|c|c|c|c|c|c|c|c|}
\hline $\mathrm{DMA}^{\mathrm{V}}$ & & sediment & $\begin{array}{l}(\mathrm{NH} 4)_{2} \mathrm{HPO}_{4} \\
\text { and } 50 \mathrm{mmol} \mathrm{L}^{-} \\
{ }^{1} \text { EDTA }\end{array}$ & $\mathrm{mmol} \mathrm{L}^{-1} \mathrm{NH}_{4} \mathrm{NO}_{3}$ & $\begin{array}{l}0.2 \\
\mu g \mathrm{~L}^{-1} \\
\text { Sedi } \\
\text { ment } \\
: \leq 0.1 \\
\mu \mathrm{g} \\
\mathrm{kg}^{-1} \\
\end{array}$ & & \\
\hline $\begin{array}{l}\text { As }^{\text {III, }} \text { As } \\
M^{v} \text {, } \\
D^{v} \text {, } \\
\text { AMAv, } \\
\text { AB, lipid } \\
\text { soluble } \\
\text { As }\end{array}$ & NAA & Seafood & $\begin{array}{l}\text { SLLE, } \mathrm{H}_{2} \mathrm{O}+ \\
\text { MeOH + MIBK. } \\
\text { C-18 clean up, } \\
\text { SCX SPE, HPLC, } \\
\text { fraction } \\
\text { collection }\end{array}$ & $\begin{array}{l}\text { AEC: } \mathrm{As}^{\mathrm{III}}, \mathrm{As}^{\mathrm{V}} \text {, } \\
\mathrm{MMA}^{\mathrm{V}} \text {, isocratic, } 75 \\
\mathrm{mmol}^{-1} \mathrm{NH}_{4} \mathrm{H}_{2} \mathrm{PO}_{4} \\
+\left(\mathrm{NH}_{4}\right)_{2} \mathrm{HPO}_{4} \mathrm{pH} 5.5 \\
\mathrm{DMA}^{\mathrm{V}} \text { and } \mathrm{AB} \text { same } \\
\text { except } 10 \mathrm{mmol} \mathrm{L}^{-1} \\
\text { eluent at } \mathrm{pH} 6.5\end{array}$ & $\begin{array}{l}20 \mu \mathrm{g} \\
\mathrm{kg}^{-1}\end{array}$ & $\begin{array}{l}\text { NRCC DORM-2 } \\
\text { and DOLT-2, } \\
\text { IRMM CRM 627, } \\
\text { spike recovery }\end{array}$ & 110 \\
\hline $\mathrm{Sb}^{\prime \prime \prime}, \mathrm{Sb}^{\mathrm{V}}$ & ETV-ICP-MS & $\begin{array}{l}\text { Tea } \\
\text { infusions }\end{array}$ & $\begin{array}{l}2.0 \mathrm{~g} \text { of } \\
\text { dried tea } \\
\text { leaves } \\
\text { extracted } \\
\text { with } 20 \mathrm{~mL} \\
\text { water }(5 \mathrm{~min} \\
\left.95^{\circ} \mathrm{C}\right)\end{array}$ & $\begin{array}{l}\text { DSPME: } \mathrm{pH} \text { adjusted } \\
\text { to } 5.0, \mathrm{UAE} \text { of } \mathrm{Sb}^{\vee} \\
\text { onto } \mathrm{TiO}_{2} \\
\text { nanofibers, } \\
0.5 \mathrm{~mol} \mathrm{~L}^{-1} \mathrm{HNO}_{3} \\
\text { DLLME: APDC } \mathrm{pH} 5.0 \\
\text { shaken, sonicated, } \\
13: 1 \mathrm{EtOH}: \mathrm{CHCl}_{3} \text {, } \\
\text { centrifuged. }\end{array}$ & $\begin{array}{l}\leq \\
0.03 \\
\mathrm{pg} \\
\mathrm{mL}^{-1}\end{array}$ & $\begin{array}{l}\text { GBW 076059, } \\
\text { spike recovery }\end{array}$ & 111 \\
\hline
\end{tabular}

\subsection{Chromium}

Most of the published research into $\mathrm{Cr}$ speciation analysis in the current review period has featured HPLC-ICP-MS methods, though several methods in which ETAAS was used have also been described. The toxicity of $\mathrm{Cr}^{\mathrm{Vl}}$ continues to drive interest in the determination of $\mathrm{Cr}$ species in consumer products, and so the focus of the majority of the methods is on the determination of $\mathrm{Cr}^{\mathrm{VI}}$, and not necessarily on $\mathrm{Cr}^{\text {III }}$. However, if possible redox interconversions are to be monitored, it is necessary to be able to detect $\mathrm{Cr}^{\prime \prime \prime}$ as well.

There have been a number of reviews covering $\mathrm{Cr}$ speciation this year. Methods for $\mathrm{Cr}$ speciation in foodstuffs published in the past 20 years have been reviewed ( 84 references) ${ }^{112}$. Despite the title, the reviewers do include some discussion of the analysis of waters and soils. Speciation analyses are divided into two categories: off-line and on-line, by which the reviewers mean methods incorporating a separation step linked directly with an element specific detector. The reviewers warn of the possibilities of changes in speciation that can occur during all stages of the method (from sample preparation to detection), which may be difficult to detect, and extol the benefits of speciated IDA with ${ }^{50} \mathrm{Cr}^{\mathrm{III}}$ and ${ }^{53} \mathrm{Cr}^{\mathrm{VI}}$. By this procedure not only can interspecies conversion be followed, but also such artefacts can be corrected. The reviewers highlight the discrepancies in the literature for the analysis of bread and tea for $\mathrm{Cr}^{\mathrm{VI}}$, whose concentrations have been reported to be much lower when determined by an ID method. They consider that alkaline extraction is not 
guaranteed to be specific for $\mathrm{Cr}^{\mathrm{VI}}$. In the wake of reports of the genotoxicity of $\mathrm{Cr}^{\mathrm{III}}$ (in yeast) and the possibility of oxidation following ingestion, they also consider that the demand for reliable determination of both species in foodstuff will increase, and call for the development of CRMs for $\mathrm{Cr}^{\mathrm{Vl}}$ in a range of foodstuffs, particularly bread, dairy products and tea that may be contaminated by manufacturing and processing methods. That there is still some way to go in the development of reliable $\mathrm{Cr}$ speciation analyses, is shown in a comprehensive review (161 references) of the determination of $\mathrm{Cr}^{\mathrm{Vl}}$ in various solid environmental, industrial and food matrices ${ }^{113}$ in which the reviewers make comments similar to those just elaborated about the problems of extraction without interconversion and of the benefits of speciated IDA. It is pointed out that there has been a shift from spectrophotometry (with diphenylcarbazide) to HPLC-ICP-MS, which allows the quantification of $\mathrm{Cr}^{\mathrm{VI}}$ by speciated IDA. The use of $0.5 \mathrm{~mol} \mathrm{~L}^{-1} \mathrm{NaOH}+0.28 \mathrm{~mol} \mathrm{~L}^{-1} \mathrm{Na}_{2} \mathrm{CO}_{3}$ solutions with heating at $90-95{ }^{\circ} \mathrm{C}$ seems to a widespread procedure that extracts and stabilises the $\mathrm{Cr}^{\mathrm{VI}}$

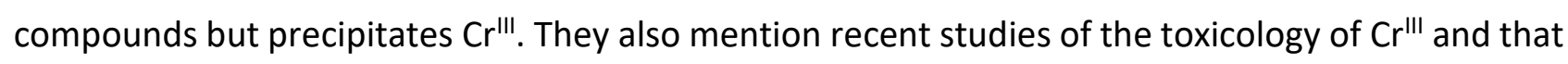
for the simultaneous determination of the two $\mathrm{Cr}$ species, they can be extracted with alkaline EDTA. The sample materials featured in a review (99 references) entitled, 'Nanomaterial's based chromium speciation in environmental samples' ${ }^{\prime 14}$ turn out to be waters of various types. The review is difficult to read because almost every sentence needs the input of an editor familiar with standard written scientific English. Much of the review is occupied by 6 summary tables, each devoted to a different nanomaterial, from which it is clear that much of the published literature features separation by SPE with carbon nanomaterials. Such methods do have the advantage that the separation step is often combined with preconcentration, so that LOD values down to single-digit $p g \mathrm{~L}^{-1}$ have been reported. One table summarises applications of magnetic nanomaterials, which offer the further advantage of high-efficiency separation.

Sadiq and Beauchemin have developed a procedure for assessing the bioaccessible fractions of As, $\mathrm{Cr}$ and Se species in rice ${ }^{68}$. Rice (either before or after cooking) was packed into a mini-column and sequentially eluted with artificial versions of saliva, gastric juice, and intestinal juice. The fractions were collected and the species of all three elements determined by ICP-MS following separation in one anion-exchange chromatographic run with three-step gradient elution. The $\mathrm{Cr}$ species were eluted last in a mobile phase of $0.8 \mathrm{~mol} \mathrm{~L}^{-1}$ nitric acid and monitored at $\mathrm{m} / \mathrm{z} 52$ and 53 . A collision reaction interface was operated with hydrogen as the collision gas. The LOD values for the $\mathrm{Cr}$ species were 1, 30 and $4 \mu \mathrm{g} \mathrm{L}^{-1}$ for $\mathrm{Cr}^{\prime \prime \prime}$ and 1, 20 and $3 \mu \mathrm{g} \mathrm{L}^{-1}$ for $\mathrm{Cr}^{\mathrm{VI}}$ in water, saliva, and gastric juice respectively. They showed that on cooking (by a method in which all the cooking water was 
adsorbed), all $\mathrm{Cr}^{\mathrm{VI}}$ was reduced to $\mathrm{Cr}^{\mathrm{III}}$, and that washing raw rice with room temperature water removed $60-70 \%$ of the total $\mathrm{Cr}$. They also found that saliva and gastric juice extracted most of the bioaccessible species, which in the case of $\mathrm{Cr}$ amounted to about $50 \%$ of the total remaining after cooking, when the concentration was about $250 \mu \mathrm{g} \mathrm{kg}^{-1}$. No information was provided about how the moisture content of the rice was accounted for.

The speciation analysis of environmental samples for $\mathrm{Cr}$, such as sediments, is still a considerable challenge because of the possibility of species interconversion during the analytical procedure. A speciated IDA HPLC-ICP-MS method has been developed and applied to the determination of $\mathrm{Cr}^{\mathrm{VI}}$ in sediments from the Sava river in Slovenia ${ }^{115}$. The extraction procedure, slightly modified from a previous method, consisted of ultrasonication of $2 \mathrm{~g}$ of wet sediment at $80^{\circ} \mathrm{C}$ (for $1 \mathrm{~h}$ at $700 \mathrm{~W}$ ) with

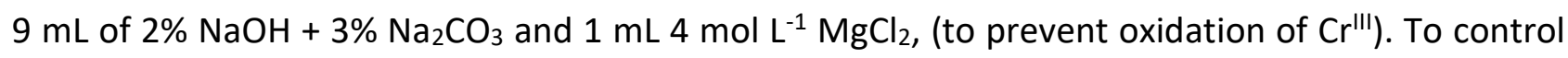
for species interconversion during the extraction procedure, $100 \mu \mathrm{L}$ of ${ }^{53} \mathrm{Cr}^{\prime \prime \prime}$ and $100 \mu \mathrm{L}$ of ${ }^{50} \mathrm{Cr}^{\mathrm{VI}}$ $\left(10,000 \mu \mathrm{g} \mathrm{L}^{-1}\right.$ each) were added. After cooling and filtering $(0.45 \mu \mathrm{m})$, the extract was diluted 10 times prior to analysis. The species were separated by a previously published anion-exchange HPLC method with gradient elution from water to $0.7 \mathrm{~mol} \mathrm{~L}^{-1} \mathrm{NaCl}$ over $10 \mathrm{~min}$, followed by a $10 \mathrm{~min}$ regeneration. The LOD in the diluted extract was $2 \mu \mathrm{g} \mathrm{L}^{-1}$, corresponding to $1 \mu \mathrm{g} \mathrm{kg}^{-1}$ in the sediment. The procedure was validated by the analysis of CRM $041\left(\mathrm{Cr}^{\mathrm{Vl}}\right.$ in soil, from Merck), whose concentration is $130 \mathrm{mg} \mathrm{kg}^{-1}$. When applied to 14 real river sediment samples with total $\mathrm{Cr}$ concentrations ranging from 24 to $191 \mathrm{mg} \mathrm{kg}^{-1}, \mathrm{Cr}^{\mathrm{VI}}$ was only detected in three of them at singledigit $\mu \mathrm{g} \mathrm{kg}^{-1}$ concentrations. The introduction to the paper consists of a comprehensive survey of previously published methods. A new HPLC-ICP-MS method has been developed for the speciation analysis of waste waters ${ }^{116}$ in which the species were separated at room temperature on a mixed anion-cation exchange column (Dionex lonPac CG5A $4 \times 50 \mathrm{~mm}$ ) by isocratic elution with $2 \mathrm{mmol} \mathrm{L}^{-}$ ${ }^{1}$ 2,6-pyridinedicarboxylic acid, $2 \mathrm{mmol} \mathrm{L}^{-1}$ disodium hydrogen phosphate, $10 \mathrm{mmol} \mathrm{L}^{-1}$ sodium iodide and $50 \mathrm{mmol} \mathrm{L}^{-1}$ ammonium acetate at $\mathrm{pH}$ 6.8. All forms of $\mathrm{Cr}^{\prime \prime \prime}$ were converted to a common species by incubation with 2,6-pyridinedicarboxylic acid for $30 \mathrm{~min}$ in a hot water bath at $80^{\circ} \mathrm{C}$. The results of a detailed optimisation of the chromatography and of an extensive investigation of potential interferences are provided, together with the spike recoveries of each species from 15 different kinds of industrial wastewater. For a $20 \mu \mathrm{L}$ injection volume, the LOD values (measured at $\mathrm{m} / \mathrm{z} 53$ ) were $0.7 \mu \mathrm{g} \mathrm{L}^{-1}$ for both species, recoveries of 50 and $500 \mu \mathrm{g} \mathrm{L}^{-1}$ spikes were $>90 \%$ for almost all the waters. The results were also in agreement with those obtained by a standard spectrophotometric method (ISO 11083), except for biologically treated effluent from a food factory, for which the 
spectrophotometric method caused significant reduction of $\mathrm{Cr}^{\mathrm{Vl}}$. As there is a clear link between increased concentration of fine particulates in the atmosphere and harmful and adverse effects on the human population, there is continuing interest in speciation analysis of atmospheric aerosols. Researchers have examined fractionated atmospheric aerosols whose sizes ranged from $0.25 \mu \mathrm{m}$ to $>16 \mu \mathrm{m}$ collected on silicon wafers with a 7-stage cascade impactor from the centre Jeddah city, Saudi Arabia ${ }^{117}$. Two fractions $(0.5-0.25 \mu \mathrm{m}$ and 1.0-2.0 $\mu \mathrm{m})$, selected because their mass concentrations were the greatest, were examined by SR-TXRF and SR-XANES spectroscopy techniques at the IAEA experimental end station at Elettra Sincrotrone Trieste, Italy. They found that of the $\mathrm{Cr}$ present in the particles, just over $90 \%$ was $\mathrm{Cr}^{\mathrm{III}}$ with the remainder $\mathrm{Cr}^{\mathrm{VI}}$. For the smaller fraction, $\mathrm{Cr}$ was present at $0.1 \mathrm{ng} \mathrm{m}^{-3}$ and for the larger fraction the concentration was $0.9 \mathrm{ng} \mathrm{m}^{-3}$. However, the relative uncertainties in the $\mathrm{Cr}^{\mathrm{VI}}$ values were approaching $50 \%$.

A method for the analysis of the dilute $\mathrm{HCl}$ leachate of children's toys has been developed ${ }^{118}$ to test for compliance with European standard EN-71. Following extraction with $0.07 \mathrm{~mol} \mathrm{~L}^{-1} \mathrm{HCl}$ by agitation for $1 \mathrm{~h}$ at $37{ }^{\circ} \mathrm{C}$ (intended to mimic the effect of gastric juice should a component be swallowed), dilution and addition of EDTA and ammonia to bring the $\mathrm{pH}$ to 7 , the $\mathrm{Cr}$ species were separated by anion-exchange HPLC with detection by ICP-MS. Two HPLC methodologies were investigated: one involved a Hamilton PRP X100 column, and the other an Agilent Bio WAX shorter column (50 mm as opposed to $250 \mathrm{~mm}$ ) with smaller particles (5 $\mu \mathrm{m}$ compared with $10 \mu \mathrm{m}$ ). The mobile phases (isocratic elution) were almost identical (60-75 mmol L- $1 \mathrm{NH}_{4} \mathrm{NO}_{3}$, adjusted to $\mathrm{pH}$ 7.0 - 7.1 with $\mathrm{NH}_{4} \mathrm{OH}$ ). Because of the shorter retention times (the later eluting $\mathrm{Cr}^{\mathrm{V} l}$ peak returned to the baseline by $2.5 \mathrm{~min}$ ), the Bio WAX column was chosen. The researchers indicated that the separations were performed at ambient temperature, but a value of $30{ }^{\circ} \mathrm{C}$ is given in a summary table. The LOD values were 1 and $0.7 \mu \mathrm{gg}^{-1}$ in a solid sample, and 3 and $0.7 \mathrm{ng} \mathrm{L}^{-1}$ in solution, for $\mathrm{Cr}^{\mathrm{III}}$ and $\mathrm{Cr}^{\mathrm{VI}}$, respectively. The researchers reported that the concentrations of $\mathrm{Cr}^{\mathrm{Vl}}$ in all the $\mathrm{HCl}$ extracts were below the LOD, which they attributed to the inability of the dilute acid to liberate any $\mathrm{Cr}^{\mathrm{VI}}$, though amounts of $\mathrm{Cr}^{\mathrm{III}}$ equivalent to several hundred $\mu \mathrm{g} \mathrm{kg}^{-1}$ were leached. There was no discussion of the possible reduction of $\mathrm{Cr}^{\mathrm{VI}}$ to $\mathrm{Cr}^{\mathrm{III}}$, nor was any method validation, such as spike recovery or analysis of a CRM, reported. The researchers stated that the addition of EDTA and ammonia preserved $\mathrm{Cr}$ species for $24 \mathrm{~h}$, but did not cite a source or provide any results to support this statement. Attempts to detect $\mathrm{Cr}$ in the toys with EDXRF spectrometry were not successful.

An RP ion-pair HPLC-ICP-MS method to determine the species released from metal implants into blood and joint effusion has been developed ${ }^{119}$. The separation was at room temperature on an Page 37 of 96 
Agilent ZORBAX Eclipse XDB-C8 column, (C8 $5 \mu \mathrm{m}, 2.1 \times 150 \mathrm{~mm}$ ) with isocratic elution with a mobile phase consisting of $5 \mathrm{mmol} \mathrm{L}^{-1}$ tetrabutylammoniumiodide and $0.6 \mathrm{mmol} \mathrm{L^{-1 }}$ disodium EDTA salt in at $\mathrm{pH}$ 7. The isotopes monitored were ${ }^{52} \mathrm{Cr}$ and ${ }^{45} \mathrm{Sc}$ (internal standard) and a collision cell with helium as collision gas was used to mitigate isobaric interferences. Samples for speciation analysis were prepared by centrifuging $250 \mu \mathrm{L}$ through Amicon $30 \mathrm{kDa}$ ultra centrifugal filters at 16,000 g for $10 \mathrm{~min}$ at $10{ }^{\circ} \mathrm{C}$ followed by dilution $(1+9)$ in the mobile phase and equilibration at room temperature for $30 \mathrm{~min}$. Spiked samples were first prepared by incubation with $100 \mu \mathrm{L}$ of a standard solution containing $1 \mathrm{mg} \mathrm{L}^{-1}$ of $\mathrm{Cr}^{\prime \prime \prime}$ and $\mathrm{Cr}^{\mathrm{VI}}$. The LOD values were $0.1 \mathrm{\mu g} \mathrm{L}^{-1}$ for both $\mathrm{Cr}^{\mathrm{III}}$ and $\mathrm{Cr}^{\mathrm{VI}}$. Part of the validation involved the analysis of the Seronorm ${ }^{\mathrm{TM}}$ Trace Elements in Whole Blood L-3 and the researchers claim that the results show the obtained values are fit for our purpose and serve as evidence of no interconversion or other changes between both species during sample preparation,' though it is difficult to see how they arrived at this conclusion from the results presented in the paper. They found significantly higher concentrations in joint effusion samples from patients with implants compared to those of the control group. However, there were no differences between the concentrations of both species and total chromium in blood. They concluded that $\mathrm{Cr}$ was mostly present in the trivalent form bound to proteins.

Studies of the interaction of $\mathrm{Cr}$ species with a standard ecotoxicological test medium were supported by measurement with HPLC-ICP-MS and SpICP-MS ${ }^{120}$. Almost all of the relevant analytical information is contained in the supplementary information. The anion-exchange HPLC method (which is in the French language) was based on an earlier 1999 publication and involves a Dionex Thermo AG7 $2 \times 50 \mathrm{~mm}$ column and isocratic elution with $0.4 \mathrm{~mol} \mathrm{~L}^{-1} \mathrm{HNO}_{3}$ spiked with $1 \mu \mathrm{g} \mathrm{L}^{-1}$ of Rh as internal standard. The instrument was operated in kinetic energy discrimination mode with hydrogen/helium, and the ions monitored were ${ }^{52} \mathrm{Cr}^{+},{ }^{53} \mathrm{Cr}^{+}$, and ${ }^{103} \mathrm{Rh}^{+}$. The sp work was performed on a different instrument, the operating conditions were again chosen based on previously published work, to verify the hypothesis of the presence of $\mathrm{Cr}$-containing particles in the samples. No details are given of the composition of the test medium, which is described as the standard algal medium of the ISO 8692, and featured the green alga Raphidocelis subcapitata as test organism. The researchers found no redox interconversions between $\mathrm{Cr}^{\mathrm{III}}$ and $\mathrm{Cr}^{\mathrm{VI}}$ either in the presence or absence of algal cells, but that the concentration of ionic $\mathrm{Cr}^{\text {III }}$ decreased to $<$ LOD (not given) in under $2 \mathrm{~h}$ with the corresponding precipitation of colloidal particles of carbonates and hydroxides of variable diameters. They concluded that $\mathrm{Cr}^{\mathrm{III}}$ was 4 to 10 times more toxic than $\mathrm{Cr}^{\mathrm{VI}}$ which is opposite to the normal findings that $\mathrm{Cr}^{\mathrm{V} l}$ is more toxic than $\mathrm{Cr}^{\mathrm{III}}$. 
A number of non-chromatographic separations have also been developed with quantification by AAS. A UAE emulsification microextraction method with ETAAS for speciation in waters has been devised ${ }^{121}$ in which $\mathrm{Cr}^{\mathrm{VI}}$ was selectively extracted into tributylphosphate from an aqueous samples to which $\mathrm{HCl}$ and $\mathrm{NaCl}$ had been added. No disperser solvent was needed and the extraction procedure, optimised with a rotatable central composite design procedure, consisted of transferring $9.0 \mathrm{~mL}$ of sample to a centrifuge tube followed by the addition of $1.0 \mathrm{~mL}$ of $5 \mathrm{~mol} \mathrm{~L}^{-1} \mathrm{HCl}, 1.0 \mathrm{~mL}$ of $30 \% \mathrm{NaCl}$ solution and the rapid injection of $60.0 \mu \mathrm{L}$ of tributyl phosphate. The tube was immersed into an ultrasonic bath for $10 \mathrm{~min}$ then centrifuged for $5 \mathrm{~min}$ at $2000 \mathrm{rpm}$ to break the emulsion and separate the aqueous and organic phases. The organic phase was diluted with $0.1 \mathrm{~mol} \mathrm{~L}^{-1} \mathrm{HNO}_{3}$ in methanol (volume not given) to reduce the viscosity, and $10.0 \mu \mathrm{L}$ of this solution was directly injected into the graphite furnace. Total $\mathrm{Cr}$ was determined after oxidation of $\mathrm{Cr}^{\mathrm{III}}$ to $\mathrm{Cr}^{\mathrm{VI}}$ by $\mathrm{KMnO}_{4}$ (0.02 $\mathrm{mol} \mathrm{L}^{-1}$ for $10 \mathrm{~min}$ ). A number of possible interferents were investigated. The LOD values were $0.8 \mathrm{ng} \mathrm{L}^{-1}$ for $\mathrm{Cr}^{\mathrm{VI}}$ and $2 \mathrm{ng} \mathrm{L}^{-1}$ for total $\mathrm{Cr}$, with an enrichment factor of about 77 . The method was validated by spike recoveries of both species from three samples (mineral, tap and natural waters) at concentrations of $0.02 ; 2.0$ and $10.0 \mu \mathrm{g} \mathrm{L}-1$, and ranged from 90 to $114 \%$. The procedure was applied to the analysis of ten mineral water samples in PET bottles purchased in supermarkets in Paraná State, Brazil. Both species were detected in all samples, with total Cr concentrations ranging from 0.47 to $3.9 \mu \mathrm{g} \mathrm{L}^{-1}$ and those for $\mathrm{Cr}^{\mathrm{VI}}$ from 0.02 to $2.3 \mu \mathrm{g} \mathrm{\textrm {L } ^ { - 1 }}$. A CPE extraction procedure has been developed for the analysis of the artificial saliva extracts of snuff ${ }^{122}$, in which $\mathrm{Cr}^{\text {III }}$ was selectively extracted as the complex with 8-hydroxyquinoline into a non-ionic surfactant (Triton X114) followed by back CPE into dilute nitric acid solution prior to measurement by ET-AAS. Both the extraction and back extraction required many minutes of heating in a water bath. Ultrasound may also have been involved. The LOD was $0.04 \mu \mathrm{g} \mathrm{L}^{-1}$ and total $\mathrm{Cr}$ in the extract was determined after reduction of $\mathrm{Cr}^{\mathrm{VI}}$ with sodium sulfite, so that $\mathrm{Cr}^{\mathrm{VI}}$ was determined by difference. The total $\mathrm{Cr}$ method was validated by the analysis of a Virginia tobacco leaf CRM and by spike recovery. The method was applied to 23 real samples for which both species were found in the extracts at concentrations ranging from $0.27-1.0 \mu \mathrm{g}$-1 for $\mathrm{Cr}^{\mathrm{III}}$ and $0.72-2.5$ for $\mathrm{Cr}^{\mathrm{V} \mathrm{l}}$. A somewhat similar method, in which the extraction was aided by microcrystalline cellulose, has been described ${ }^{123}$. At around $\mathrm{pH} 7, \mathrm{Cr}^{\prime \prime \prime}$ was adsorbed from $10 \mathrm{~mL}$ of sample onto $5 \mathrm{mg}$ cellulose, which was collected in the surfactant-rich phase by CPE with Triton X-100 that formed on heating at $80^{\circ} \mathrm{C}$ for $10 \mathrm{~min}$. After centrifuging, and discarding the aqueous phase, the residue was ultrasonicated with $0.1 \mathrm{~mL}$ of an ethanol + hydrogen peroxide mixture, and, after centrifuging again, $\mathrm{Cr}$ was measured by ET-AAS with $5 \mu \mathrm{g}$ of palladium 
as a chemical modifier. The enrichment factor was 95 and the LOD was $6 \mathrm{ng} \mathrm{L}^{-1}$. Total $\mathrm{Cr}$ was determined after reduction of $\mathrm{Cr}^{\mathrm{VI}}$ with $\mathrm{Fe}^{\mathrm{Il}}$ in a sulfuric acid solution, and hence the $\mathrm{Cr}^{\mathrm{VI}}$ concentration was calculated by difference. The procedure was validated by the analysis of five water CRMs and by spike recoveries (at concentrations of 50 and $100 \mathrm{ng} \mathrm{L}^{-1}$ ) from five real water samples, in two of which $\mathrm{Cr}^{\text {III }}$ was detected but in none of which was $\mathrm{Cr}^{\mathrm{VI}}$ detected. A SPE-FAAS method has been devised in which $\mathrm{Cr}^{\text {III }}$ was selectively retained on a column of aminated Amberlite $X A D-4$ resin at $\mathrm{pH} 8^{124}$. To constrain the time involved to reasonable values, the maximum sample volume was $100 \mathrm{~mL}$ at a loading flow rate of $4 \mathrm{~mL} \mathrm{~min}^{-1}$ As neither reagent could elute the retained species completely, elution was by sequential washing with $1 \mathrm{~mL}$ of $3.0 \mathrm{M} \mathrm{HCl}$ and $1 \mathrm{~mL}$ of $2.0 \mathrm{M}$ $\mathrm{NaOH}$ at $5 \mathrm{~mL} \mathrm{~min}{ }^{-1}$. The LOD was $0.04 \mu \mathrm{g} \mathrm{L}^{-1}$. Total $\mathrm{Cr}$ was determined after reduction of $\mathrm{Cr}^{\mathrm{VI}}$ with ethanol and sulfuric acid. The method was validated by the analysis of three CRMs, one of which (BCR-544 lyophilised water) is certified for both $\mathrm{Cr}$ species (at concentrations around $25 \mu \mathrm{g} \mathrm{L}^{-1}$ ) and by spike addition (at concentrations of 20 and $40 \mu \mathrm{g} \mathrm{L}^{-1}$ ) to five real water samples, only two of which contained measurable concentrations of both species.

\subsection{Gold}

Four papers report on methods for the speciation of Au in the dissolved phase and as nanoparticles in the period covered by this update. In the first of these a PLRP-S400 column, with a mobile phase of $10 \mathrm{mmol} \mathrm{L}^{-1}$ Sodium dodecyl sulfate (SDS) and $5 \%$ methanol as flowing at $0.5 \mathrm{~mL} \mathrm{~min}^{-1}$, was coupled with a triple quadrupole ICP-MS instrument, operating in single $Q$ mode, using PEEK tubing ${ }^{125}$. The reported LOD values were $2.2 \mathrm{ng} \mathrm{L}^{-1}$ for $\mathrm{Au}^{\mathrm{III}}, 2.8 \mathrm{ng} \mathrm{L}^{-1}$ for $10 \mathrm{~nm}$ AuNPs and $3.7 \mathrm{ng}$ $\mathrm{L}^{-1}$ for $40 \mathrm{~nm}$ AuNPs respectively. The observed elution order, $40 \mathrm{~nm}$ NPs then $10 \mathrm{~nm}$ NPs followed by dissolved $\mathrm{Au}$, suggests that the separation was based on size exclusion. The method was validated using NIST SRM 8011 Au NPs with a nominal diameter of $10 \mathrm{~nm}$ with a found diameter of $9 \mathrm{~nm}$. The HPLC-ICP-MS method was then used for the size characterisation of gold species in lysates of green algae, Acutodesmus obliquus, incubated with both $10 \mathrm{~nm}$ and $40 \mathrm{~nm}$ diameter AuNPs. Recoveries from these experiments ranged from $86.3 \pm 1.2 \%$ to $115 \pm 5.0 \%$ whilst recoveries from tap water spiked with varied between $69.3 \pm 1.2 \%$ to $103.4 \pm 2.7 \%$ for both $10 \mathrm{~nm}$ Au NPs nanoparticles and $\mathrm{Au}^{\prime \prime \prime}$. The second paper covered here used a similar HPLC-ICP-MS set up, although with no MeOH in the SDS mobile phase, to separate Au NPs of 5, 10 and $30 \mathrm{~nm}$ and $\mathrm{Au}^{\prime \prime 1126}$. Particle size measurements were obtained using linear regression of particle size versus retention time. The recoveries obtained for $30 \mathrm{~nm}$ Au NPs spiked into locally collected environmental waters samples ranged from $39.5 \pm$ $0.7 \%$ to $91.3 \pm 1.7 \%$. The lowest recovery values were obtained from spiked sewage influent and 
effluent samples which the authors attributed to agglomeration of the NPs to a size of $60 \mathrm{~nm}$ or greater as particles of this size were retained on the column. Recovery values of 90 to $101 \%$ for the

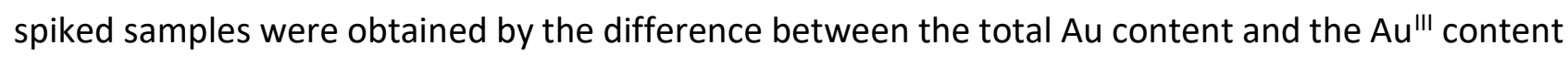
obtained from the HPLC-ICP-MS data. The use of CE-ICP-MS for the separation and detection of Au NPs and $\mathrm{Au}^{\prime \prime \prime}$ has also been reported this year ${ }^{127}$. In this work the separation was achieved using a polyimide-coated fused silica capillary (i.d. $75 \mu \mathrm{m}$; o.d. $375 \mu \mathrm{m}$; length $70 \mathrm{~cm}$ ) and a running buffer of $40 \mathrm{mmol} \mathrm{L}^{-1}$ 4-(2-hydroxyethyl)piperazine-1-ethanesulfonic acid (HEPES) at pH 7.4 with an applied potential of 10-30 kV. The CE system was directly coupled to a self-aspirating nebuliser and included a sheath flow of $4 \mathrm{mmol} \mathrm{L}^{-1} \mathrm{HEPES}$ and $20 \mu \mathrm{g} \mathrm{L}^{-1} \mathrm{Ge}$ again at $\mathrm{pH}$ 7.4. Under these conditions the linear response, between peak area and Au concentration, was found to be from 1.7 to $57.0 \mathrm{mg} \mathrm{L}^{-1}$ with the LOD value reported as $1.0 \mu \mathrm{g} \mathrm{L} \mathrm{L}^{-1}$. The LOD values for Au NPs were $1.4(5 \mathrm{~nm})$ to $4.2(50 \mathrm{~nm}) \mu \mathrm{g}$ $\mathrm{L}^{-1}$ respectively. The authors then spiked simulated cytosol solution with $\mathrm{Au}$ NPs of varying diameters with the aim of understanding the mechanisms of Au NPs as an anti-cancer agent. It was found that, when spiked into normal cytosol, albumin Au NP conjugates evolved in human serum remained intact but that under simulated cancer cytosol conditions, the nanoconjugates decomposed. The chromatographic separations reported in these three papers all show a degree of peak overlap and this, combined with the low recovery values also reported, highlight the difficulties involved in analytical methods for NPs. A selective extraction method for the determination of Au NPs by GFAAS has also been reported this year ${ }^{128}$. The addition of ascorbic acid, to give a concentration of $0.1 \mathrm{mmol} \mathrm{L}^{-1}$, enabled the quantitative extraction of both AuNPs and $\mathrm{Au}^{\prime \prime \prime}$ by $\mathrm{Fe}_{3} \mathrm{O}_{4}$ NPs from spiked superficial water, groundwater, seawater and synthetic wastewater samples. For the selective extraction of Au NPs sodium thiosulfate $\left(0.01 \mathrm{mmol} \mathrm{L}^{-1}\right.$ final concentration) was also added to the water samples to reduce $A u^{\prime \prime \prime}$ to $A u^{\prime}$ and form an $\left[\mathrm{Au}\left(\mathrm{S}_{2} \mathrm{O}_{3}\right)_{2}\right]^{-3}$ complex that is not extracted by the $\mathrm{Fe}_{3} \mathrm{O}_{4}$ NPs. The method yielded detection limits of 19.5 and $19.7 \mathrm{ng} \mathrm{L}^{-1}$ for AuNPs and $A u^{\prime \prime \prime}$ respectively with a repeatability lower than $6 \%$. An enrichment factor of greater than 196 , corresponding to an extraction efficiency of $98 \%$, was obtained for both species. The method was applicable to Au NPs ranging in diameter from 8 to $96 \mathrm{~nm}$ with no apparent effect from any particle coating and recoveries of $86-96 \%$ and $53-100 \%$ are reported for Au NPs and Au ${ }^{\prime \prime \prime}$ respectively.

\subsection{Halogens}

The speciation of I and the identification of I containing metabolites in marine animals has been the focus of two recent research papers using HPLC coupled to different MS sources. The use of a $\mathrm{C}_{18}$ HPLC separation with a water to methanol gradient (0-100\% in $20 \mathrm{~min}$ ) connected in parallel to ICP- 
MS and ES-MS/MS ${ }^{129}$ is a powerful tool for speciation measurements, encompassing both elemental and molecular information simultaneously on the same species. In this work it was used to investigate 13 species of marine ascidian or sea squirt, recording for the first time iodinated metabolites in South African marine invertebrates. A number of iodinated and brominated tyrosines and tyramines, including 3,5-diiodo-4-methoxyphenethylamine, 3,5-datromo-4methoxyphenethylamine, dibromotetramethyltyrosine and 3-iodotetramethyltyrosine, were all identified in extracts from the marine species studied. Some of the major I containing species were not fully identified, partly it seems because of the small amount of material available, which did not allow further, more in-depth characterisation, such as NMR to be carried out. This is one of the advantages of using these detectors in parallel, that for some elemental species identification is possible with a small sample mass and shows what an excellent analytical platform this is for natural products research, allowing as it does a method to locate the hetero-atom containing species of interest via ICP-MS and their rapid identification by ES-MS/MS. However, HPLC-ICP-MS alone has also been shown ${ }^{130}$ to be a useful approach to studying hetero-atom containing species, as demonstrated by the investigation of the bioavailable I in Abalone (Haliotis discus hannai). In this study, the in vitro dialysability approach was used to assess the bioavailability of iodide, iodate, 3-iodo-L-tyrosine (MIT), and 3,5diiodo-L-tyrosine (DIT), using an lonPac AS7 AEC ( $250 \mathrm{~mm} \times 4 \mathrm{~mm}$ i.d.) and a AG7 guard column with an isocratic eluent consisting of $175 \mathrm{mM}$ ammonium nitrate plus $5 \%(\mathrm{v} / \mathrm{v})$ methanol at $\mathrm{pH} 4.9$ to separate the 4 iodine species. Clearly the disadvantage of this approach compared to the former, is that well-defined molecular standards are required for identification by retention time, rather than by direct structural characterisation using ES-MS/MS. The results of this study indicated that abalone is feasible as a new nutritional I source and may find application in fortified foods.

Two methods based on GC coupled to ICP-MS have been developed for the measurement of polybrominated diphenyl ether (PBDPE) flame retardants by monitoring the signal for ${ }^{79} \mathrm{Br}$. To measure these persistent organic pollutants in fish tissue ${ }^{131}$ a number of factors including the effect of the sample introduction conditions, the flow rate of the carrier gas, the splitless injection delay time and the matrix of the sample, were investigated, to determine whether compound independent calibration (CIC) could be used. Clearly one of the major advantages of using ICP-MS as a chromatography detector is that quantitation is possible without the need for the use of the exact same molecular standard as the analyte being measured. However, as part of the validation procedure it needs to be shown that the detector response for the isotope being monitored is 
independent of the compounds being measured. In this work the authors used two calibration approaches based on ssIDMS to measure nine PBDEs in the NIST SRM 1947 Lake Michigan fish tissue. In the first method, only BDE 28 was quantified using IDMS and was then used to quantify the other analytes as a reference compound by $\mathrm{CIC}$; recoveries were in the range 75 to $97 \%$ for the tetra or less substituted compounds, whereas for the congeners with greater $\mathrm{Br}$ substitution the recoveries were not so good ( 23 to $54 \%$ ), showing a decrease with increase in molecular weight. In the second method IDMS was undertaken for all the distinctive isotopically enriched ${ }^{81} \mathrm{Br}$-containing standards available (BDE 28, BDE 47, BDE 99, BDE 100, BDE 153, and BDE 154), whereas when enriched standards were not available isomers of the analyte were used as a reference compound for $\mathrm{CIC}$ quantification. Recovery values of all target analytes ranged between 86 to $118 \%$. The assessment ${ }^{132}$ of human exposure to six PBDE congeners (BDE 28, BDE 47, BDE 99, BDE 100, BDE 153, BDE 154) by GC-ICP-MS used serum samples as the matrix of choice. The aim was to develop a method that could be used on typical $1 \mathrm{~mL}$ serum sample sizes available in routine human biomonitoring studies. The effect of different extracting agents, including: formic acid; formic acid in 2-propanol (4:1, v/v); 0.1 $\mathrm{mol} \mathrm{L}^{-1} \mathrm{HCl}$ in $\mathrm{MeOH}$; and 25\% $\mathrm{TMAH}$, and subsequent addition of iso-octane on the extraction efficiency when applying different modes of extraction including: mechanical shaking; microwave; and ultrasound-assisted extraction, was systematically studied. In the final developed method the PBDEs were extracted from serum by 30 min of mechanical shaking with formic acid, this was then extracted with iso-octane with 30 min of mechanical shaking, followed by clean-up of the extract on a Florisil column. The protocol was validated by analysis of human serum NIST SRM 1957 (nonfortified human serum) and NIST SRM 1958 (fortified human serum). The recoveries were between 96 and 101\% for SRM 1957 and from 89 to 114\% for SRM 1958. The repeatability and reproducibility of the analytical method was within $5.9 \%$ and $6.1 \%$, respectively, whereas the LOD values for the PBDEs analysed were between 1.6 and $3.9 \mathrm{ng} \mathrm{L}^{-1}$. The method was tested by analysing human serum samples from 6 subjects from Slovenia and the concentrations determined were in a range similar to that reported for other European countries.

In a similar vein to the analysis of volatile Br-containing compounds the trend of using GC coupled to ICP-MS has been used for the analysis of stable volatile and semi-volatile Cl-containing compounds and has encompassed the use and development of advanced MS instrumentation. It is exciting to see the development of new instrumental approaches ${ }^{133}$ that can be applied to the measurement of elemental species particularly, as in this case, where the MS source can be used in elemental and molecular modes, within the same instrumentation. A GC was coupled to a He atmospheric-pressure 
dielectric barrier discharge (AP-DBD) plasma coupled to a single quadrupole API MS instrument for the analysis of organochlorine pesticides spiked into orange juice. This approach using GC and working on halogens was chosen because of the difficulties in the formation of positive elemental ions from such a low-gas temperature plasma. The authors report that quantitation was compound independent when using low concentrations of oxygen (11 ppm v/v) added to the plasma to reduce post-column peak broadening, but that this was lost when the oxygen levels increased to >110 ppm v/v. Quantitation was limited to only 2 orders of magnitude, which is poor compared to an argon plasma, but for a much lower energy plasma is acceptable and delivered an LOD of $0.5-1 \mathrm{pg}$ of $\mathrm{Cl}$ on column. The development of a generic GC-MC-ICP-MS system ${ }^{134}$ for the online isotope ratio measurement of ${ }^{37} \mathrm{Cl}:{ }^{35} \mathrm{Cl}$, has been applied to chlorinated methanes, ethanes and ethenes, various chlorinated benzenes and phenols, as well as semi-volatile organic chlorine containing pesticides such as the hexachlorocyclohexanes, dichlorodiphenyltrichloroethane (DDT), chlordecone and related derivatives with boiling points up to $350^{\circ} \mathrm{C}$. Together with the well established methods for $\mathrm{H}$ and $\mathrm{C}$ isotope ratio methods, stable $\mathrm{Cl}$ isotope analysis would allow for three dimensional studies to distinguish the source of environmental contamination. To be able to separate the semi-volatile compounds of interest the authors developed a specific transfer line that eliminated the potential for condensation of the compounds. This was facilitated by redirecting the argon carrier gas through the heated GC oven and then down the heated $\left(350{ }^{\circ} \mathrm{C}\right)$ transfer line $(1 / 1600$ i.d. stainless steel tubing) containing the fused silica GC column $(0.32 \mathrm{~mm}$ i.d.). The separated compounds were released from the fused silica capillary into the argon gas stream in the hottest zone of the transfer line, where they were strongly diluted and then transported to the argon plasma in the ICP torch. The high argon flow within the transfer line facilitated the coaxial fast transport of the compounds from the end of the GC capillary into the plasma and produced sharp and well-defined chromatographic peaks. The developed method was evaluated by using offline characterised inhouse RMs, such as chloroethenes, chloroacetic acid and hexachlorocyclohexenes. The analytical precision ( 1 sigma) was usually better than $\pm 0.2 \%$ o for a single compound and $\pm 0.3 \%$ for compound-specific analysis of mixtures. The accuracy of the method was within $\pm 0.2 \%$ o compared to the available offline values. The isotopic LOD was improved by one order of magnitude to 250 pmol $\mathrm{Cl}$ on column, corresponding to similar to $10 \mathrm{ng} \mathrm{Cl}$.

\subsection{Iron}

Iron is considered an essential element for many organisms, from microorganisms to plants to humans. It has a central role in many chemical processes. For instance, an excess or deficiency of 
this element can cause health problems such as anaemia, retinal degeneration, hemochromatosis and cancer. Lately, new findings have discovered the relationship between the concentration of intracellular iron and cancer. Iron is generally found as Fe" and Fe"II and its important functions are dependent on the oxidation state.

AlChaubossi et al ${ }^{135}$ review this year the state of the art and latest developments of mass spectrometry for iron speciation in plants. Particular attention is given to the advantages of chromatography with mass spectrometer detectors as ICP-MS, high resolution electrospray MS/MS, QTOF-MS and Q orbitrap-MS. The growing role of molecular mass spectrometry in speciation is highlighted. According to the authors opinion, the increasing sensitivity and robustness of high resolution MS techniques are the main causes of the progressive replacement of ICP-MS by ES-MS detection. Sample introduction miniaturisation by using on-chip HPLC is also covered in depth as a future trend of special importance when performing iron speciation in intracellular fluids (xylem and phloem) at the picolitre volume range. Of interest for the reader is the section focused on the validation of iron speciation data. The review includes 52 references.

Two papers report on Fe speciation in the clinical field this year. The relationship between iron and cancer was evaluated by X-Ray absorption near edge spectroscopy (XANES) ${ }^{136}$. The technique was applied to determine the ratio between $\mathrm{Fe}^{\mathrm{II}}$ and $\mathrm{Fe}^{\mathrm{III}}$ in ovarian cancer samples of different types. Results showed changes in the valence state of iron depending on the type of cancer. Comparing to inorganic references, XANES spectra of the different cancer samples showed a shift of Fe" absorbance edge to lower energy while Fe $\mathrm{F}^{\text {III }}$ showed a shift to higher energy. Borderline serious tumour and high grade serious carcinoma I spectra show features suggesting a mixture of iron in the second and third oxidation states. In contrast, high grade serious carcinoma II and endometroid cystadenocarcinoma spectral features display a similarity to the Fe ${ }^{\text {III } X A N E S ~ s p e c t r u m . ~ T h e ~ r e s u l t s ~}$ obtained are very promising and evidence the potential of XANES for clinical applications. However, as the authors pointed out, more investigations are needed with the aim of determining the chemical structure of the organic-iron compounds contained in the samples. One of the most important health problems related to iron is iron overload. In patients with iron overload diseases such as hemochromatosis, iron accumulates mainly in liver and heart as a non-transferrin bound iron (NTBI) fraction composed of non-proteinaceous and low molecular mass compounds. Despite this, this fraction remains poorly characterised. To this end SEC-ICP-MS analysis of plasma samples from humans, pig and horses was performed as a first attempt to characterise the NTBI fraction ${ }^{137}$. The resulting chromatograms provide from 2 to 6 iron containing peaks (depending on the origin of 
the plasma samples) with molecular masses ranging from 400 to $2500 \mathrm{Da}$. Ferric citrate standards gave similar chromatograms that those of the tested samples but not the same. This finding evidence that ferric citrate is not the main iron specie in blood. No significant differences in the chromatographic profiles were detected between hemochromatosis and control patients.

One interesting approach focused on Fe is the work developed by Garcia-Fernandez et a/ ${ }^{138}$ related to the transformations of in-house synthesised iron oxide NPs coated with tartaric and adipic acids (TA-Fe NPs) in cell cultures (Caco-2 and HT29). Cells were exposed to different concentrations of 4 $\mathrm{nm}$ Ta-FeNPs (from 0.1 to $2 \mathrm{mmol} \mathrm{L}^{-1}$ ) for $48 \mathrm{~h}$. Afterwards, cell pellets were collected for total Fe quantification and NP extraction. For evaluating NP transformations, a reversed-phase $C_{18}$ (Nucleosil 250x4,6 mm, $7 \mathrm{~mm}$ ) column and $\mathrm{NH}_{4} \mathrm{CH}_{3} \mathrm{CO}_{2}$ buffer containing $10 \mathrm{mmol} \mathrm{L} \mathrm{L}^{-1} \mathrm{SDS}$ as mobile phase were used in combination with ICP-MS. Quantification was by suIDA with a ${ }^{57} \mathrm{Fe}$ isotopically enriched-standard. To assess the capability of the method, two types of Fe NPs were studied: commercially available sucrose-coated Fe NPs and TA-FeNPs. Due to the tendency of Fe ${ }^{\text {III }}$ to

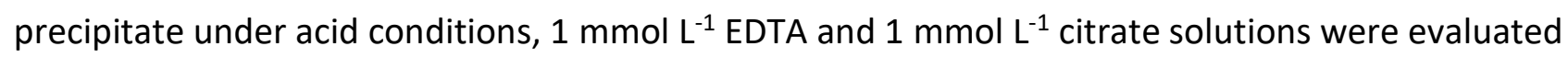
as complexing agents. The resulting chromatograms showed the presence of two-baseline separated peaks corresponding to particulate and ionic iron forms. Both complexing solutions facilitated the elution of ionic Fe but the presence of EDTA significantly decreased the peak area of the sucrose-coated Fe NPs which did not occur in the case of TA-FeNPs. Recoveries of 81 and $78 \%$ were obtained from sucrose-coated Fe NPs and TA-FeNPs, respectively whereas only a 30\% was achieved for the ionic species. The low recovery was attributed to the strong interaction of the ionic species with the SDS. The developed method was subsequently applied to the cell extracts exposed to TA-FeNPs. Three different fractions appeared in the chromatograms at retention times that corresponded to NP aggregates, dispersed NPs and soluble Fe, respectively. The presence of aggregates was verified by TEM measurements. The sum of the NP fraction accounted for about $70 \%$ of the total eluted Fe which evidences the slow release of ionic Fe from NPs.

Finally, two papers on the application of microextraction procedures following the principles of green chemistry have appeared this year for the speciation of $\mathrm{Fe}^{\prime \prime}$ and $\mathrm{Fe}^{\prime \prime \prime}$. The first work ${ }^{139}$ describes a rapid and simple method based on dispersive liquid-liquid microextraction for the determination of Fe" and Fe"ll followed by FAAS measurements. The factors affecting the microextraction procedure are described in detail. The developed protocol includes the use of 4-5-dihydroxy-1,3 benzene disulfonic acid (Tiron) as complexing agent to form the anionic complex with Fe $\mathrm{e}^{\text {III }}$ at $\mathrm{pH} 3.0$, and the addition of cetylpyridinium chloride (CPC) as cationic surfactant to form the hydrophobic complex 


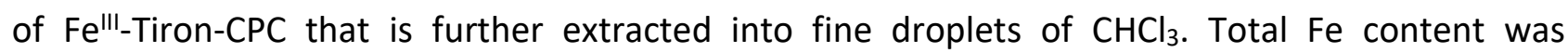
determined after performing the oxidation of $\mathrm{Fe}^{\text {II }}$ to $\mathrm{Fe}^{\text {III }}$ with $\mathrm{H}_{2} \mathrm{O}_{2}$ and the concentration of Fe " was calculated by difference. Under optimal conditions a LOD value of $5.6 \mu \mathrm{g} \mathrm{L}^{-1}$ was obtained with a preconcentration factor of 25 . The accuracy of the method was validated by analysing a drinking water CRM with a certified value for total Fe content of $100 \mu \mathrm{g} \mathrm{L}^{-1}$ that agreed well with the value found $99.6 \pm 2.7 \mu \mathrm{g} \mathrm{L}^{-1}$. The method was further applied to water samples of different nature and rice samples. The second paper ${ }^{140}$ describes the use of an aqueous two phase system (ATP) to selectively separate Fe" and Fe"ll. The ATP system consists of two immiscible liquid phases formed by combining aqueous solutions of a polymer and an electrolyte. Any Fe" present reacts with 1,10 phenanthroline that concentrates in the top of the polymer rich phase (containing PEO1500 polymer) while Fe ${ }^{\text {III }}$ remains in the bottom phase of the system (salt-rich phase containing the electrolyte $\mathrm{Na}_{3} \mathrm{C}_{6} \mathrm{H}_{5} \mathrm{O}_{7}$ ). Parameters affecting separation of the species such as the nature of the macromolecule (L64 triblock copolymer or PEO1500 polymer), the use of electrolytes $\left(\mathrm{Na}_{3} \mathrm{C}_{6} \mathrm{H}_{5} \mathrm{O}_{7}\right.$ or $\mathrm{Na}_{2} \mathrm{SO}_{4}$ ), the effect of $\mathrm{pH}$ and the quantity of extractant were thoroughly investigated. The best extraction conditions for $\mathrm{Fe}^{\text {II }}$ in presence of Fe $\mathrm{III}^{\mathrm{II}}$ was found to be $\mathrm{PEO} 1500+\mathrm{Na}_{3} \mathrm{C}_{6} \mathrm{H}_{5} \mathrm{O}_{7}$ at $\mathrm{pH}=7.0$ and $5 \mathrm{mmol}^{-1} \mathrm{~L}^{-1}$ of phenanthroline. The developed method was further employed to selectively determine Fe"I and Fe" in water samples spiked with known amounts of both oxidation states. Recovery values ranged from 89 to $106 \%$ were achieved.

\subsection{Mercury}

There is one review covering $\mathrm{Hg}$ speciation this year, on the topic of the role of Se in mercury toxicity $^{141}$. The comprehensive review covers the current analytical techniques for sample preparation from biological tissues and blood, $\mathrm{Hg}$ species separation, $\mathrm{Hg}$ species structural identification and quantification including direct analytical techniques and cites 128 references. The authors conclude that progress in this field has been slow, due to current analytical techniques having a limited capability to answer the questions posed by the subject, and that the extraction of the molecular species is the most crucial step as regardless of the strong affinity between $\mathrm{Hg}$ and $\mathrm{Se}$, decomposition of $\mathrm{Hg}$ containing bio-selenols is very often observed. They also suggest that there is an urgent need for improved validation studies of naturally formed $\mathrm{Hg}$-Se heteroatomic particles, which possess various shapes and sizes and that NPs extraction protocols need to provide assurances that coagulation or decomposition of the clusters is not taking place during the extraction steps. This latter conclusion also applies to the wider field of toxicology as many toxic species undergo storage/removal processes from the body in the 'particulate' form. 
In recent years the number of published papers on $\mathrm{Hg}$ speciation has risen, with one growth area being the use of $\mathrm{Hg}$ isotopic measurements to elucidate reaction mechanisms and pollution sources with GC-ICP-MS as the separation and detection techniques. This year sees the first report of the use of HPLC followed by CV-MC-ICP-MS for the measurement of natural $\mathrm{Hg}$ isotopic ratios ${ }^{142}$. A $\mathrm{C}_{18}$ column $(100 \times 10 \mathrm{~mm})$ and a mobile phase of $0.05 \% \mathrm{~m} / \mathrm{m}$ L-cysteine and $0.006 \% \mathrm{v} / \mathrm{m}$ acetic acid, adjusted to $\mathrm{pH} 4$ with ammonia, flowing at $1 \mathrm{~mL} \mathrm{~min}^{-1}$ was used to separate $\mathrm{iHg}$ and $\mathrm{MeHg}$ in $15 \mathrm{mins}$ with an elution time difference between the two compounds of about five minutes. This time difference allowed the collection of the fractions containing each $\mathrm{Hg}$ species, into $10 \mathrm{~mL}$ microwave digestion vessels containing $50 \mu \mathrm{L}$ of $5 \% \mathrm{~m} / \mathrm{m}$ pyrogallol, without any carryover. Prior to this HPLC separation $\mathrm{Hg}$ species were extracted from fresh frozen fish with a solution of $0.5 \% \mathrm{~m} / \mathrm{m}$ of Lcysteine, $0.2 \% \mathrm{~m} / \mathrm{m}$ of pyrogallol and protease and lipase, at a concentration of 0.01 and $0.075 \mathrm{~g}$ $\mathrm{mL}^{-1}$, respectively with vortex mixing and UAE at $37^{\circ} \mathrm{C}$ for one hour, centrifugation and filtering through a $0.45 \mu \mathrm{m}$ PTFE filter membrane. The collected fractions were then dried and subjected to a microwave digestion with $\mathrm{HNO}_{3}$ and $\mathrm{H}_{2} \mathrm{O}_{2}, 0.5$ and $0.1 \mathrm{~mL}$ respectively. The isotopic composition of the $\mathrm{Hg}$ in the digests was measured using CV-MC-ICP-MS with $\mathrm{SnCl}_{2}$ as the reductant. The generated $\mathrm{Hg}^{0}$ vapour was combined via a T-piece with a solution of $100 \mathrm{ng} \mathrm{L}^{-1} \mathrm{Tl}$, produced from a desolvating inlet system, which was used for mass bias correction.

Combined standard uncertainties of $\delta^{199 / 198} \mathrm{Hg}, \delta^{200 / 198} \mathrm{Hg}, \delta^{201 / 198} \mathrm{Hg}$ and $\delta^{202 / 198} \mathrm{Hg}$ values determined for MeHg in BCR 463 and NIST SRM 1947 CRMs ranged from 0.10\%o to 0.22\%, a comparable precision to that obtainable with GC-MC-ICP-MS. Delta Hg values determined for both MeHg and total Hg in the above CRMs agreed very well with indicative values of NIST SRM 1947 and results previously reported for BRC 463. The authors also report that $\mathrm{Hg}$ isotope fractionation can occur during both dissociation of $\mathrm{MeHg}$ and $\mathrm{Hg}^{0}$ volatilisation from solutions containing reduced sulphur. A detailed discussion of the steps needed to minimise experimentally derived $\mathrm{Hg}$ fractionation is also included in the paper. One of the limitations of MC-ICP-MS, unless ion counters are fitted instead of the more common Faraday cup detectors, is the need for relatively concentrated samples, typically in the $1-10 \mathrm{ng} \mathrm{mL}^{-1}$ range or greater. The paper just discussed used fraction collection from HPLC to overcome this and an alternative strategy, the preconcentration of $\mathrm{Hg}$ species by a programmed temperature vaporisation (PTV) injector fitted with a packed liner has also been reported this year ${ }^{143}$. A 'large injection volume' interface, consisting of a straight liner ( 2 $\mathrm{mm}$ i.d., $2.75 \mathrm{~mm}$ o.d., $120 \mathrm{~mm}$ length) packed with styrenedivinylbenzene (SDVB) resin, specific area $500 \mathrm{~m}^{2} \mathrm{~g}^{-1}$, and stable to $245^{\circ} \mathrm{C}$ which is above the boiling points for $\mathrm{Hg}$ species was fitted to 
the inlet of a GC. The GC outlet was coupled to an MC-ICP-MS using a commercially available heated transfer line. A full discussion of the optimisation and performance characteristics are given in the paper and the system allowed the measurement of $\mathrm{Hg}$ isotopic ratios in samples with an $\mathrm{Hg}$ content down to approximately $150 \mathrm{ng} \mathrm{g}^{-1}$. A compound specific bracketing procedure was required for mass bias correction due to the differential behaviour of $\mathrm{Hg}$ species in the PTV injector. The external repeatability for $\mathrm{MeHg}$ and $\mathrm{Hg}$ was found to be 0.31 and $0.39 \%$ respectively, again comparable to other transient signal methods.

Probably the most common sample types analysed for their $\mathrm{Hg}$ content are biota and food stuffs. A comparison has been made between the use of graphene and graphene oxide (GO) functionalised $\mathrm{SiO}_{2}$ microspheres for suitability as the HPLC stationary phase for $\mathrm{Hg}$ speciation ${ }^{144}$. The previously synthesised and characterised (reference cited) stationary phases were packed to give columns of $5 \mu \mathrm{m}, 4.6 \mathrm{~mm}$ i.d. $\times 5 \mathrm{~cm}$ long. A suite of reagents, ammonium acetate, L-cysteine, thiourea, 2 thiosalicylic acid (TSA) and L-phenylalanine (PHE) were used to prepare a variety of mobile phases. The optimal mobile phase was found to be $2 \mathrm{mmol} \mathrm{L}^{-1} \mathrm{TSA}-5 \mathrm{mmol} \mathrm{L}^{-1}$ Phe at a pH of 8.0 flowing at $1 \mathrm{ml} \mathrm{min}{ }^{-1}$ through a GO/ $\mathrm{SiO}_{2}$ column which gave a good separation of $\mathrm{iHg}, \mathrm{MeHg}$, EtHg and PheHg in 12 minutes with detection by ICP-MS. The linear range of the HPLC-ICP-MS system was found to be $0.5-500 \mu \mathrm{g} \mathrm{L}^{-1}$ and the reported LOD values for the four $\mathrm{Hg}$ species under study ranged from $0.16-0.68 \mu \mathrm{g} \mathrm{L}-1$, comparable to those obtained using commercial $\mathrm{C}_{18}$ columns, with a repeatability of $<5 \%$. The method was validated using a fish CRM (GBW 100299), which was subjected to an UAE procedure with L-cysteine and $\mathrm{HCl}$, with the found and certified results being in good agreement. An ion-pair HPLC-ICP-MS method has been developed with and sodium dodecylbenzene sulfonate (SDBS), where sodium 3-mercapto-1-propysulfonate (MPS) and L-cysteine (Cys) were individually added in mobile phases to transform mercury species into negative or positive $\mathrm{Hg}$-complexes ${ }^{144}$. Phenylalanine (PHE) was also used to allow for rapid baseline separation in a combination of short $\mathrm{C}_{18}$ guard columns. The optimum mobile phase was $2.0 \mathrm{mmol} \mathrm{L}^{-1} \mathrm{SDBS}+2.0 \mathrm{mmol} \mathrm{L}^{-1} \mathrm{Cys}+1.0 \mathrm{mmol}$ $\mathrm{L}^{-1} \mathrm{Phe}$ at $\mathrm{pH}$ 3.0. Baseline separation of $\mathrm{iHg}, \mathrm{MeHg}, \mathrm{EtHg}$ and $\mathrm{PhHg}$ was achieved in three minutes on two $12.5 \mathrm{~mm} \mathrm{C}_{18}$ columns coupled consecutively. Detection limits were reported as $0.015,0.014$, 0.028 and $0.042 \mu \mathrm{g} \mathrm{L}^{-1}$ for $\mathrm{iHg}, \mathrm{MeHg}, \mathrm{EtHg}$ and $\mathrm{PhHg}$ respectively. Recoveries of $>94 \%$ are reported for iHg and MeHg in two CRMs, GBW 10029 fish tissue and BCR-463 tuna fish. The method was then applied to $\mathrm{Hg}$ in extracts $\left(0.5 \% \mathrm{~m} / \mathrm{m}\right.$ of L-cysteine with vortex mixing and UAE at $\left.40{ }^{\circ} \mathrm{C}\right)$ of local fish where MeHg was present at 3.7-20.3 $\mu \mathrm{g} \mathrm{kg}^{-1}$. A hyphenated system has been developed for iHg and MeHg preconcentration, separation and quantification by the online coupling of SPE-HPLC-ICP- 
$\mathrm{MS}^{145}$. Both analytes, were preconcentrated on a microcolumn, fitted in a six port injection valve, filled with multiwalled carbon nanotubes (MWCNTs) functionalised with poly-L-methionine (polymet-MWCNTs). Mercury species were extracted from BCR-463 tuna fish and NRCC TORT-2 lobster hepatopancreas CRMs with $5 \mathrm{~mL}$ of $5 \mathrm{~mol} \mathrm{~L}^{-1} \mathrm{HCl}$ and $\mathrm{UAE}$ for 15 minutes followed by $\mathrm{pH}$ neutralisation. The extract was then loaded onto the microcolumn, eluted on to an HPLC column with $1 \mathrm{~mL} \mathrm{10 \%} \mathrm{HCl;} 0.1 \%(\mathrm{v} / \mathrm{v})$ 2-mercaptoethanol flowing at $1.7 \mathrm{~mL} \mathrm{~min}^{-1}$. An enrichment factor of 190 for both $\mathrm{Hg}$ species was obtained when $20 \mathrm{~mL}$ of sample was passed through the microcolumn. For the HPLC separation a mobile phase composed of a ternary mixture of $0.5 \%$ formic acid $+0.2 \%$ 2-mercaptoethanol $+20 \%$ methanol was used. Separation of both $\mathrm{Hg}$ species was accomplished in $10 \mathrm{~min}$ on a $250 \mathrm{~mm} \mathrm{C}_{18}$ column. Sample throughput was five per hour and the microcolumn was stable for at least 575 injection/elution cycles. The method LOD values were $15 \mathrm{ng} \mathrm{L}^{-1}$ for $\mathrm{iHg}$ and 17 $\mathrm{ng} \mathrm{L^{-1 }}$ for MeHg. The peak area RSD values for $5 \mathrm{ng} \mathrm{L}^{-1}$ of each $\mathrm{Hg}$ species were below $5 \%$. Recoveries of $\mathrm{Hg}^{\prime \prime}$ and $\mathrm{MeHg}$ were $93 \%$ or better for both species for the two CRMS analysed. Mercury species were subsequently analysed for in spiked fish oil-based dietary supplements and Antarctic water. Recoveries of the spiked samples ranged from 96 to $114 \%$ at spiking levels of 5, 10 and $15 \mathrm{ng} \mathrm{g}^{-1}$. No $\mathrm{Hg}$ species were detectable in unspiked Antarctic waters, which is unsurprising for a $20 \mathrm{~mL}$ sample volume as $\mathrm{Hg}$ levels are typically sub $\mathrm{ng} \mathrm{L}^{-1}$ in these waters hence a much larger sample volume would be required. The separation of three $\mathrm{Hg}$ species ( $\mathrm{iHg}$, $\mathrm{MeHg}$ and $\mathrm{EtHg}$ ) in 12 minutes using a $\mathrm{C}_{18}$ column and a gradient elution, by mixing methanol and a solution composed of $0.4 \%$ (v/v) 1-octyl-3-methylimidazolium chloride, $100 \mathrm{mmol} \mathrm{L}^{-1} \mathrm{NaCl}$ and $20 \mathrm{mmol} \mathrm{L}^{-1}$ of a citric acid/citrate buffer at $\mathrm{pH} 2.0$, has been reported ${ }^{146}$. The HPLC eluent was passed through a UV reactor, consisting of a PTFE tube (0.5 m length, $0.8 \mathrm{~mm}$ I.D. and $1.2 \mathrm{~mm}$ O.D.) wrapped around a $20 \mathrm{~W}$ Hg UV lamp, before $\mathrm{CV}$ generation with $\mathrm{NaBH}_{4}$ and detection by AFS. The LOD values obtained using this system were in the range of $0.05-0.11 \mu \mathrm{g} \mathrm{L}^{-1}$ whilst the linear range was between 0.2 to $1000 \mu \mathrm{g} \mathrm{L}^{-1}$ with retention time and peak area RSD values of 0.6 and $2 \%$ respectively. Locally purchased seafood, yeast and garlic were subjected to an acidic leaching procedure $\left(5 \mathrm{~mL}\right.$ of $5 \mathrm{~mol} \mathrm{~L}^{-1} \mathrm{HCl}$ and UAE for 10 minutes) and the method LOD values for these samples ranged between 10 and $35 \mathrm{ng} \mathrm{g}^{-1}$ depending on the $\mathrm{Hg}$ species and food type. Spike recovery values for the food samples were in the range of 95 to $99 \%$ at a spiking level of $20 \mu \mathrm{gg} \mathrm{L}^{-1}$.

Although banned in the EU thiomersal is still in use in the USA and other countries hence research is still conducted on its quantification and behaviour in vaccines. In a recent study using TXRF EtHg, from the breakdown of thiomersal (THI), has been shown to bind to the protein fraction and the 
extent of this binding quantified using SEC-ICP-MS ${ }^{147}$. For the TXRF experiments a tetravalent influenza vaccine (IV) solution containing THI (10 $\left.\mathrm{mg} \mathrm{L}^{-1} \mathrm{Hg}\right)$ and a control sample (THI) in $0.9 \%$ sodium chloride, $10 \mathrm{mg} \mathrm{L}^{-1} \mathrm{Hg}$ ) were desalted using ultrafiltration, with a $10 \mathrm{kDa}$ cut off, with the filtrate then diluted with high purity water and the extracts again subjected to the ultrafiltration protocol to remove any $\mathrm{Hg}$ not bound to the IV. Subsequently, $20 \mu \mathrm{L}$ filtrate, $20 \mu \mathrm{L}$ Se standard in $20 \%$ nitric acid ( $10 \mathrm{mg} \mathrm{L}^{-1} \mathrm{Se}$ ) and $20 \mu \mathrm{L}$ meso-2,3-dimercaptosuccinic acid ( $2.5 \mathrm{mmol} \mathrm{L}^{-1}$ ) were mixed and aliquots of this solution placed on siliconised quartz glass discs and dried at $80^{\circ} \mathrm{C}$ for 10 min for analysis by TXRF. Mercury was only detectable in the samples prepared from the IV solution leading the authors to conclude that the EtHg from THI was able to bind to the protein fraction of the vaccine. To further investigate this conclusion two different SEC columns were separately coupled to an ICP-MS instrument and the $\mathrm{Hg}$ signal monitored. In each case a gradient elution was used and full details of the method are given in the paper. The mercury-containing fraction was larger than $133 \mathrm{kDa}$, which indicated the binding of EtHg to hemagglutinin, the active ingredient in the influenza vaccine. The method allowed for external calibration with EtHg and a binding of $141 \mu \mathrm{g} \mathrm{L}^{-1} \mathrm{Hg}$ was shown for a vaccine solution, $1.5 \mathrm{mg} \mathrm{L}^{-1}$, that was incubated with $25 \mathrm{mg} \mathrm{L}^{-1} \mathrm{Hg}$. The authors "would like to emphasise that vaccination is highly important for public health and that this work should not be misinterpreted as being directed against the use of vaccines in general, but rather as an approach to better understand the chemical consequences of the addition of organomercurials to thiomersal containing vaccines". A non-chromatographic method has also been reported for the quantification of $\mathrm{THI}$ and $\mathrm{iHg}$ in vaccine samples ${ }^{148}$. The method is based on the "degradation" of EtHg from THI by Fe ${ }^{I l l+}$ and FI-CV-AFS. The mechanisms of this are not discussed in the paper but references where this is so are cited. To determine $\mathrm{iHg}$ the reductant was $0.005 \% \mathrm{~m} / \mathrm{v} \mathrm{KBH} 4(0.005 \%$, $\mathrm{m} / \mathrm{v}$ ) in $0.2 \% \mathrm{w} / \mathrm{v} \mathrm{KOH}$, the carrier fluid was $10 \% \mathrm{v} / \mathrm{v} \mathrm{HCl}$ and the carrier gas was Ar flowing at 400 $\mathrm{mL} \mathrm{min}^{-1}$. For total $\mathrm{Hg}$ measurements the reductant was $15 \% \mathrm{~m} / \mathrm{v} \mathrm{KBH} 4(0.005 \%, \mathrm{~m} / \mathrm{v})$ in $0.2 \% \mathrm{w} / \mathrm{v}$ $\mathrm{KOH}$, the carrier fluid was $10 \mathrm{mg} \mathrm{L}^{-1} \mathrm{Fe}^{I I I+}$ in $10 \% \mathrm{v} / \mathrm{v} \mathrm{HCl}$ and the carrier gas was Ar flowing at $200 \mathrm{~mL}$ $\mathrm{min}^{-1}$. The amount of EtHg and hence $\mathrm{THI}$ is then determined by difference. Under these conditions LOD values for $\mathrm{THI}$ and $\mathrm{iHg}$ were $0.03 \mathrm{mg} \mathrm{L}^{-1}$ and $0.02 \mathrm{mg} \mathrm{L}^{-1}$, respectively. Spike recovery values, into commercially available vaccines at 10,50 and $100 \mathrm{mg} \mathrm{L}^{-1}$ for THI and 10, 50 and $100 \mu \mathrm{g} \mathrm{L}^{-1}$ for $\mathrm{iHg}$, ranged from 96 to $104 \%$.

Finally in this section, methods for the determination of $\mathrm{Hg}$ species in waters are reported on. An on-line digestion method has been developed, based on oxidation of organic mercury (Org- $\mathrm{Hg})$ species at ambient temperature using potassium permanganate in the presence of sulphide, for the 
speciation of $\mathrm{Hg}$ in waters ${ }^{149}$. The digestion of $\mathrm{Org}-\mathrm{Hg}$ was reported to be instantaneous and quantitative. The developed system utilises a sequential injection sequence in conjunction with AFS and calibration using only $\mathrm{Hg}^{2+}$. After acidification and decomposition of the organic matter with $\mathrm{KMnO}_{4} \mathrm{iHg}$ was quantified whilst total $\mathrm{Hg}(\mathrm{THg})$ was determined after online Org- $\mathrm{Hg}$ digestion and Org-Hg was calculated by difference. After optimisation the LOD for $\mathrm{Hg}$ was $3 \mathrm{ng} \mathrm{L}^{-1} \mathrm{Hg}$. The method was applied to the analysis of lake water samples for the determination of $\mathrm{iHg}$ and $\mathrm{Org}-\mathrm{Hg}$. Relative recoveries of $94-97 \%$ for $\mathrm{iHg}$ and $94-95 \%$ for $\mathrm{T}-\mathrm{Hg}$, with $\mathrm{RSD}$ values of $1.1-3.1 \%$, were obtained in samples spiked with $100 \mathrm{ng} \mathrm{L^{-1 }} \mathrm{Hg}^{2+}$ and $100 \mathrm{ng} \mathrm{L-1} \mathrm{Org}-\mathrm{Hg}$, respectively. The paper includes a discussion on the possible role of sulphide in the digestion of Org- $\mathrm{Hg}$. To improve LOD values for the simultaneous determination of $\mathrm{Hg}, \mathrm{Pb}$ and $\mathrm{Sn}$ species at ultra-trace levels using GC-ICP-MS, an online automated pre-concentration method using large volume injections with a PTV injector fitted with a sorbent packed liner has been used ${ }^{150}$. The influence of parameters such as the transfer temperature and time, carrier gas flow rate and amount of packing material was investigated. The maximum volume injected through single or multiple injection modes were also optimised to obtain the best compromise between chromatographic resolution and sensitivity. After optimisation, LOD values down to the $\mathrm{pg} \mathrm{L}^{-1}$ level were achieved for all species studied. Molybdenum disulfide nanosheets, prepared by a hydrothermal method coupled with a UAE liquid exfoliation method have been used for SPE of Hg species ${ }^{151}$. The $\mathrm{Hg}$ species, $\mathrm{iHg}$, MeHg and EtHg, were adsorbed onto the nano-MoS 2 at a pH of 5 and desorbed with 4 mol L-1 $\mathrm{HCl}$. An HPLC-UV-HG-AFS system, with a $\mathrm{C}_{18}$ column and a mobile phase of $10 \% \mathrm{MeOH} / 0.46 \% \mathrm{NH}_{4} \mathrm{CH}_{3} \mathrm{COOH} / 0.12 \% \mathrm{~L}$-cysteine flowing at $1.0 \mathrm{~mL}$ $\mathrm{min}^{-1}$, was used to separate and quantify $\mathrm{Hg}$ species extracted from water samples. The LOD values obtained were 0.017, 0.037 and $0.021 \mathrm{ng} \mathrm{mL}^{-1}$ for $\mathrm{Hg}$, MeHg and EtHg, respectively. Spike recoveries from water samples ranged from $83-113 \%$. On a similar theme an aminated Amberlite XAD-resin has been prepared and used for SPE of $\mathrm{Hg}$ species ${ }^{152}$. The material was packed into a column and $\mathrm{iHg}$ and $\mathrm{MeHg}$ were adsorbed from spiked waters and fish tissue extracts at a $\mathrm{pH}$ of 4 . A sequential elution of $\mathrm{iHg}$, with $0.1 \%(\mathrm{~m} / \mathrm{v})$ thiourea, and $\mathrm{MeHg}$, with $3 \%(\mathrm{v} / \mathrm{v}) \mathrm{HCl}$ followed by digestion with $\mathrm{KMnO}_{4}$, allowed each specie to be quantified by FI-CV-AAS. Under optimised conditions the LOD values for $\mathrm{iHg}$ and $\mathrm{MeHg}$ ions were 0.15 and $0.16 \mu \mathrm{g} \mathrm{L}^{-1}$, respectively. The method was validated by analysing extracts of NRCC DORM-4 dogfish muscle with recoveries for $\mathrm{iHg}$ and $\mathrm{MeHg}$ of $>97 \%$. A pyrolysis stage, for the production of $\mathrm{Hg}^{\circ}$, is usually included between a GC and an AFS detector however, a report on the use of a DBD device for this purpose has been published this year ${ }^{153}$. After optimisation of the DBD input discharge voltage, DBD discharge distance, $\mathrm{N}_{2}$ gas purge time and the 
thermal desorption time an RSD value of $2.0 \%$ an LOD for MeHg $0.0008 \mathrm{ng} \mathrm{L}^{-1}$ were obtained. The method was validated using GBW08675 MeHg solution, with a recovery of $104 \%$ and applied to the measurement of sub $\mathrm{ng} \mathrm{L}^{-1}$ levels of $\mathrm{MeHg}$ in two seawater samples. Table 2 shows examples of other applications of $\mathrm{Hg}$ speciation presented in the literature during the time period covered by this ASU.

Table 2 Applications of Speciation Analysis: Hg

\begin{tabular}{|c|c|c|c|c|c|c|c|}
\hline $\begin{array}{l}\text { Analyte } \\
\text { species }\end{array}$ & Technique & Matrix & Sample treatment & Separation & LOD & Validation & Reference \\
\hline $\begin{array}{l}\text { iHg EtHg, } \\
\text { MeHg }\end{array}$ & $\begin{array}{l}\text { HPLC-ICP- } \\
\text { MS }\end{array}$ & $\begin{array}{l}\text { Sea } \\
\text { cucumber, } \\
\text { freeze dried }\end{array}$ & $\begin{array}{l}\text { UAE with } 0.10 \% \\
\mathrm{HCl}, 0.12 \% \mathrm{~L}- \\
\text { cysteine, } 0.10 \% 2- \\
\mathrm{ME} 40 \mathrm{kHz} \text { for } 0.5 \\
\mathrm{hr} \text {, centrifuged, } \\
\text { supernatant } \\
\text { freeze dried, } \\
\text { redissolved in } 0.5 \\
\mathrm{~mL} \text { mobile phase }\end{array}$ & $\begin{array}{l}\mathrm{RP} \mathrm{C}_{18}, 8 \% \\
\mathrm{MeOH}, 0.12 \% \\
\mathrm{~L}-\text { cysteine, } \\
0.01 \mathrm{~mol} \mathrm{~L}^{-1} \\
\mathrm{NH}_{4} \mathrm{CH}_{2} \mathrm{COOH}, \\
0.8 \mathrm{~mL} \mathrm{~min}^{-1} \\
\text { for } 10 \text { mins, }^{\circ} \\
35^{\circ} \mathrm{C}\end{array}$ & $\begin{array}{l}\mathrm{iHg}, \mathrm{EtHg}, \\
\mathrm{MeHg}: 0.12 \text {, } \\
0.20 \text { and } \\
0.08 \mu \mathrm{g} \mathrm{L}^{-1} \\
\text { respectively }\end{array}$ & $\begin{array}{l}\text { GBW 10024: } \\
\text { total Hg } \\
\text { certified. Sum } \\
\text { of species, in } \\
\text { agreement with } \\
\text { total. Spike } \\
\text { recoveries of } 93 \\
-104 \%\end{array}$ & 154 \\
\hline $\begin{array}{l}\text { Total Hg, } \\
\text { MeHg }\end{array}$ & $\begin{array}{l}\text { GC-pyro- } \\
\text { AFS, CV-AAS }\end{array}$ & $\begin{array}{l}\text { Cyanobacte } \\
\text { ria, freeze } \\
\text { dried }\end{array}$ & $\begin{array}{l}\text { Total Hg: Direct } \\
\text { analysis of solids. } \\
\mathrm{MeHg}: 25 \% \mathrm{KOH} \\
\text { in } \mathrm{MeOH}, 75^{\circ} \mathrm{C} \\
\text { for } 3 \mathrm{hr} . \mathrm{NaBEt}_{4} \\
\text { derivatisation }\end{array}$ & $\begin{array}{l}\text { Selective } \\
\text { extraction. GC } \\
\text { conditions not } \\
\text { given }\end{array}$ & $\begin{array}{l}0.0025 \%, \text { of } \\
\text { what is not } \\
\text { stated }\end{array}$ & $\begin{array}{l}\text { DORM-3, 89\% } \\
\text { recovery }\end{array}$ & 155 \\
\hline $\begin{array}{l}\text { Total Hg, } \\
\text { MeHg }\end{array}$ & $\begin{array}{l}\text { GC-pyro- } \\
\text { AFS, CV-AAS }\end{array}$ & $\begin{array}{l}\text { Cyanobacte } \\
\text { ria, freeze } \\
\text { dried }\end{array}$ & $\begin{array}{l}\text { Total Hg: Direct } \\
\text { analysis of solids. } \\
\text { MeHg: acetate @ } \\
\text { pH 5, cellulase, } 40 \\
{ }^{\circ} \mathrm{C}, 24 \mathrm{hr} \text { then } \\
\mathrm{UAE}, 6 \mathrm{~mol} \mathrm{~L}^{-1} \\
\mathrm{HCl}, 40^{\circ} \mathrm{C}, 4 \mathrm{hr} \text {, } \\
\mathrm{NaBEt}_{4} \\
\text { derivatisation }\end{array}$ & $\begin{array}{l}\text { GC conditions } \\
\text { not given }\end{array}$ & $\begin{array}{l}\text { Total Hg: } \\
0.1 \mu \mathrm{g} \mathrm{kg}{ }^{-1} \\
\text { MeHg: } 4 \mu \mathrm{g} \\
\mathrm{kg}^{-1}\end{array}$ & $\begin{array}{l}\text { BCR-482, 64\% } \\
\text { of total Hg } \\
\text { recovery. MeHg } \\
\text { content of CRM } \\
\text { is not known. } \\
\text { Spike recovery } \\
100 \% \text {. }\end{array}$ & 156 \\
\hline $\begin{array}{l}\text { Total Hg, } \\
\text { MeHg }\end{array}$ & CV-AFS & $\begin{array}{l}\text { Waters, } \\
\text { Sediments }\end{array}$ & $\begin{array}{l}\text { MeHg: EPA } \\
\text { method } 1630 \\
\text { Total Hg: } 7: 3 \\
\mathrm{HNO}_{3}: \mathrm{HCL} 24 \mathrm{hr} \\
\text { @ room temp }\end{array}$ & $\begin{array}{l}\text { Selective } \\
\text { extraction }\end{array}$ & Not given & $\begin{array}{l}\text { MeHg IAEA } \\
433,113 \% \\
\text { recovery. Total } \\
\text { Hg NRCC MESS- } \\
3, \text { PACS- } 2 \\
100 \% \text { recovery. }\end{array}$ & 157 \\
\hline $\begin{array}{l}\text { Total Hg, } \\
\text { MeHg, iHg }\end{array}$ & GFAAS & Blood & $\begin{array}{l}\text { vortex assisted } \\
\text { dispersive } \\
\text { liquid-liquid } \\
\text { microextraction } \\
\text { based on the } \\
\text { freezing of deep } \\
\text { eutectic solvent } \\
\text { (DES) }\end{array}$ & $\begin{array}{l}\mathrm{CH}_{3} \mathrm{CN}, 15 \%, \\
\mathrm{ZnSO}_{4}, \text { vortex, } \\
10 \text { min, } 4{ }^{\circ} \mathrm{C} \text {, } \\
\text { supernatant } \\
\text { collected, } \\
\text { ODMIM, } \\
\text { DDTP, } \mathrm{NaCl} \\
\text { added, } 50^{\circ} \mathrm{C} \text {. } \\
\text { Mix, } \\
\text { centrifuge, } \\
\text { DES } \\
\text { extracted, UV }\end{array}$ & $0.1 \mu \mathrm{g} \mathrm{L}^{-1}$ & $\begin{array}{l}\text { NIST SRM 955C, } \\
\text { total and iHg. } \\
\text { MeHg by } \\
\text { difference. }\end{array}$ & 158 \\
\hline $\begin{array}{l}\text { Total Hg, } \\
\text { MeHg }\end{array}$ & $\begin{array}{l}\text { GC-pyro- } \\
\text { AFS, CV-AFS }\end{array}$ & Rice, soil & $\begin{array}{l}\text { Total Hg: Direct } \\
\text { analysis of solids. } \\
\text { MeHg: rice, } 25 \%\end{array}$ & $\begin{array}{l}\text { GC conditions } \\
\text { not given }\end{array}$ & $\begin{array}{l}\text { Total Hg: } \\
0.1 \mathrm{ng} \mathrm{g}^{-1} \text {. } \\
\text { MeHg: } 0.05 \\
\end{array}$ & $\begin{array}{l}\text { MeHg: NRCC } \\
\text { TORT-2, IAEA } \\
405,96 \% \\
\end{array}$ & 159 \\
\hline
\end{tabular}




\begin{tabular}{|c|c|c|c|c|c|c|c|}
\hline & & & $\begin{array}{l}\mathrm{KOH} \text { in } \mathrm{MeOH}, 75 \\
{ }^{\circ} \mathrm{C} \text { for } 3 \mathrm{hr} \text {, soils, } \\
\mathrm{CuSO}_{4} \mathrm{MeOH} \text {. } \\
\text { Both sample } \\
\text { types then } \mathrm{CH}_{2} \mathrm{Cl}_{2} \\
\text { extraction, } \mathrm{NaBEt}_{4} \\
\text { derivatisation }\end{array}$ & & $\mathrm{ng} \mathrm{g}^{-1}$ & $\begin{array}{l}\text { recovery. } \\
\text { Total Hg: } \\
\text { GBW07403 and } \\
\text { GBW10020, } \\
101 \text { and } 97 \% \\
\text { respectively }\end{array}$ & \\
\hline $\begin{array}{l}\text { Total Hg, } \\
\text { organoHg }\end{array}$ & CV-AFS & Fish muscle & $\begin{array}{l}\text { Total Hg: direct } \\
\text { analysis of solids. } \\
\text { MeHg: } 47 \% \mathrm{HBr} \text {, } \\
\text { shaking, toluene } \\
\text { added, vortexed, } \\
\text { separated, back } \\
\text { extracted into } 1 \% \\
\text { L-cysteine }\end{array}$ & $\begin{array}{l}\text { Selective } \\
\text { extraction }\end{array}$ & $\begin{array}{l}\text { Total Hg: } \\
0.2 \mathrm{ng} \mathrm{g}^{-1} \text {. } \\
\text { MeHg: } 3 \mathrm{ng} \\
\mathrm{g}^{-1}\end{array}$ & $\begin{array}{l}\text { BCR-463, ERM- } \\
\text { CE464, NRCC } \\
\text { DOLT-4 and } \\
\text { TORT, NIST } \\
\text { SRM 2976. } \\
\text { MeHg } \\
\text { recoveries } 95- \\
109 \%\end{array}$ & 160 \\
\hline $\begin{array}{l}\text { iHg, } \\
\text { organoHg }\end{array}$ & ETAAS & Waters & $\begin{array}{l}\text { OrganoHg: 1- } \\
\text { undecanol added } \\
\text { and fraction } \\
\text { collected. Then, } \\
\text { at } \mathrm{pH} 2,4 \text {-nitro-o- } \\
\text { phenylenediamin } \\
\text { e and 1- } \\
\text { undecanol to } \\
\text { extract remainder } \\
\text { of } \mathrm{Hg}\end{array}$ & $\begin{array}{l}\text { Selective } \\
\text { extraction }\end{array}$ & $0.25 \mu \mathrm{g} \mathrm{L}^{-1}$ & $\begin{array}{l}\text { NRCC DORM-4, } \\
\text { NIST SRM } \\
\text { 1566b. } \\
\text { Recoveries > } \\
98 \% .\end{array}$ & 161 \\
\hline MeHg & GC-AFS & $\begin{array}{l}\text { Waters, } \\
\text { sediment, } \\
\text { aquatic } \\
\text { plants }\end{array}$ & $\begin{array}{l}\text { Total Hg: Aqua } \\
\text { Regia. } \\
\text { MeHg: } 25 \% \mathrm{KOH} \\
\text { in } \mathrm{MeOH}, \mathrm{NaBEt}_{4} \\
\text { derivatisation }\end{array}$ & $\begin{array}{l}\text { GC conditions } \\
\text { not given. }\end{array}$ & $\begin{array}{l}\text { Total Hg } 1 \\
\text { ng g }^{-1} \text {. } \\
\text { MeHg: } 1.7_{\text {pg g }^{-1}}\end{array}$ & $\begin{array}{l}\text { IAEA } 140 \text { and } \\
356, \text { recoveries } \\
91 \text { and } 96 \% \\
\text { respectively }\end{array}$ & 162 \\
\hline $\mathrm{iHg}, \mathrm{MeHg}$ & $\begin{array}{l}\text { HPLC-ICP- } \\
\text { MS }\end{array}$ & $\begin{array}{l}\text { Biological } \\
\text { CRMs }\end{array}$ & $\begin{array}{l}10 \% \mathrm{TMAH}, 80^{\circ} \mathrm{C}, \\
2 \mathrm{hr}\end{array}$ & $\begin{array}{l}\text { Four } \mathrm{RP}_{18} \\
\text { columns. } 0.5 \mathrm{~g} \\
\mathrm{~L}^{-1} \mathrm{~L}-\mathrm{cysteine}, \\
1 \% \mathrm{MeOH}, \mathrm{pH} \\
2.3 \text { flowing at } \\
\text { either } 0.5 \text { or } \\
0.75 \mathrm{~mL} \mathrm{\textrm {min } ^ { - 1 }}, \\
400 \mathrm{~s}\end{array}$ & $0.1 \mathrm{ng} \mathrm{g}^{-1}$ & $\begin{array}{l}\text { NMIJ CRM } \\
7402-a \text { and } \\
7403 \text { a, NRCC } \\
\text { DORM-2, NIES } \\
\text { No 13. All } \\
\text { results in } \\
\text { statistical } \\
\text { agreement }\end{array}$ & 163 \\
\hline EtHg & $\begin{array}{l}\text { GC-pyr-CV- } \\
\text { AFS }\end{array}$ & $\begin{array}{l}\text { Thiomersal } \\
\text { in spiked } \\
\text { pharmaceut } \\
\text { ical effluent } \\
\text { and spiked } \\
\text { urine }\end{array}$ & $\begin{array}{l}\text { Photodegradation } \\
\text { with visible light } \\
\text { in presence of } \\
\text { graphene } \\
\text { quantum dots, } \\
\text { NaBEt }_{4} \\
\text { derivatisation }\end{array}$ & $\begin{array}{l}\text { GC conditions } \\
\text { not given }\end{array}$ & $1 \mathrm{ng} \mathrm{L}^{-1}$ & $\begin{array}{l}\text { Spike } \\
\text { recoveries, 95\% } \\
\text { or greater. }\end{array}$ & 164 \\
\hline $\begin{array}{l}\text { Total Hg, } \\
\text { MeHg }\end{array}$ & $\begin{array}{l}\text { GC-pyro- } \\
\text { AFS, CV-AAS }\end{array}$ & $\begin{array}{l}\text { Cyanobacte } \\
\text { ria, freeze } \\
\text { dried }\end{array}$ & $\begin{array}{l}\text { Sediments: } \\
\text { distillation, } 8 \mathrm{~mol} \\
\mathrm{~L}^{-1} \mathrm{H}_{2} \mathrm{SO}_{4}, 20 \% \\
\mathrm{KCl} \text {. } \\
\text { Cyanobacteria: } \\
25 \% \mathrm{KOH}, \mathrm{MeOH} \text {. } \\
\mathrm{NaBEt}_{4} \\
\text { derivatisation in } \\
\text { each case }\end{array}$ & 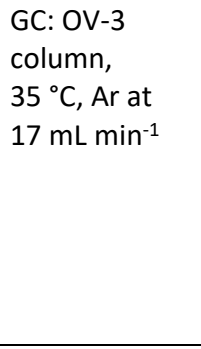 & $\begin{array}{l}\text { Sediments } \\
0.04 \mu^{-1 \mathrm{~kg}^{-1}} \text {. } \\
\text { Cyanobacte } \\
\text { ria } 1.3 \mu \mathrm{g} \\
\mathrm{kg}^{-1}\end{array}$ & $\begin{array}{l}\text { CRM-580 } \\
\text { (BCR?), NRCC } \\
\text { DORM-3. } \\
\text { Recovery > 95\% } \\
\text { in each case }\end{array}$ & 165 \\
\hline $\begin{array}{l}\text { EtHg, } \\
\mathrm{MeHg}\end{array}$ & GC-CVAFS & Waters & $\begin{array}{l}\text { Distillation with } \\
1 \% \text { saturated } \\
\mathrm{CuSO}_{4} . \mathrm{NaBPh}_{4} \\
\text { derivatisation }\end{array}$ & $\begin{array}{l}\text { GC conditions } \\
\text { not given }\end{array}$ & $\begin{array}{l}\mathrm{MeHg} 0.007 \\
\mathrm{ng} \mathrm{L} \mathrm{L}^{-1}, \mathrm{EtHg} \\
0.004 \mathrm{ng} \mathrm{L}^{-1} \\
\text { both as Hg }\end{array}$ & $\begin{array}{l}\text { Spike } \\
\text { recoveries for } \\
\text { ground, river, } \\
\text { sea and } \\
\text { wastewaters all } \\
>83 \% \\
\end{array}$ & 166 \\
\hline $\mathrm{iHg}, \mathrm{MeHg}$ & $\begin{array}{l}\text { HS-SPME- } \\
\text { GC-point } \\
\text { discharge- } \\
\text { OES }\end{array}$ & Hair & $\begin{array}{l}30 \% \mathrm{HNO}_{3}, 60{ }^{\circ} \mathrm{C} \text {, } \\
12 \mathrm{~h}, \mathrm{NaBEt}_{4} \\
\text { derivatisation }\end{array}$ & $\begin{array}{l}\mathrm{GC}: 60^{\circ} \mathrm{C}(3 \\
\mathrm{min}), 60-120 \\
{ }^{\circ} \mathrm{C} \text { at } 15^{\circ} \mathrm{C} \\
\mathrm{min}^{-1}, \text { Ar at } 2\end{array}$ & $\begin{array}{l}\text { iHg: } 0.35 \mu \mathrm{g} \\
\mathrm{kg}^{-1} \text {. } \\
\mathrm{MeHg}: 1.0 \\
\mu \mathrm{kg}^{-1}\end{array}$ & $\begin{array}{l}\text { GBW09101b; } \\
\text { sum of species } \\
84 \% \text { recovery } \\
\text { of total Hg }\end{array}$ & 167 \\
\hline
\end{tabular}




\subsection{Neptunium}

As knowledge of the kinetics of redox reactions of actinides is important in the design of separation processes in nuclear fuel reprocessing and in gaining a better understanding of the biogeochemistry of relevant species, a CE-ICP-MS method for studying the reduction of $N p^{V}$ by hydroxylamine hydrochloride has been developed ${ }^{168}$. An CE system was connected to an ICP-MS instrument via a MiraMist CE nebuliser and a Scott-type spray chamber. A make-up electrolyte consisting of 1.25\% $\mathrm{HNO}_{3}$ solution with $10 \%$ ethanol and $5 \mathrm{ng} \mathrm{mL}^{-1}{ }^{89} \mathrm{Y},{ }^{103} \mathrm{Rh},{ }^{140} \mathrm{Ce}$, and ${ }^{209} \mathrm{Bi}$ (internal standards) was delivered by a syringe pump at $5 \mu \mathrm{L} \mathrm{min}^{-1}$. Separation (in about $15 \mathrm{~min}$ ) of $\mathrm{Np}^{\vee}$ and $\mathrm{Np}^{\mathrm{IV}}$ occurred in a fused silica capillary with an inner diameter of $50 \mu \mathrm{m}$ and a length of $76 \mathrm{~cm}$, when a voltage of 25 $\mathrm{kV}$ was applied. The background electrolyte was $1 \mathrm{~mol} \mathrm{~L}^{-1}$ acetic acid. The samples were prepared in conical micro-inserts of borosilicate glass placed in polyethylene vials sealed with polyethylene olefin snap caps and introduced by hydrodynamic injection (100 mbar for $8 \mathrm{~s}$ ). Measurements were made at concentrations around $7.5 \times 10^{-7} \mathrm{~mol} \mathrm{~L}^{-1}$, but it was considered that concentrations down to $10^{-11} \mathrm{~mol} \mathrm{~L}^{-1}$ are feasible. The pseudo first-order rate constant ranged from 0.0029 to $0.039 \mathrm{~min}^{-}$ 1 , depending on the temperature.

\subsection{Niobium}

Two papers have been published this year on the use of HPLC-ICP-OES for characterising polyoxoniobiates compounds of special interest in applications such as catalysis and photovoltaics. In the first paper ${ }^{169}$ the combined HPLC-ICP-OES technique was employed to evaluate the formation of tungsteniobiates and phosphomolybdoniobiates. Separations were performed by using a HPLC system equipped with a reversed-phase (ProntoSIL $120-5-C_{18}, 2 \times 75 \mathrm{~mm}$ ) column. In the case of Lindquist-type anions, a gradient elution was applied by using a borax buffer $(\mathrm{pH}=9.7)$ containing $0.04 \%$ tetrabutylammonium hydroxide (TBAH) as mobile phase $\mathrm{A}$, and acetonitrile as mobile phase B. For niotungstophosphates, $1 \%$ acetic acid $(\mathrm{pH}=2.7)$ with the addition of $0.04 \%$ TBAH was used as eluent $A$. Results showed that the reaction of potassium hexaniobiate with tungstic acid produced mixed Nb/W Lindquist anions. The degree of substitution was dependent on the amount of $\mathrm{H}_{2} \mathrm{WO}_{4}$ and reaction time. Reaction of the phosphomolybdic acid with niobium oxalate led to the formation of [PMO11 $\left.\mathrm{NbO}^{40}\right]^{4-}$ and $[\mathrm{PMO} 1 \mathrm{ONbO} 40]^{5-}$ whose presence were detected for first time. Similarly, the same HPLC-ICP-OES experimental set-up was employed for screening for the presence of $[\mathrm{XW} 11 \mathrm{NbO} 40]^{\mathrm{n}-}{ }^{170}$ The results from both studies show the capability of HPLC-ICP-OES as an efficient 
tool for rapid screening of products originated from complex reactions.

\subsection{Rare Earth Elements}

The small number of speciation studies of REEs are all based on solid-state XANES measurements. The oxidation states of Eu species are considered key characteristics in defining the properties of a variety of Eu-containing phosphors that are widely used in the construction of light-emitting diodes, long-lasting materials, scintillators and other devices. Yamamoto and Yukumoto investigated discrepancies in the determination of Eu species in sulfide phosphors by K-, L1- and L3-edge XANES spectrometry ${ }^{171}$. Experiments, in a quick scan mode, were performed at the BL01B1 beamline33 at the SPring-8 facility located in Harima Science Park City, Hyogo Prefecture, Japan. They found that K- and L1-edge XANES characterisation the Eu species appeared to be almost exclusively Eu", but the L3-edge experiments showed the presence of up to 35\% Eu ${ }^{\prime \prime \prime}$. They concluded that K-edge XANES characterisation was the most reliable, although a multi-edge analysis for XANES and/or a combination with other techniques may be needed to characterise Eu species at low concentrations. A promising alternative source of REEs is coal combustion ash, extraction from which depends critically on the location and speciation of these elements. Two studies have studied the speciation and distribution of REE in coal combustion products. Taggart et al. determined the major chemical forms of $\mathrm{Y}$, as a representative REE, in coal fly ash at both the bulk scale (sequential extractions, XANES) and at the micron scale (micro-XRF and micro-XANES) ${ }^{172}$. Bulk analysis, performed at beam line 11-2 at the Stanford Synchrotron Radiation Lightsource, revealed that $Y$ (and other lanthanoids) were dispersed throughout the aluminosilicate glass in fly ash with coordination states resembling a mixture of $\mathrm{Y}$-oxides, and $\mathrm{Y}$-carbonate; however, the microanalysis, performed at beam line 2-3, found hotspots of $Y$ (approximate to $10-50 \mu \mathrm{m}$ ) in some samples that included different $Y$ species (such as Y-phosphate) not observed in the bulk measurements. They concluded that aggressive leaching or alkaline digestion methods would be needed to recover REEs from the glass phase. A slightly earlier study, by a different research group, in which Ce was selected as the representative REE, came to very similar conclusions ${ }^{173}$. The speciation measurements, also made at the Stanford Synchrotron Radiation Lightsource, identified $\mathrm{Ce}^{\text {III }}$ as the predominant (> 85\%) oxidation state in both bottom ash and fly ashes and that Ce was either dispersed throughout the aluminosilicate glass phase, or existed as micro-particles in large glass grains, or as independent trace phases. It was found that both ashes contained mainly Ce $\mathrm{III}^{\text {III }}$ micro-hotspots $(<40 \mu \mathrm{m})$, co-localised with a range of elements, including, calcium, manganese, phosphorus, silicon, and titanium. In addition, Ce ${ }^{\mathrm{IV}}$ oxide microparticles were detected. The researchers discussed the formation of these phases in terms of 
the characteristics of the combustion processes and conclude that effective extraction approaches will involve dissolving the glass phase in sodium hydroxide and/or digestion with HF or lithium borate.

\subsection{Selenium}

Three reviews on selenium speciation focused on different applications have appeared this year. The role of selenium in protecting against mercury toxicity has been summarised by Gajdosechova et $a l^{141}$. The article is divided into three parts. The first one is devoted to mercury and selenium characteristics, the former as a potent neurotoxin agent and the latter as an essential element. The second part critically describes the analytical methods which are divided into 2 groups: 1) chromatographic techniques (GC and LC) with special attention to the use of RP and SEC chromatography and 2) detection techniques such as ICP-MS, ES-MS and LA-ICP-MS. The last section outlines potential future trends such as the use of tandem chromatography, NP determination and isotopic fractionation. The review contains a number of tables that compile relevant information on the experimental protocols employed for each of the target analytes and samples. The review includes 128 references. The state of the art of selenium speciation in water samples has been reviewed this year by Leblanc et al. ${ }^{174}$. Initially, the review focuses on the presence of Se in aquatic ecosystems including a description of anthropogenic sources, chemical forms of Se and levels of Se reported in contaminated waters. The second section is dedicated to evaluating different analytical methods for performing Se speciation in natural and industrial water samples. Methods are divided into two types: fractionation and chromatographic separation methods. Among the first group, attention is focused on the application of LLME methods and the use of environmentally friendly extraction solvents such as those formed by the combination of quaternary ammonium salts with hydrogen bond donors (carboxylic acids, polyhydric alcohols). Solid phase microextraction is also considered, especially those procedures involving the application of nanoparticles as the solid phase. Chromatographic methods such as GC (including derivatisation protocols and ICP-MS and MS detection) and HPLC (with different stationary phases and by using ICP-MS as detector) are then

discussed. Finally, different biological treatment methods for the remediation of Se-contaminated waters are described. The review includes nearly 160 references. The third review by, Bierla et $a l^{175}$, compiles the recent advances in high resolution-MS for Se speciation. The work is focused on selenised yeast that is selected by the authors as "model sample" because of its high content of Se species of different types. The study opens with a discussion on the growing role of high resolution ES-MS techniques in selenometabolomic and selenoproteomic studies and how these techniques 
have started surpassing ICP-MS for speciation studies. For instance, the use of HPLC-TOF-MS and HPLC-Orbitrap-MS instruments has allowed the acquisition of metabolomic fingerprints containing 200-Se containing compounds in selenised yeast. The authors predict a secondary role of ICP-MS in Se speciation as a complementary technique for determining extraction and column recoveries.

Elucidation of Se species and metabolites in Se supplements is still a topic of much research. One problem that still remains is the accurate determination of SeCys in protein extracts as the determination of SeCys is not straightforward. Often, SeCys is confused with SeCyst 2 in studies reported in the literature without any proof of the release of SeCyst $\mathrm{S}_{2}$ after proteolytic digestion of selenoproteins. Peptides containing Se-Cyst are also quite unstable, losing Se and producing dehydroalanine. Moreover, Se-Cyst residues are highly reactive, therefore reduction with dithiothreitol (DTT) to break Se-Se and Se-S bonds and alkylation with iodoacetamide (IAM) for preventing the formation of unwanted novel Se-Se and Se-S bonds should be always applied. As such, a method for determining SeCys in the protein fraction of selenised-yeast ${ }^{176}$ has been developed. Selenised compounds were first extracted from yeast by using $0.1 \mathrm{M}$ Tris- $\mathrm{HCl}$, subsequently treated with DTT and IAM and finally subjected to proteolysis with protease to produce amino acids. Selenium speciation was carried out by HPLC-ICP-MS using different chromatographic columns. Best results in terms of SeCys recovery, baseline resolution and minimum number of chromatographic peaks were achieved by applying ion-paring reversed phase and by using $C_{8}(4.6 \times 250 \mathrm{~mm} \times 5 \mu \mathrm{m}), C_{18}(2.1 \times 100 \mathrm{~mm} \times 2.6 \mu \mathrm{m})$ and Hypercarb $(2.1 \times 100 \mathrm{~mm} \times$ $3 \mu \mathrm{m}$ ) columns. Five Se containing peaks: SeMet, carbamidomethylated(CAM)-SeCys, and Se(CAM) ${ }_{2}$ ) were identified by retention time matching with available standards and by HPLC-ES-MS/MS measurements. The application of HPLC-ES-MS/MS was not straightforward due to interferences from ion pairing reagent and iodine from IAM. To overcome these problems, the mixture was first fractionated with SEC-ICP-MS to remove the excess of iodine and the Se-containing fractions were collected and analysed by HPLC-ES-MS/MS by using a RP( $\left.C_{18}, 4.6 \times 100 \mathrm{~mm} \times 3.5 \mu \mathrm{m}\right)$ and a HILIC $(2.1 \times 150 \mathrm{~mm} \times 2.6 \mu \mathrm{m})$ columns. The origin of $\mathrm{Se}(\mathrm{CAM})_{2}$ was attributed to the presence of any type of iSe $\left(\mathrm{Se}^{\mathrm{IV}}, \mathrm{Se}^{\mathrm{VI}}\right.$ and $\left.\mathrm{Se}^{0}\right)$. The method was applied to three commercial samples of selenised-yeast and results were validated by performing a mass balance calculation and accurate analysis of a yeast CRM (SELM-1). A separate study reports on the metabolism of Se in Se-enriched Candida utilis ATCC9950 yeast ${ }^{177}$. The Se-enriched cell biomass was obtained after $24 \mathrm{~h}$ culture in a medium containing Se $\mathrm{IV}^{\mathrm{V}}$ at a dose of $20 \mathrm{mg} \mathrm{L}^{-1}$. After acid digestion of cell biomass measurements by ICP-MS provided Se contents of $624 \mu \mathrm{g} \mathrm{g}^{-1}$ which corresponds to a low bioaccumulation value. Selenium 
compounds were subsequently extracted using a mixture of protease and lipase and further analysed by HPLC-ICP-MS using a PRP-X100 (250mm x $4.1 \mathrm{~mm} \times 10 \mu \mathrm{m})$ column and a mobile phase composed of increasing concentrations of $\mathrm{NH}_{4} \mathrm{CH}_{3} \mathrm{COOH}$ at $\mathrm{pH} 4.7$ under gradient elution. The method enabled the detection of five Se-containing peaks (SeMet, MeSeCys, Se ${ }^{\mathrm{IV}}$, Se $\mathrm{VI}^{\mathrm{VI}}$ and $\gamma$ glutamyl MeSeCys) by retention time matching to commercial standards. Subsequently, HPLC-ESOrbitrap-MS measurements were performed with the aim of confirming the identity of Se metabolites produced by the yeast. For this purpose, Se-containing peaks fraction from the ICP-MS were collected and analysed by HPLC-ES/MS/MS by using a HyperCarb (150 mm x4.6mm, $5 \mu \mathrm{m}$ ) column with a mobile phase of $0.1 \%$ formic acid in ACN flowing at $0.5 \mathrm{~mL} \mathrm{~min}{ }^{-1}$. These analyses identified SeMet and its metabolites (SeMetO, SeMet-NH ), methylthioselenoglutathione, 23-DHP selenocysteine-cysteine and Se-S conjugate of selenoglutathione-cysteine. However, MeSeCys was not found. This study clearly reflects the need for the use of atomic and molecular MS techniques for correctly assessing the structure of Se compounds which is of special relevance for establishing the metabolism of Se in biological systems. In an outstanding study selenonine (a Se analogue of ergothioneine with biological and health relevance) was isolated from the genetically modified fission yeast Schizosaccharomyces pombe grown in a medium containing $10 \mathrm{mM}$ of Se ${ }^{\mathrm{VI}} \cdot{ }^{178} \mathrm{~S}$. pombe was modified to overexpress an enzyme involved in the biosynthesis pathway of ergothioneine and consequently selenonine production is expected in presence of $\mathrm{Se}^{\mathrm{VI}}$ in the growing medium. After five days of growth the cells were harvested and lysed with $\mathrm{MeOH}$. Measurements by ICP-MS showed that only $5 \%$ of the added Se remained in the growth medium while $25 \%$ was found in the pellet and $50 \%$ in the cell lysate. A crucial step was the separation of selenonine from its sulfur analogue ergothionine as they elute at similar chromatographic retention times. With the aim of differentiating the chromatographic behaviour of both species, selenonine was selectively oxidised with hydrogen peroxide. The use of a mobile phase composed of $3 \%$ aqueous $\mathrm{MeOH}$ at $\mathrm{pH} 3.0$ allowed the separation of both compounds with column recovery values of $70 \%$. Selenonine was purified by preparative reversed phase HPLC in three consecutive steps by using neutral, acidic and neutral $\mathrm{pH}$ conditions, respectively. The first step provided a fraction containing Se but not sulfur compounds, however UV measurements showed the presence of impurities. A second clean-up step was subsequently applied by decreasing the $\mathrm{pH}$ with acetic acid. Spectra from HPLC-UV measurements indicated an efficient clean-up but NMR spectra of the selenonine-containing fraction revealed that the oxidised selenonine was in the form of an acetate. Therefore, another preparative clean-up at neutral $\mathrm{pH}$ was employed. The product obtained at the mg level was 
characterised by NMR, high resolution MS and HPLC-ICP-MS. The recovery of selenonine was quantified using a SeMet standard. And the purity was greater than $98 \%$. The developed procedure is an interesting alternative to the chemical synthesis of selenoneine, which is considered an important Se compound with beneficial health effects as well as playing an important role in methylmercury detoxification.

The preparation of Se-enriched supplements based on the biotransformation of iSe to organo seleno compounds by probiotics such as Bifidobacteriium and Lactobacillus spp is receiving increasing attention due to the combined health promoting benefits of Se and probiotics. For this purpose nine L.spp (Lactobacillus reuteri KCTC 53608, Lactobacillus bulgaricus KCTC 3188, Lactobacillus acidophilus KCTC 3142, Lactobacillus casei KFRI 704, Lactobacillus cremoris ATCC 19257, Lactobacillus plantarum, Lactobacillus brevis 353, Lactobacillus brevis GABA100, and Bifidobacterium bifidum BGN4) were cultured in presence of $1 \mathrm{mmol} \mathrm{L}^{-1} \mathrm{Se}^{\mathrm{IV}}$ for 2 days ${ }^{179}$. The Seenriched microbial samples were harvested and further characterised in terms of total Se, organic Se content and Se species. Enzymatic hydrolysis with Pronase was selected for releasing the seleno compounds. For the separation and detection of the Se species a Hamilton PRP-X100 (20 mm length $\times 2.1 \mathrm{~mm}$ i.d., $10 \mu \mathrm{m}$ ) column at $40^{\circ} \mathrm{C}$, coupled to ICP-MS was employed, with a gradient elution of ammonium citrate in $2 \%$ methanol. The maximum concentration of organic Se was achieved when $\mathrm{Se}^{\mathrm{IV}}$ was added to the culture after $12 \mathrm{~h}$ incubation. B. bifidum BGA was found to incorporate the highest concentration of organic Se $(208 \mu \mathrm{g} / \mathrm{g})$ with SeMet as the main organic Se form $\left(170 \mu \mathrm{g} \mathrm{g}^{-1}\right)$. All of the aforementioned studies have addressed the ability of yeast and lactic bacteria to biotransform inorganic Se into organic Se forms, however only one work has evaluated the transformation of selenometabolites by yeast ${ }^{180}$. In this approach, S.cerevisiae yeast was exposed to $100 \mathrm{mmol} \mathrm{L}^{-1}$ of SeSug1, SeSug2, TMSe (urinary selenometabolites of animals) and MeSeCys, and SeMet (major plant and yeast selenometabolites) at $28{ }^{\circ} \mathrm{C}$ for $48 \mathrm{~h}$. The resulting pellets were incubated with protease for $24 \mathrm{~h}$ at $37{ }^{\circ} \mathrm{C}$ and subsequently analysed by using HPLC-ICP-MS and LCES-Q-TOF-MS. Analysis by HPLC-ICP-MS by using SEC (Shodex Asahipak GS-320HQ, 7.5 i.d. x 300 mm) and $50 \mathrm{mmol} \mathrm{L}^{-1} \mathrm{NH}_{4} \mathrm{CH}_{3} \mathrm{COOH}$ at $\mathrm{pH} 6.5$ as mobile phase flowing at $0.6 \mathrm{~mL} \mathrm{~min}^{-1}$. The column recoveries of SeSug1, SeSug2, TMSe, SeMet, and MeSeCys were $101 \pm 2.4,92.2 \pm 8.3,87.8 \pm 4.2$, $97.9 \pm 5.7$ and $101 \pm 2.2$, respectively. The Se-containing fractions from SEC were also collected, lyophilised, dissolved in deionised water and analysed by LC-ES-Q-TOF-MS using a SEC (Shodex Asahipak GS-220HQ (7.5 i.d x $300 \mathrm{~mm}$ with a guard column, 7.5 i.d.x75 mm) column and $10 \mathrm{mmol} \mathrm{L}^{-}$ ${ }^{1} \mathrm{NH}_{4} \mathrm{CH}_{3} \mathrm{COOH}$ as the eluent at a flow-rate of $0.6 \mathrm{~mL} \mathrm{~min}{ }^{-1}$. The Se specie most efficiently 
incorporated into yeast was SeMet $\left(2781 \pm 359 \mathrm{nmol} \mathrm{g}^{-1}\right)$ followed by MeSeCys $\left(1567 \pm 129 \mathrm{nmol} \mathrm{g}^{-}\right.$ $\left.{ }^{1}\right)$, TMSe $\left(911 \pm 57 \mathrm{nmol} \mathrm{g}^{-1}\right)$ whilst urinary selenosugars were poorly incorporated. The accumulation data showed that yeast is able to transform selenoamino acids and selenosugars into SeMet while TMSe remains unaltered. The study postulates yeast as a tool for recovering Se as SeMet from Se metabolites produced by other organisms in different ecosystems.

An approach using ID-ICP-MS has been reported for SeMet quantification in different CRM matrices: ERM DB151 skimmed powder milk, ERM DC210a wheat flour and SELM 1 enriched yeast ${ }^{181}$. Both ssand su-IDA were employed and compared in terms of the estimated uncertainty budgets of the measurements. The former procedure was also applied to track the source of SeMetO in the extracts. Selenium was released from the samples by adding a mixture of protease and lipase in water under magnetic stirring $(22 \mathrm{~h})$ at $37^{\circ} \mathrm{C}$ ). For ssIDA samples were spiked with a ${ }^{76}$ SeMet isotopically enriched standard (LGC7330) followed by $22 \mathrm{~h}$ of equilibration whereas for su-IDA, an isotopically enriched ${ }^{77} \mathrm{Se}$ standard was added continuously after the chromatographic column. Selenium species in the extracts were separated on PRP X-100 $(250 \mathrm{~mm} \times 4.6 \mathrm{~mm}$ i.d. and $5 \mu \mathrm{m})$ column. The mobile phase was a gradient consisted of increasing concentration of acetate buffer ( $\mathrm{pH} 4.7$ ). The isotope ratios ${ }^{77} \mathrm{Se}:{ }^{76} \mathrm{Se},{ }^{78} \mathrm{Se}:{ }^{76} \mathrm{Se}$ and ${ }^{78} \mathrm{Se}:{ }^{77} \mathrm{Se}$ were measured for both types of IDA. Best results were obtained by using ssIDA that enabled the accurate determination of SeMet in the CRMs. Additionally, the isotope ratios of ${ }^{77} \mathrm{Se}:{ }^{76} \mathrm{Se}$ and ${ }^{78} \mathrm{Se}:{ }^{76} \mathrm{Se}$ were the same for both SeMetO and SeMet suggesting SeMet oxidation during sample treatment and storage as the only source of SeMetO in the samples. With suIDA only the found SeMet content was close to the certified value when 2-mercaptoethanol was added to prevent SeMet oxidation before extraction. Although both approaches provide accurate SeMet results ssIDA offers the added value of the potential for correcting for SeMet instability during sample treatment and storage.

The metabolism of Se in plants and animals supplemented with Se remains of research interest. Most of these studies have used a PRPX-100 column to separate Se-species. It is well documented that $\mathrm{SeCys}_{2}$ and SeMetO coelute in this column. In fact, these species are hardly retained in AEC and coelute close to the chromatographic void volume. Unfortunately, this consideration is not taken into account in some of the studies described below and the presence of SeCys 2 is given without performing further experiments to validate the data obtained. The variation of Se-species and bioaccesibility during the growth of Se-enriched mushroom, Pleurotus eryngii, was assessed by using $\mathrm{SEC}$ and $\mathrm{AEC}$ coupled to the ICP-MS ${ }^{182}$. Mushrooms were cultivated in the presence of $\mathrm{Se}^{\mathrm{IV}}$ at $50 \mathrm{mg}$ $\mathrm{Kg}^{-1}$ for 20 days. The total content of Se, determined by ICP-MS, in mature Se-enriched mushrooms 
was $23 \mathrm{mg} \mathrm{Kg}^{-1}$ with most of the Se present (about 89\%) as organic Se compounds. The distribution of Se in several fractions, (polysaccharides, nucleic acids and proteins) was determined at different growing stages of the mushrooms. Selenium was mainly present as organic Se (SeMet) with inorganic Se only accounting for $13 \%$ of the total Se. Selenium was mainly distributed in the albumin and glutelin fraction (60\%) followed by Se-containing polysaccharides (10\%) and Se-containing nucleic acids (0.45\%). Selenium species measurements in the protein fraction and their transformation during the growing stage was achieved by using a PRPX-100 ( $250 \mathrm{~mm} \times 4.6 \mathrm{~mm} ; 10$ $\mathrm{mm}$ ) column, with citric acid ( $\mathrm{pH}=4.7$ ) from 5 to $15 \mathrm{mmol} \mathrm{L}^{-1}$ in gradient mode as mobile phase flowing at $1 \mathrm{~mL} \mathrm{~min}^{-1}$, and ICP-MS. The main species found in the enzymatically prepared extracts of mushrooms were reported to be SeMet, SeCyst ${ }_{2}$ and $\mathrm{Se}^{\mathrm{IV}}$, however their content was different in different samples, $\mathrm{Se}^{\mathrm{IV}}$ was not detected in the early fruiting stage while the content of SeCyst 2 and SeMet was relatively high. The concentration of SeMet increased with the growth of P.eryngii with the highest levels in the mature mushroom. In contrast, SeCyst ${ }_{2}$ content significantly decreases with mushroom growth. Unfortunately, the lack of data on how the structural assignment of SeCyst 2 was performed makes it difficult for a correct evaluation of the proposed transformation of Secompounds during mushroom growing stages. The ability of common buckwheat (Fagopyrum esculentum) and tartary buckwheat (F. tartaricum) to accumulate and tolerate Se as either $\mathrm{Se}^{\mathrm{IV}}$, $\mathrm{Se}^{\mathrm{VI}}$ and MetSeCys has also been evaluated ${ }^{183}$. Plants were exposed to Se for different durations ( 2 and $24 \mathrm{~h}, 7$ days and 10 weeks) and in the presence or absence of sulfate and phosphate. Plants were analysed in terms of growth, Se uptake, translocation and accumulation. Furthermore, X-ray microprobe analysis was applied for determining the chemical form and location of Se in buckwheat seeds. Regardless of plant species and the chemical form of Se, XRF mapping revealed the presence of Se in the embryo in organic form with a C-Se-C structure that resembles SeMet, MeSeCys and $\gamma$ Glu-MeSeCys. Selenium transformation was highly dependent on the type of Se specie and exposure time. Over $24 \mathrm{~h}$ of exposure, MeSeCys was accumulated faster than $\mathrm{Se}^{\mathrm{IV}}$ and $\mathrm{Se}^{\mathrm{VI}}$ and rapidly translocated via the xylem to the shoots. These results suggest a faster plant uptake for Se when amino acid transporters are involved instead of the phosphate and sulfate carriers employed for uptake of $\mathrm{Se}^{\mathrm{IV}}$ and $\mathrm{Se}^{\mathrm{VI}}$, respectively. In contrast, when longer term exposure studies (7 and 10 weeks) were conducted, the levels of MeSeCys were not greater than, and sometimes less, those of inorganic forms of Se. The authors attributed these differences in behaviour to losses of Se by volatilisation of MeSeCys at longer exposure time. Sulfate and phosphate supplementation affected Se uptake, and conversely iSe enhanced $\mathrm{S}$ and $\mathrm{P}$ accumulation in both plant species. This interesting 
finding suggests that low levels of Se supplementation enhance the nutritional value of crops by increasing Se, P and S levels. Gao et al. evaluated the use of AEC (Hamilton PRPX-100 and Dionex AS19) and RP $C_{18}$ (Eclipse Plus, Waters $X$ and Stable-Bond SB-Aq) for Se specie separation in rice extracts $^{184}$. Reversed-phase chromatography, particularly the SB-Aq column, was selected as the best choice since five Se compounds (SeCys, MetSeCys, SeMet, Se ${ }^{\mathrm{IV}}$ and $\mathrm{Se}^{\mathrm{VI}}$ ) were baseline separated within 14 minutes by using a mobile phase composed of $0.5 \mathrm{mmol} \mathrm{L}^{-1} \mathrm{TBAH}$ as ion-pairing reagent and $10 \mathrm{mmol} \mathrm{L}^{-1} \mathrm{NH}_{4} \mathrm{CH}_{3} \mathrm{COOH}$ at $\mathrm{pH}$ 5.5. To overcome interferences ICP/MS/MS, with $\mathrm{H}_{2}$ as a reaction gas, was used to detect eluted Se compounds. The LOD values were determined as 0.1 $\mu \mathrm{g} \mathrm{L}^{-1}$ for MeSeCys, SeCys and Se ${ }^{\mathrm{IV}} ; 0.2 \mu \mathrm{g} \mathrm{L}^{-1}$ for SeMet and $0.4 \mu \mathrm{g} \mathrm{L}^{-1}$ for Se ${ }^{\mathrm{Vl}}$. The method was further applied to naturally grown and Se-enriched rice with total a total Se content of $28-47 \mu \mathrm{gg}^{-}$ ${ }^{1}$ and $600-942 \mu \mathrm{Kgg}^{-1}$, respectively. SeMet was the dominant Se species in all samples tested with small quantities of SeCys, $\mathrm{Se}^{\mathrm{IV}}$ and $\mathrm{Se}^{\mathrm{VI}}$. Due to the lack of a reference material, accuracy of the method was evaluated by conducting recovery studies in non-enriched rice spiked at four concentrations of the mixed standard solutions. The recovery of all analytes was in the range of 75$114 \%$ with RSD values lower than $9.4 \%$.

With regard to studies of Se in animals, Se speciation in chicken breast samples from a controlled feeding study has been carried out by Bakirdere et al. ${ }^{185}$. For this purpose, 225 chickens were randomly categorised into three groups: control group (basal diet), an inorganic Se-fed group (basal diet containing $0.15 \mathrm{mg} \mathrm{Se} \mathrm{Kg}^{-1}$ in the form of Se $\mathrm{IV}^{\mathrm{IV}}$ ) and an organic Se-fed group (basal diet containing $0.15 \mathrm{mg} \mathrm{Se} \mathrm{Kg}{ }^{-1}$ as SeMet). At the end of the $42^{\text {nd }}$ day, chickens were sacrificed and their breast and buttocks parts were selected for Se speciation studies. Identification and quantification of Se species was performed by HPLC-ICP-MS following an enzymatic hydrolysis. A detailed description of this procedure, using Tris- $\mathrm{HCl}$ and protease, is given. The best extraction conditions for $200 \mathrm{mg}$ of chicken breast were $10 \mathrm{~mL}$ of $30 \mathrm{mmol} \mathrm{L}^{-1} \mathrm{TRIS}-\mathrm{HCl}$ (pH 7.2) containing $20.0 \mathrm{mg}$ of protease XIV and $24 \mathrm{~h}$ of incubation which gave an average extraction efficiency of $61 \pm 7 \%$. Separation of Se-species was carried out by using chromatographic columns involving different separation mechanisms. Data on the chromatographic separations is given in detail. A SCX column was used to for SeCys and SeMet determinations whilst a SAX column was employed for $\mathrm{Se}^{\mathrm{IV}}$ and $\mathrm{Se}^{\mathrm{VI}}$ analyses. The LOD values for $\mathrm{Se}^{\mathrm{IV}}$, Se ${ }^{\mathrm{VI}}$, SeMet and SeCys were found to be $0.75,0.80,0.55$ and $0.46 \mathrm{ng} \mathrm{mL}^{-1}$, respectively. Total Se concentration in the control, inorganic Se-fed and organic Se-fed groups were $675 \pm 85,1084 \pm$ 198 and $887 \pm 139 \mathrm{ng} \mathrm{g}^{-1}$, respectively. Accuracy of the total Se determination was evaluated by using a DOLT-4 (a dogfish muscle CRM) and the result obtained $\left(9.05 \pm 0.45 \mathrm{mg} \mathrm{Kg}^{-1}\right.$ ) was in good 
agreement with the certified value $\left(8.3 \pm 1.3 \mathrm{mg} \mathrm{Kg}^{-1}\right)$. The main organic Se species found was SeMet with the highest concentration in those samples from the organic Se-fed group $\left(633 \pm 89 \mathrm{ng} \mathrm{g}^{-1}\right)$. Interestingly, one-way ANOVA gave no statistical differences in SeMet content between the control and inorganic Se-Fed group. In an interesting study ${ }^{186}$ the metabolic transformation and urine excretion of Se has been evaluated in rats fed with three different types of Se-enriched diets: a) a commercial soya feed, b) a selenised defatted rapeseed (Brassica napus, $L$ ) mixture called selenisedDRS and c) a commercial feed mixture supplemented with selenite, and called selenite-salt. The total Se content in the individual feed mixtures by ICP-MS analysis provided values of $0.379,0.453$ and $0.598 \mathrm{mg} \mathrm{kg}^{-1} \mathrm{Se}$, respectively. Male Wistar rats were randomly divided into three groups and fed with the experimental diets for 28 days. Urine was collected daily at regular times in the morning and blood serum collected post-mortem. Total Se in the urine digests were made by ICP-MS with the aim of establishing total Se urinary excretion dynamics. The highest Se content was found in rats supplemented with the selenised-DRS diet while the other two groups showed similar urinary Se concentrations. The Se compounds in the urine and serum samples were determined by HPLC-ICP$\mathrm{MS}$, SeSug1 and SeSug2 were separated by using a RP $\mathrm{C}_{18}$ column, Se ${ }^{\mathrm{IV}}$ and $\mathrm{Se}^{\mathrm{VI}}$ on an AEC column and TMSe, SeMet and SeSug3 on a SCX column. Regardless of the type of diet or day, SeSug1 was the major Se-compound in urine with increasing excretion at the beginning of the experiments for those rats fed with a selenite-containing diet while TMSe and SeSug3 concentration remained constant through the experiment. The SeSug2 was only found in the urine of those animals of the selenised-DRS groups and its presence was attributed to the transformation of SeMet, the main seleno compound found in the selenised-DRS diet. The results evidence the influence of Se source on the proportion of Se species in urine. In contrast, similar Se speciation patterns in serum samples were observed in all the three groups regardless of the total Se intake or Se source.

Studies on the effect of cooking and food processing on Se species stability are scarce in the literature. One of the most interesting papers covered this year is by Sadiq and co-workers ${ }^{68}$. The paper describes the simultaneous speciation of $\mathrm{As}, \mathrm{Cr}$ and $\mathrm{Se}$ in the bioaccesible fraction of cooked and uncooked rice samples by employing an on-line leaching procedure. In the experimental set-up, artificial saliva, gastric juice and intestinal fluids were pumped through a mini-column made of PTFE tube ( $8 \mathrm{~cm}$ long) containing $0.25-0.20 \mathrm{~g}$ of rice sample rolled in quartz wool and maintained at 37 ${ }^{\circ} \mathrm{C}$. The leaching time for each reagent was kept at 5 minutes. The total bioaccessible As, $\mathrm{Cr}$ and Se content was determined by on-line coupling of the column to the ICP-MS detector. For speciation analysis in the bioaccesible fraction aliquots of $2 \mathrm{~mL}$ of saliva leachates and $4 \mathrm{~mL}$ of gastric juice 
leachates were collected from the column. These leachates were analysed by HPLC-ICP-MS using a IonPac AS7(25cm long x $4 \mathrm{~mm}$ diameter) anion-exchange column. Separation was performed under a gradient elution consisted of increasing concentrations of $\mathrm{HNO}_{3}$ in $1 \% \mathrm{MeOH}$. Under these conditions four As species ( $\mathrm{As}^{\prime \prime \prime}, \mathrm{As} \mathrm{v}^{\mathrm{V}}, \mathrm{MMA}$ and $\left.\mathrm{DMA}\right)$, two $\mathrm{Cr}$ species ( $\mathrm{Cr}^{\prime \prime \prime}$ and $\mathrm{Cr}^{\mathrm{VI}}$ ) and two Se species ( $\mathrm{Se}^{\mathrm{IV}}$ and $\mathrm{Se}^{\mathrm{VI}}$ ) were separated within 12 minutes. The LOD values obtained for all the species in water, saliva and gastric juice ranged from 0.06 to $30 \mu \mathrm{g} \mathrm{L}^{-1}$ with the highest values for $\mathrm{Cr}^{\text {III }}$ and $\mathrm{Cr}^{\mathrm{VI}}$. Compounds of $\mathrm{As}$, Se and $\mathrm{Cr}$ were released from rice samples after applying the saliva and gastric juice. The bioaccessibility of all three elements in raw rice ranged between 80 and $95 \%$ with an important percentage in the form of $\mathrm{As}^{\mathrm{III}}, \mathrm{As}^{\mathrm{V}}, \mathrm{Cr}^{\mathrm{III}}, \mathrm{Cr}^{\mathrm{VI}}$ and $\mathrm{Se}^{\mathrm{IV}}$. Interestingly, the results revealed the positive impact of cooking on the presence of $\mathrm{Cr}^{\mathrm{VI}}$ as this promotes its transformation into the safer $\mathrm{Cr}^{\text {III }}$ form. Moreover, washing rice prior to cooking seems to decrease at least half of the original $\mathrm{Cr}$ and As content. The developed method allowed the authors to both determine the target species in the bioaccessible fraction and provided a fast evaluation of the effect of food processing on species distribution.

Several works have appeared this year with the aim of quantifying selenoproteins, especially SelP in serum samples. Selenium essentiality for humans is related to its presence as SeCys in three major selenoproteins which are Selenoprotein P (SelP), gluthatione peroxidase (GPx) and selenoalbumin (SelAl). It is agreed that SelP contains most of the Se in serum and its use as possible biomarker for Se-status is being taken into serious consideration by a great number of researchers. Among the analytical approaches employed, the use of affinity chromatography with two chromatographic columns (Heparin sepharose, HEP, and blue sepharose, BLUE) coupled to ICP-MS seems to be the method of choice for determining simultaneously SeIP, GPx and SeAl. The HEP column is able to selectively retain SelP while the BLUE column strongly binds both SelP and SelAl, whilst GPX and other non-retained compounds are eluted since they lack affinity for both columns. Quantification is mostly performed by post-column isotopic analysis. The aforementioned method was employed by Heithland et $a^{187}$ to determine SelP in human serum of occupationally non-exposed persons. With the aim of decreasing analysis time, separation was performed by using a HEP column and two mobile phases consisting of $0.7 \mathrm{~mol} \mathrm{~L}^{-1} \mathrm{NH}_{4} \mathrm{CH}_{3} \mathrm{COOH}$ in $2 \%$ ethanol (A) and $1.3 \mathrm{~mol} \mathrm{~L}^{-1} \mathrm{NH}_{4} \mathrm{CH}_{3} \mathrm{COOH}$ in $2 \%$ ethanol (B). The gradient program employed was $0-1 \mathrm{~min}(A), 1-4 \min (B)$ and $4-5 \min (A)$ at a constant flow rate of $1 \mathrm{~mL} \mathrm{~min}{ }^{-1}$. The optimised conditions allowed the separation of SelP in only 5 minutes. The first Se-containing chromatographic peak was a mixture of GPx-3, SeAl and nonretained species which elutes when applying mobile phase $A$ while after switching to mobile phase 
B, SelP eluted in a completely resolved second peak. The method enabled the determination of SelP on one chromatographic column. However, the use of two columns is mandatory when the simultaneous determination of the three selenoproteins is required. The LOQ in undiluted serum was $0.2 \mu \mathrm{g} \mathrm{L}^{-1}$ for Se (SelP). Quality assurance of SelP determination was assessed by analysing the NIST SRM 95 with a reference value of $50.2 \mu \mathrm{g} \mathrm{L}^{-1}$ with value of Se (SelP) of $52 \mu \mathrm{g} \mathrm{L}^{-1}$ being obtained. The procedure was also used to evaluate the stability of SelP in serum samples over a period of 18 days and under different storage conditions (room temperature, -20 and $4{ }^{\circ} \mathrm{C}$ ). The SelP was stable for at least for 2 weeks at all temperatures tested. A biomonitoring study involving of 50 occupationally non-exposed persons found that SelP ranged from 31 to $60 \mu \mathrm{g} \mathrm{L}^{-1}$. One of the problems when determining selenoproteins by using two affinity columns and ICP-MS in human blood serum or plasma is the interference of $\mathrm{Br}^{-}$or $\mathrm{Cl}^{-}$in $\mathrm{GPx}$ determinations. To overcome this problem, Lee et $a l^{188}$ employed $\mathrm{D}_{2}$ as a collision gas to avoid the $\mathrm{BrH}^{+}$interference that appears when the more usual reaction gas, $\mathrm{H}_{2}$, is used in ICP-MS. Even with mathematical corrections, $\mathrm{H}_{2}$ alone did not provide accurate results in determining GPx while $D_{2}$ effectively suppressed isobaric interferences. Additionally, the use of $\mathrm{D}_{2}$ allowed authors to use the ratio of ${ }^{78} \mathrm{Se}:{ }^{80} \mathrm{Se}$ that provides a higher precision in IDA techniques. The paper also includes a comparison of mobile phases in terms of separation resolution and constant background even under gradient elution. Three mobile phases were evaluated, $\mathrm{NH}_{4} \mathrm{CH}_{3} \mathrm{COOH}, \mathrm{NH}_{4} \mathrm{COOH}(\mathrm{AF})$ and $\mathrm{NH}_{4} \mathrm{NO}_{3}$, with $\mathrm{AF}$ giving the best separation and constant background. The gradient program applied consisted of two mobile phases: Mobile phase A $0.05 \mathrm{~mol} \mathrm{~L}^{-1} \mathrm{AF}$ and mobile phase $B 1.5 \mathrm{~mol} \mathrm{~L}^{-1} \mathrm{AF}$ with 0-5 minutes $100 \% \mathrm{~A} ; 5-11$ minutes $100 \% \mathrm{~B}$ for a HEP column and 11-17 minutes $100 \%$ B for a BLUE column. The accuracy of the method was verified by analysing a reference blood serum from BCR with a total Se certified content. The obtained value $\left(130 \pm 6.4 \mathrm{ng} \mathrm{g-}^{1}\right)$ agreed with the certified value $\left(133 \pm 12 \mathrm{ng} \mathrm{g}^{1}{ }^{1}\right)$ with a protein distribution of 41,48 and $11 \%$ for GPx, SelP and SelAl, respectively.

The interest in evaluating selenoproteins has also been associated with their beneficial effects in several diseases and against the toxic effects of $\mathrm{Hg}$. It is known that SelP plays a key role against the toxicity of mercury. Several mechanisms have been proposed, among them the formation of an equimolar Hg-Se complex that is bound to SelP is the most accepted. Based on that, the effect of Se in $\mathrm{MeHg}$ poisoned rats has been investigated ${ }^{189}$. The rats were exposed to $\mathrm{MeHg}\left(4 \mathrm{mg} \mathrm{Kg}^{-1} \mathrm{as} \mathrm{Hg}\right)$ and, after 4 weeks of exposure, MeHg poisoned rats were divided into two groups: Se ${ }^{\mathrm{IV}}$ exposed (to $2.74 \mathrm{mg} \mathrm{Kg}^{-1}$ as Se) and a control group. Blood and serum samples were collected and stored at -20 ${ }^{\circ} \mathrm{C}$. The concentration of total Se, $\mathrm{Hg}$ and $\mathrm{MeHg}$ was determined by ICP-MS, CV-AFS and GC-pyr-CV- 
AFS, respectively. Compared to the control group, the presence of $\mathrm{Se}^{\mathrm{IV}}$ produced a decrease in the concentration of $\mathrm{MeHg}$ and total $\mathrm{Hg}$ of around $50 \%$ in the rat blood and serum samples. As expected, $\mathrm{MeHg}$ was the major $\mathrm{Hg}$ specie in serum. The fractionation of Se-containing proteins in the rat serum was achieved by affinity chromatography by using the HEP and BLUE columns and two mobile phases composed of 0.05 and $1.5 \mathrm{~mol} \mathrm{~L}^{-1} \mathrm{NH}_{4} \mathrm{CH}_{3} \mathrm{COOH}$, respectively. Quantification was performed by post-column ID-ICP-MS using a ${ }^{78} \mathrm{Se}$ and ${ }^{199} \mathrm{Hg}$ enriched isotope solution. The resulting chromatograms showed the presence of most of the $\mathrm{Hg}$ in serum being bound to SelP with a minor amount of Hg bound to GPx and SeAl. The amount of SelP bound $\mathrm{Hg}(73 \%)$ was higher in the selenite treatment group than that of the control group. The results suggest serum SelP as the major transporter for mercury in MeHg poisoned rats. A paper reports the protective effect of selenoproteins in retinal pigment epithelium against oxidative stress mediated by glucose ${ }^{190}$. Human RPE cell line, HRPEsv, was independently treated with (i) selenite ( ${ }^{77} \mathrm{Se}, 100 \mathrm{nmol} \mathrm{L-1}$ ) for 24 and $48 \mathrm{~h}$; ii) glucose ( 5 or $20 \mathrm{mmol} \mathrm{L}^{-1}$ ) for 24 and $48 \mathrm{~h}$ and by different combination of both treatments. The speciation of Se in the cytosolic fraction of the treated cells was carried out using SEC-ICP-MS which revealed the presence of two major proteins characterised by a MW of 88 and $120 \mathrm{kDa}$. The peak at $88 \mathrm{kDa}$ was assigned by the authors to GPx (according to data previously reported in the literature for similar studies). An increase in selenoprotein concentration at 24 and $48 \mathrm{~h}$ treatment time with respect to the control was detected. The total concentration of Se-bound to the two protein fractions was quantified using isotopic pattern deconvolution analysis ICP-MS. Results obtained indicated that glucose does not affect the levels of total Se but produced a GPX activity decrease due to the glycation of the enzyme. Moreover, selenoprotein seems to act as a protective agent against oxidative stress when incorporated to the HRPEsv cells. Finally, an interesting paper has appeared this year on evaluating the selenoproteome hierarchy in four types of cells in response to changes in Se concentration ${ }^{191}$. The cell lines tested (kidney HEK293 immortalised, prostate LNCaP cancer, skin HaCaT immortalised, and liver HepG2 cancer) were cultured in presence of Se within concentration levels ranging from $45 \mathrm{nmol} \mathrm{L}^{-1}$ to $3 \mathrm{mmol} \mathrm{L}^{-1}$. A plethora of techniques and determinations were employed: ICP-MS (total Se), enzymatic activity of GPx and TxnRD, RT-qPCR, isoelectric-focusing electrophoresis (IEF) (protein separation), LA-ICP-MS (selenoproteome profile from IEF strips) and chemiluminescence (luciferase and $\beta$-galactosidase activity for evaluating SeCys insertion efficiency). Results revealed an important increase of GPx activity in presence of Se for all the cell lines tested. In contrast, a minor increase in TXnRD activity was noticed in response to Se supplementation in HEK293, LNCaP and HepG2 but not in HaCaT. 
Changes observed in both GPx and TxnRD activities were not due to a modification of GPx mRNA and TxnRD mRNA transcription levels but only to an increment of protein levels. Measurements by IEF-LA-ICP-MS showed the presence of several selenoproteins in all four cell lines: Seleno F, Sephs2, SelenoO or Seleno M, GPx1 and TxnRD1. GPx1 appeared as the most abundant in HEK293and HaCaT and among the most abundant in LNCaP and $\mathrm{HepG}_{2}$, confirming GPx1 as ubiquitous selenoprotein in human cells. Interestingly, TxnRDs were the most abundant selenoproteins in LNCaP. The quantitative integration of ${ }^{76} \mathrm{Se}$ electropherograms obtained information on the hierarchy of selenoprotein expressions in the cells lines as response to Se supplementation. The results obtained were compared to that provided by Western immunoblots. Different results were achieved by the two detection methods. Measurements by IEF-LA-ICP-MS indicated that selenoproteins are less sensitive to Se concentration variation than that of the detection using antibodies. The authors highlighted the advantages of using Se total content measurements in terms of providing realistic cell-line specific hierarchy of selenoprotein expressions. Finally, the mechanisms of selenoprotein biosynthesis were evaluated. Among factors affecting SeCys incorporation are Se levels and the nature of the selenocysteine insertion sequence (SECIS). Data for a luciferase-report construct showed the presence of weak SECIS elements (poor regulation of UGA recording efficiency by Se concentration as in SelenoO , GPx6, SelenoS and GPx3 proteins) and strong SECIS elements (strong dependency on Se levels as in GPx1, GPx2, GPx3 and GPx4 and in less extent in TxnRD1, TxnRD2 and Sephs 2 proteins). These findings clearly demonstrate the key role of SECIS in response to Sesupplementation.

One paper has appeared this year on the determination of Se in environmental samples with the novelty of incorporating 3D printing technology 51 . A micro-column, made with acrylate-based resins functionalised with $\mathrm{TiO}_{2}$ NPs, was fabricated to be used as sampling tool for selectively extracting iAs and iSe in high salt content samples in a FI-ICP-MS system. A complete description on the design and fabrication of $\mathrm{TiO}_{2} \mathrm{NP}$-incorporated microcolumns is given. Using this system As ${ }^{\text {III }}$ was extracted, with minimal co-extraction of $A s^{v}$, under basic conditions. Consequently, $A s^{\prime \prime \prime}$ was selectively retained at $\mathrm{pH} 12$ and afterwards $\mathrm{As}^{\mathrm{V}}$ was accumulated at $\mathrm{pH}$ 2.0. For $\mathrm{Se}$, only $\mathrm{Se}^{\mathrm{IV}}$ was retained on the column under neutral $\mathrm{pH}$. Therefore, once $\mathrm{Se}^{\mathrm{IV}}$ was removed, both $\mathrm{Se}^{\mathrm{IV}}$ and $\mathrm{Se}^{\mathrm{VI}}$ were retained at $\mathrm{pH} 2.0$ and a $2.5 \% \mathrm{HNO}_{3}$ solution was employed to elute the extracted species. The LOD values were $0.004 \mu \mathrm{g} \mathrm{L}^{-1}$ for As and $0.063 \mu \mathrm{g} \mathrm{L}^{-1}$ for Se. Validation of the method was achieved through analysis of four CRMs (NRCC SLEW-3 estuarine and CASS-4 nearshore waters, NIST SRM 1643 fresh water and SRM 2678 human urine). The measured concentrations were in good agreement with the 
certified values. Spike recovery studies of water and human urine ranged from 83 to $93 \%$. The developed microcolumns were rigid and chemically inert enabling their use for several weeks without losing analytical capabilities. Without doubt 3D printing techniques open new insights into the development of analytical components combining flexibility, speed and low-cost.

Table 3 shows examples of other applications of Se speciation presented in the literature during the time period covered by this ASU.

Table 3 Applications of Speciation Analysis: Se

\begin{tabular}{|c|c|c|c|c|c|c|c|}
\hline $\begin{array}{l}\text { Analyte } \\
\text { species }\end{array}$ & Technique & Matrix & $\begin{array}{l}\text { Sample } \\
\text { treatment }\end{array}$ & Separation & LOD & Validation & $\begin{array}{l}\text { Referenc } \\
\text { e }\end{array}$ \\
\hline $\begin{array}{l}\mathrm{Se}^{\mathrm{IV}}, \mathrm{Se}^{\mathrm{VI}} \\
\text { SeCys2, } \\
\text { SeMet, } \\
\text { Total Se }\end{array}$ & HPLC-UV-AFS & $\begin{array}{l}\text { Se- } \\
\text { enriched } \\
\text { mushroo } \\
\mathrm{m}\end{array}$ & $\begin{array}{l}\text { Total } \mathrm{Se}: \mathrm{MAE} \text {, } \\
\mathrm{HNO}_{3}, \mathrm{H}_{2} \mathrm{O}_{2} \cdot \mathrm{HCl} \text { to } \\
\text { reduce } \mathrm{Se}^{\mathrm{Vl}} \text { to } \mathrm{Se}^{\mathrm{VI}} \\
\text { Se speciation: } \mathrm{UAE} \text {, } \\
25 \mathrm{mmol} \mathrm{L}^{-1} \\
\mathrm{NH}_{4} \mathrm{CH}_{3} \mathrm{COOH}, 45 \\
\text { minutes at } 40 \mathrm{MHz} \text {. }\end{array}$ & $\begin{array}{l}\text { AEC: } 40 \mathrm{mmol} \mathrm{L}^{-1} \\
\left(\mathrm{NH}_{4}\right)_{2} \mathrm{HPO}_{4} \mathrm{pH} 6.0\end{array}$ & $\begin{array}{l}1.34,0.784, \\
3.24, \text { and } \\
3.65 \mu \mathrm{L} \mathrm{L}^{-1} \\
\text { for SeCys }_{2} \text {, } \\
\mathrm{Se}^{\mathrm{IV}}, \mathrm{SeMet} \\
\text { and Se }{ }^{\mathrm{VI}} \text {, } \\
\text { respectively. }\end{array}$ & $\begin{array}{l}\text { Mass balance } \\
\text { calculations were } \\
\text { performed for method } \\
\text { validation. Identity of } \\
\text { the Se-containing peak } \\
\text { assigned as SeCyst } 2 \\
\text { was not corroborated }\end{array}$ & 192 \\
\hline $\begin{array}{l}\mathrm{Se}^{\mathrm{IV}}, \mathrm{Se}^{\mathrm{VI}} \\
\text { SeCys, } \\
\text { SeMet }\end{array}$ & HPLC-ICP-MS & $\begin{array}{l}\text { Se- } \\
\text { enriched } \\
\text { mushroo } \\
\text { m }\end{array}$ & $\begin{array}{l}0.2 \mathrm{~g}, 4 \mathrm{mg} \text { Protease } \\
\mathrm{K}, 4 \mathrm{~h} \text { at } 37^{\circ} \mathrm{C} .\end{array}$ & $\begin{array}{l}\mathrm{RP}: \mathrm{C}_{18}, 50 \% \mathrm{MeOH} \\
0.1 \% \\
\text { mercaptoethanol, } \mathrm{pH} \\
5.0\end{array}$ & Not given & $\begin{array}{l}\text { Details on SeCys } \\
\text { integrity preservation } \\
\text { during sample } \\
\text { treatment are not } \\
\text { given }\end{array}$ & 193 \\
\hline $\begin{array}{l}\mathrm{Se}^{\mathrm{IV}}, \mathrm{Se}^{\mathrm{VI}} \\
\text { SeMet, } \\
\text { SeCys, } \\
\text { MeSeCys } \\
\text { SeMet } \\
\text { Total Se }\end{array}$ & $\begin{array}{l}\text { HPLC-ICP- } \\
\text { MS, HPLC- } \\
\text { orbitrap-MS }\end{array}$ & $\begin{array}{l}\text { Brasil } \\
\text { nut, } \\
\text { golden } \\
\text { berries } \\
\text { and } \\
\text { heart of } \\
\text { palm }\end{array}$ & $\begin{array}{l}\text { Total } \mathrm{Se}: \mathrm{MAE}, \mathrm{HNO}_{3} \\
\text { and } \mathrm{H}_{2} \mathrm{O}_{2} \\
\text { Se speciation: ASE, } \\
0.25 \mathrm{~g} \text { of sample, } 25 \\
\mathrm{mg} \text { DTT, } 25 \mathrm{mg} \text { of } \\
\text { protease, } 1.25 \mathrm{~g} \text { of } \\
\mathrm{C}_{18} \text { dispersing agent, } \\
\mathrm{TRIS}-\mathrm{HCl}, \mathrm{pH} 8.0,7 \\
\text { minutes. } \\
\text { MAE: } 0.25 \mathrm{~g} \text { of } \\
\text { sample, } 3.0 \mathrm{~mL} \text { of } \\
60 \mathrm{mmol} \mathrm{L}^{-1} \mathrm{TRIS}-\mathrm{HCl} \text {, } \\
\text { containing } 25 \mathrm{mg} \text { of } \\
\text { protease and } 20 \mathrm{mg} \\
\text { of DTT pH } 7.0,12 \\
\text { min }\end{array}$ & $\begin{array}{l}\text { AEC: gradient elution } \\
\text { with increasing } \\
\text { concentration of } 25 \\
\text { mmol L-1 citric acid, } \mathrm{pH} \\
5.0,2 \% \mathrm{MeOH} \text {. }\end{array}$ & $\begin{array}{l}\text { ASE: } 0.014 \text { to } \\
0.060 \mu g^{-1} \text {. } \\
\text { MAE: } 0.066 \\
\text { to } 0.24 \mu \mathrm{g} \mathrm{g}^{-1}\end{array}$ & $\begin{array}{l}\text { Mass balance } \\
\text { calculations were } \\
\text { performed for method } \\
\text { validation. The sum of } \\
\text { all Se species was } \\
\text { equal to the total Se } \\
\text { found in the samples. } \\
\text { The presence of SeMet } \\
\text { and SeCys and the } \\
\text { absence of SeMetO } \\
\text { were confirmed by } \\
\text { Orbitrap mass } \\
\text { spectrometry. }\end{array}$ & 194 \\
\hline $\begin{array}{l}\mathrm{Se}^{\mathrm{lV}}, \mathrm{Se}^{\mathrm{Vl}} \\
\text { SeMet, } \\
\text { SeCys2, } \\
\text { MeSeCys } \\
\text { Total Se }\end{array}$ & HPLC-AFS & $\begin{array}{l}\text { Se } \\
\text { biofortifi } \\
\text { ed } \\
\text { cereals } \\
\text { (rice, } \\
\text { wheat } \\
\text { and } \\
\text { corn) } \\
\text { and soy } \\
\text { beans. } \\
\text { Effect of } \\
\text { cooking } \\
\text { processe } \\
\text { s }\end{array}$ & $\begin{array}{l}\text { Total Se: } 0.2 \mathrm{~g} \\
\text { sample, } \mathrm{HCLO}_{4}, \mathrm{HNO}_{3} \\
\text { at rt overnight, } \\
\text { further heating. } \mathrm{HCl} \\
\text { added to reduce } \mathrm{Se}^{\mathrm{VI}} \\
\text { to } \mathrm{Se}^{\mathrm{VI}} \\
\mathrm{Se} \text { species extraction } \\
0.1 \mathrm{~g} \text { sample, } 5 \mathrm{~mL} \\
\mathrm{Tris}-\mathrm{HCl}(100 \mathrm{mmol} \\
\left.\mathrm{L}^{-1}, \mathrm{pH} 7.5\right) \text { and, } 0.4 \\
\mathrm{mg} \text { Protease } \mathrm{K}, 50 \\
{ }^{\circ} \mathrm{C}, 24 \mathrm{hr} \text { shaking } \\
\text { then } 0.2 \mathrm{mg} \\
\text { Protease XIV } \\
\text { incubated for } \\
\text { another } 18 \mathrm{~h}\end{array}$ & $\begin{array}{l}\text { AEC: } 40 \mathrm{mmol} \mathrm{L}^{-1} \\
\mathrm{NH}_{4} \mathrm{H}_{2} \mathrm{PO}_{4}, \mathrm{pH}^{6.0} . \\
\mathrm{A} \text { mixture of } 0.8 \% \\
\mathrm{H}_{2} \mathrm{O}_{2} \text { in } 3.5 \mathrm{~g} \mathrm{~L}^{-1} \mathrm{NaOH} \\
\text { under UV irradiation } \\
\text { as oxidising agent with } \\
\text { the aim of } \\
\text { transforming organic } \\
\text { Se species to } \mathrm{Se}^{\mathrm{IV}} \text { prior } \\
\mathrm{HG}-\mathrm{AFS} \\
\text { measurements }\end{array}$ & $\begin{array}{l}\text { SeCys } 2, \\
\text { MetSeCys, } \\
\text { SeMet and } \\
\text { Selv }^{\mathrm{IV}} \text { were } 2.3 \text {, } \\
4.9,7.4 \text { and } \\
2.0 \mu \mathrm{LL}^{-1}, \\
\text { respectively } \\
\text { with RSD } \\
\text { values as low } \\
\text { as } 2 \% \text {. }\end{array}$ & $\begin{array}{l}\text { GBW } 07602-G S V-1 \\
\text { Recovery } 85 \text { to } 118 \% \\
\text { Mass balance } \\
\text { calculations. } \\
\text { Recovery of the sum of } \\
\text { the identified species } \\
\text { to the total Se content } \\
\text { varied from } 47 \text { to } 89 \% \text {. } \\
\text { Losses of all Se species } \\
\text { were detected during } \\
\text { the process of cooking. } \\
\text { Identity of the Se- } \\
\text { containing peak } \\
\text { assigned as SeCyst }{ }_{2} \\
\text { was not corroborated }\end{array}$ & 195. \\
\hline
\end{tabular}




\subsection{Silver}

The detection and quantification of Ag NPs, required due to their heavy use as an anti-microbial agent, is now maturing to involve on-line separation techniques to differentiate between the 'ionic' and NP forms of Ag. An approach to accomplish this using CE-ICP-MS has been reported on this year ${ }^{196}$. A capillary of $90 \mathrm{~cm} \times 50 \mu \mathrm{m}$ ID was used for the CZE separation and this was coupled directly to the nebuliser of the ICP-MS instrument via a polyethylene T-piece which allowed the simultaneous introduction an auxiliary fluid. A second T-piece was incorporated in the auxiliary flow line to allow the grounding electrode to be entrained in the sheath electrolyte flow. The work focussed on the separation of MT-1, MT-2, $\mathrm{Ag}^{+}$and Ag NPs and as such the use of six different electrolyte solutions was investigated. The optimal electrolyte and auxiliary fluid was found to be TMAH at 70 and $1100 \mathrm{mmol} \mathrm{L}^{-1}$ respectively which allowed separation of all the analytes of interest in ten minutes. The experimental results showed that $\mathrm{Ag}^{+}$was fully associated with MT-1 and only partially with MT-2 with the inverse for Ag NPs. The second paper covered here utilised GFAAS, using $2 \mathrm{mmol} \mathrm{L}^{-1}$ of trisodium citrate as a stabilising agent and pyrolysis and atomisation temperatures of 550 and $1100{ }^{\circ} \mathrm{C}$ respectively, to determine the particle size of Ag NPs extracted from consumer products with water ${ }^{197}$. Particle size measurements were made from a linear regression of signal intensity versus a series of Ag NP standards, $10-100 \mathrm{~nm}$ in range, and presumably, as a zero point is included, a calibration blank. The method was validated using NIST 8017 SRM, PVP-coated Ag NPs of nominal diameter $75 \mathrm{~nm}$, with the found value being $64.9 \pm 2.3$ $\mathrm{nm}$ which the authors suggest is in good agreement with the certified value and their measured value by TEM of $74.6 \pm 3.8 \mathrm{~nm}$. A statistical analysis would probably conclude that this is not the case. Experiments involving mixtures of $\mathrm{Ag}^{+}$and $\mathrm{Ag}$ NPs produced a bimodal absorbance vs time profile suggesting that the method could be used to determine between these two forms of $\mathrm{Ag}$ with a similar conclusion for Ag NP mixtures provided that the delta diameter value was greater than 20 $\mathrm{nm}$. Only Ag NPs were detected in the water extracts of one fabric type whilst in the extracts of wipes and fabric of a different type both $\mathrm{Ag}^{+}$and $\mathrm{Ag}$ NPs were detected.

\subsection{Tellurium}

The determination of Tellurium is growing in interest because of its wide use in rewritable CDs and DVDs and in semiconductor technology, including solar panels. Vapor generation techniques based on the formation of the volatile specie $\mathrm{TeH}_{2}$ is usually the method of choice. Vapor generation modalities include chemical (by using $\mathrm{NaBH}_{4}$ ), electrochemical and UV-photochemical vapor generation. Lately, the use of electrochemical generation is gained acceptance. 
One paper on the determination of Te by electrochemical generation of volatile $\mathrm{TeH}_{2}$ followed by AFS has appeared this year ${ }^{198}$. Two types of electrolytic cells for producing $\mathrm{TeH}_{2}$ were developed. The first one (Cell I) was a thin layer type with anode and cathode compartments separated by a Nafion 117 membrane that prevents reaction between products from cathodic and anionic process. The second type of cell (Cell II) was a membrane less type having only one compartment containing both electrodes. Best results were achieved in Cell I by using $1.5 \mathrm{~mol} \mathrm{~L}^{-1} \mathrm{HCl}$ and $2 \mathrm{~mol} \mathrm{~L}^{-1} \mathrm{H}_{2} \mathrm{SO}_{4}$ as electrolyte solutions in the cathode and anode compartment, respectively both flowing at $5.0 \mathrm{~mL}$ $\mathrm{min}^{-1}$. The electrolyte current running between the $\mathrm{Pb}$ cathode and a $\mathrm{Pt}$ anode was $0.7 \mathrm{~A}$. Transport losses were significantly decreased and the sensitivity of the method improved by cooling the gasliquid separator in a water bath at $0{ }^{\circ} \mathrm{C}$ and by employing a carrier gas composed of a mixture of $\mathrm{Ar}$ (flow-rate at $400 \mathrm{~mL} \mathrm{~min}^{-1}$ ) and $\mathrm{H}_{2}$ (flow-rate at $75 \mathrm{~mL} \mathrm{~min}^{-1}$ ). The efficiency of conversion of $\mathrm{Te}^{\mathrm{IV}}$ to $\mathrm{TeH}_{2}$ was $79 \pm 4 \%$. A LOD of $0.14 \mathrm{ng} \mathrm{mL}^{-1}$ was obtained which is comparable with values provided by other Te determination methods reported in the literature. Method accuracy was validated using NIST SRM $1634 \mathrm{f}$ (Trace elements in water) CRM. After performing a preconcentration step, the determined concentration $1.01 \pm 0.24 \mu \mathrm{g} \mathrm{L^{-1 }}$ agreed with the certified concentration $0.997 \pm 0.08 \mu \mathrm{g}$ $\mathrm{L}^{-1}$

\subsection{Thallium}

Thallium is a toxic element with two inorganic oxidation states, $\mathrm{TI}^{\prime}$ and $\mathrm{TI}^{\prime \prime \prime}$, whose geochemical behaviour and biological effects are closely controlled by the environmental chemical speciation but about which little is known. An SPE-ICP-MS procedure for speciation of TI in soils and green cabbage (a TI hyperaccumulator) has been developed based on selective column SPE of TI' after UAE ${ }^{199}$. The soils were freeze-dried, sieved $(2 \mathrm{~mm})$ and ground $(<180 \mu \mathrm{m})$, whereas plant materials (roots, stems, young leaves and old leaves) were analysed as received. Both plants (500 mg) and soils (1000 mg) were extracted for $4 \mathrm{~h}$ at $60{ }^{\circ} \mathrm{C}$ in sealed centrifuge tubes with $50 \mathrm{~mL}$ of $5.0 \mathrm{mmol} \mathrm{L} \mathrm{L}^{-1}$ DTPA. After centrifuging (3000 g for $10 \mathrm{~min}$ ), filtering $(0.45 \mu \mathrm{m})$, and adjusting the $\mathrm{pH}$ (to 6-7 with ammonia), the solution, which contained TI' as free ions and TI'II as the DTPA complex, was passed through a column of SDS-coated alumina on which 8-hydroxyquinoline had immobilised (prepared according to a cited method). The free $\mathrm{Tl}^{1}$ ions were retained, and the TI"I-DPTA passed through and was collected. The retained $\mathrm{TI}^{\prime}$ was eluted with $1 \mathrm{~mol} \mathrm{~L}^{-1}$ sodium thiosulfate. Both species were determined by ICP-MS (standard additions and rhodium IS). The LOD values were 0.04 and $0.2 \mu \mathrm{g}$ $\mathrm{L}^{-1}$ for $\mathrm{TI}^{\prime}$ and $\mathrm{TI}^{\mathrm{III}}$, respectively. The procedure was validated by showing that the TI'I'-DTPA complex was stable under the sample preparation conditions and by the analysis of standards containing 
mixtures of the species at concentrations of 10 to $100 \mu \mathrm{g} \mathrm{L}^{-1}$. Total TI was determined following nitric plus hydrofluoric acid digestion with an LOD of $10 \mu \mathrm{gg}^{-1}$ for both plants and soils. Soil TI was also fractioned, according to a modified BCR procedure (a table with details of the reagents is given) into water soluble, weak acid soluble, reducible, oxidisable, and residual fractions. The researchers concluded that green cabbage mainly takes up Tl' from soil, and transports it into the aboveground biomass, and that $\mathrm{TI}^{\prime \prime \prime}$ is reduced to $\mathrm{TI}^{\prime}$ in soils, even at the surface where oxidation would be expected. The same reagent, DTPA, featured in an HPLC-ICP-MS procedure developed for the determination of $\mathrm{Tl}$ species in tobacco and cigarette ash $^{200}$. The species were quantitatively leached from the tobacco and the ash by UAE for $20 \mathrm{~min}$ into a solution of $5 \mathrm{mmol} \mathrm{L}^{-1}$ DTPA in $100 \mathrm{mmol} \mathrm{L}^{-1}$ ammonium acetate (with HF for the ash samples) and then, following filtration $(0.2 \mu \mathrm{m})$, separated by ion-pair RP chromatography for which tetrabutylammonium was the ion-pair agent. The optimised mobile phase composition was $7 \mathrm{mmol} \mathrm{L}^{-1}$ TBAP, $6 \mathrm{mmol} \mathrm{L}^{-1}$ DTPA and 2\% v/v methanol ( $\mathrm{pH} 5)$. The LOD values were $3 \mathrm{ng} \mathrm{L}^{-1}$ for both species. The method was validated by spike recoveries and the comparison of the sum of species with the total value determined by ICP-MS. The researchers found only $\mathrm{Tl}^{\prime}$ in the tobacco (at concentrations from 21 to $84 \mathrm{\mu g} \mathrm{kg}^{-1}$ ), whereas both species were found in the cigarette ash (at similar concentrations). In contrast to the behaviour for several other elements ( $\mathrm{As}, \mathrm{Cd}, \mathrm{Cr}, \mathrm{Ni}$ and $\mathrm{Pb}$ ), whose concentrations increased significantly in the ash compared with those in the original tobacco, $\mathrm{Tl}$ concentrations did not increase. The researchers speculated that this was due to the volatility of $\mathrm{Tl}$ as the chloride or nitrate. In a study of the instability of $\mathrm{TI}^{1 \mathrm{III}}$ in the presence of rice plants ${ }^{201}$, the same DTPA reagent was used to prevent reduction of $\mathrm{TI}^{\text {III }}$ by the various root exudate compounds, primarily oxalate. The work was supported by a speciation method (separation by SPE on a Chelex-100 column plus FAAS) dating from 1999.

\subsection{Tin}

Following the pattern established in recent years, there have been very few publications focusing on tin speciation. Those that have been reported are often modest modifications to existing techniques. To improve LOD values for the simultaneous determination of $\mathrm{Hg}, \mathrm{Pb}$ and $\mathrm{Sn}$ at ultratrace levels using GC-ICP-MS, an online automated pre-concentration method using large volume injections with a programmed temperature vaporisation injector fitted with a sorbent packed liner has been used ${ }^{150}$. The influence of parameters such as the transfer temperature and time, carrier gas flow rate and amount of packing material was investigated. The maximum volume injected through single or multiple injection modes were also optimised to obtain the best compromise between chromatographic resolution and sensitivity. After optimisation, LOD values down to the pg 
$\mathrm{L}^{-1}$ level were achieved for all species studied. The selective non-chromatographic determination of TBT in sediments using EDTA and diphenylcarbazone as a masking agent has been reported ${ }^{\mathbf{2 0 2}}$. The method was based on the generation of volatile TBT derivatives, separation by headspace SPME and subsequent determination using ICP-OES. A microwave-assisted leaching of Sn compounds from sediment using $25 \%(\mathrm{v} / \mathrm{v})$ acetic acid was used for sample pre-treatment. TBT chloride was released from the leachate by adding $3 \mathrm{~mol} \mathrm{~L}^{-1} \mathrm{HCl}$ prior to separation using Carboxen-poly(dimethylsiloxane). The masking agents formed stable chelates with MBT and DBT. Better sensitivity and robustness were attained following ethylation of TBT at pH 5 using NaBEt $(0.05 \%(w / v))$, giving a LOD of $3 n g ~ L^{-}$

1. The method was validated using several CRM materials, including SOPH-1 marine sediment, PACS2 marine sediment and BCR 646.

\subsection{Vanadium}

Vanadium, which is not considered to be an essential element in humans, exists in a number of oxidation states in the environment (of which $\mathrm{V}^{\mathrm{IV}}$ and $\mathrm{V}^{\mathrm{V}}$ predominate in aquatic systems) and is of concern because of the high toxicity of $\mathrm{V}^{\mathrm{V}}$, due to the strong inhibition of enzyme function. Thus, although considerable effort has been made to quantify low concentrations of $V$ in different environmental and biological samples, there is not a pressing need for speciation analysis in support of exposure studies. On the other hand, $\mathrm{V}$ is a potentially useful chemical tracer of both modern and ancient redox conditions in the Earth's oceans, assuming that the geochemistry in marine systems is well understood, which requires reliable measurements of its solid-phase speciation in marine sediments.

A study of the limitations of and opportunities for $S R$ X-ray spectroscopy for making such measurements has been reported ${ }^{203}$. Although the $\mathrm{S}: \mathrm{N}$ ratio of XANES spectra (obtained at the Australian Synchrotron) of bulk samples was not sufficient for accurate quantitative analysis, semiquantitative analysis indicated the average oxidation state of $\mathrm{V}$ was approximately 3.5 , indicating a mixture of $V^{\prime I I}$ and $V^{\prime V}$. The researchers also showed that high-resolution element mapping by scanning XRF microscopy provided useful complementary geochemical information for resolving possible $\mathrm{V}$ host phases in sediments, but was limited by its inability to distinguish between $\mathrm{V}$ and $\mathrm{Ti}$ because of the proximity of their fluorescence emission lines. The researchers concluded that the application of these methods require cautious interpretation and rigorous quality control measures, and they made two specific recommendations. First, the effect of XANES normalisation parameters on the results of linear combination fitting analysis should be examined for a systematic variation, and if the uncertainty exceeds an acceptable threshold (say 20\%), analyses should be based on prePage 73 of 96 
edge peak or main edge position approaches. Second, while rigorous 2D data analysis of scanning XRF microscopy results should be used to identify areas of interest without overlapping titanium fluorescence, there is a risk that areas where the two elements genuinely co-occur are overlooked. A SPE-ETAAS method for the speciation analysis of waters has been developed and applied to total $\mathrm{V}$ determination in foods and wine ${ }^{204}$. Multiwalled carbon nanotubes were functionalised with tetraethylenepentamine and packed into a syringe micropipette tip. No details are provided as to how the material was retained in the tip nor are the optimised conditions collected in one location, such as a table. A volume of sample $(3 \mathrm{~mL}$ ) whose $\mathrm{pH}$ was adjusted (to 4) was repeatedly drawn up and ejected through the extractant $(4.5 \mathrm{mg}$ ) by operation of the syringe pipette ( 8 times in $2 \mathrm{~min}$ ). Any $\mathrm{V}^{\mathrm{V}}$ in the sample was retained, whereas $\mathrm{V}^{\mathrm{IV}}$ was not. The retained $\mathrm{V}^{\mathrm{V}}$ was desorbed by flushing (number of times not given, so maybe once) with $100 \mu \mathrm{L}$ of $2 \mathrm{~mol} \mathrm{~L}^{-1}$ nitric acid and measured by ETAAS with pyrolysis at $1400^{\circ} \mathrm{C}$ and atomisation at $2000^{\circ} \mathrm{C}$. Total $\mathrm{V}$ was determined after oxidation with permanganate. The speciation method was validated by spike recoveries $\left(0.5\right.$ and $\left.1.0 \mu \mathrm{g} \mathrm{L}^{-1}\right)$ from three different water samples, each of which contained measurable concentrations of both species. The total V method was validated by the accurate analysis of two CRMs: NRCC SLRS-4(riverine water) and NIST SRM 1515 (apple leaves). No details were given of the preparation of the solid samples, which in addition to the NIST material included spinach, mushrooms, apples, tomatoes and bananas, other than microwave digestion in a mixture of nitric acid and hydrogen peroxide. This procedure would oxidise any $\mathrm{V}^{\mathrm{IV}}$ present to $\mathrm{V}^{\mathrm{V}}$ so is not suitable for section studies of V.

\section{$4 \quad$ Biomolecular Speciation Analysis}

Following on from the short review discussed in last year's elemental speciation ASU $^{1}$ a more detailed treatise on absolute protein quantification and quantitative protein mapping using ICP-MS, containing 93 refs has been published ${ }^{205}$. Using a number of papers from his own laboratory, the lead author examined the quantification of proteins and how elemental MS has significant advantages over molecular MS when it comes to the measurement of metalloproteins, proteins that contain heteroatoms such as S, P and Se, as well as proteins without any of these elements present, which can be made amenable to ICP-MS detection by tagging with a metal or metal nanoparticle. The paper illustrates that the main advantages of protein quantitation by ICP-MS compared to molecular methods are: that it does not require well characterised molecular standards to achieve absolute quantitation; the robust plasma generates signals independent of the species being 
measured, although this is tempered by the effects of any change in the eluent solution entering the plasma, such as during gradient elution; and that high accuracy isotopic calibration methods are more straightforward to use and require less complex isotopic standards. However, the main drawbacks with the approach were identified as: the requirement for high resolution chromatographic separation to isolate proteins from each other; when using covalently bound nonmetal heteroatoms, such as S, P and Se for detection, the signal can be weak and affected by polyatomic interferences; and for metalloproteins containing a non-covalently bound metal the separation must be achieved under conditions which do not result in the loss of the metal. Also, when using methods involving quantitation via elemental detection, the metal-to-protein stoichiometry is required, to convert elemental quantities to molecular. As far as labelling proteins to make them accessible for detection by elemental methods, this has the advantages that: an improvement in the LOD in comparison to the use of heteroatoms can be achieved by choosing a metal tag that responds well in the plasma; multiplexing is possible, whereby different elements are tagged onto different proteins, which are all measured simultaneously, thus negating the need for a chromatographic separation; and using this method all proteins are potentially measurable. The drawbacks include: the labelling processes are time consuming and error prone; when using antibodies to facilitate labelling these are complex to prepare and can be confounded by binding to other endogenous proteins; the antibody needs to be in excess to ensure all the proteins present are labelled; and the excess antibody needs to be removed after tagging the analyte. There are also many other well known analytical problems with the use of the current methods based on immunochemistry and these are not negated by using an elemental rather than spectroscopic detector e.g. the Hook effect.

\subsection{Direct biomolecular analysis}

The availability of atomic spectrometry methods for the measurement of non-metals such as $P$ and $S$ with LOD values sufficient for use in complex biological matrices, offers the potential for the direct measurement of biomolecules that do not contain, or are not tagged, with a metal(loid). This approach has been used for the determination of gene copy number variations (CNV) and gene expression changes, by using GE coupled to ICP-MS and measurement of DNA base-pairs (bp) via the detection of ${ }^{31} \mathrm{P}^{206}$. The coupling of GE with the SF-ICP-MS detector was achieved by preparing a gel housed in a glass tube $(20$ to $30 \times 2.2 \mathrm{~mm})$, fixed in place between glass frits permeable to the eluent stream and analytes. The outlet of the agarose gel $(2 \% \mathrm{w} / \mathrm{v})$ column was connected to a concentric nebuliser and the multiplex PCR products were separated at voltages between 200 and Page 75 of 96 
$250 \mathrm{~V}$ using an ammonium acetate $\mathrm{pH} 8.0$ buffer which acted as electrode and elution buffer. The system provided adequate, but not baseline resolved separations in $25 \mathrm{~min}$ between a 50 to $500 \mathrm{bp}$ mixture of DNA fragments, which was used to size calibrate the separation. Quantitation was performed using the initial mass of DNA used for the amplified genes studied and the area of the separated peaks using inorganic phosphate as an internal standard, which produced calibration plots with linear correlation coefficients $R^{2}>0.93$. The system was used to determine the CNVs and gene expression changes in a number of cancer cell lines. The authors make the interesting point that the method could be used to replace the use of the expensive fluorescence probes usually used when analysing PCR products, however their developed method does require the use of rather prohibitively expensive SF-ICP-MS equipment not routinely available in laboratories involved in molecular biology. The increasing availability of triple quadrupole ICP-MS instrumentation offers another avenue for the measurement of non-metal heteroatoms with LOD values that can be used for real world applications and this approach has been used or the measurement of two $S$ containing compounds, sulfate and taurine, a cardiovascular disease biomarker, in human serum and urine ${ }^{207}$. The S containing compounds were separated using an AE column (PRP-X100, $150 \mathrm{~mm} \times 2.1 \mathrm{~mm} 5$ $\mu \mathrm{m}$, Hamilton) at a temperature of $50^{\circ} \mathrm{C}$, interfaced to an AriMist PEEK nebuliser by a short piece of PEEK tubing. Gradient elution consisting of water to ammonium acetate $\mathrm{pH} 9$ buffer $(100 \mathrm{mmol}$ $\mathrm{L}^{-1}$ ) at a flow rate of $0.5 \mathrm{~mL} \mathrm{~min}^{-1}$. Use of a QQQ-ICP-MS instrument using oxygen as the collision cell gas and monitoring the formation of SO at $\mathrm{m} / \mathrm{z} 48$ and 50 was fundamental in overcoming the significant ${ }^{16} \mathrm{O}_{2}$ polyatomic interference on ${ }^{32} \mathrm{~S}$. This resulted in a LOD and LOQ for taurine of 0.2 and $0.7 \mathrm{pmol}$, respectively. There was evidence of a large number of poorly resolved compounds eluting underneath the sulfate peak which resulted in a significant "hump", which was not explained in the text. This did not affect the taurine peak, which was well resolved.

\subsection{Tagging methods for macromolecular analysis}

Methods for the imaging and spatial analysis of proteins on a microscopic level, when combined with quantification of the proteins of interest would be a powerful tool, useful in numerous scientific areas, in particular clinical and biomedical studies. A recent paper using antibody-conjugated gold nanoclusters (Ab-AuNCs) as "tags" for the quantitative bioimaging of the metallothionein protein isoforms MT1 and 2 in human retinal tissues by LA coupled to double focusing fixed sector ICP-MS, goes someway towards this complex and difficult goal ${ }^{208}$. The Ab-AuNC "tags" were conjugated to the selected antibody through carbodiimide coupling and a stoichiometry of Ab-AuNCs to available antibody of 1:1 was used. After preparation of the Ab-AuNCs the authors went to considerable Page 76 of 96 
lengths to determine the exact number of AuNCs per Ab molecule as this stoichiometry is required for quantitation. The concentration of $A b$ available for reaction with the corresponding protein was measured using a direct ELISA test whereby the purified bioconjugate ( $A b-A u N C S$ ) and the $A b$ without AuNCs were subjected to quantitative analysis. The results showed that Ab concentrations for the purified bioconjugate (Ab-AuNCs) and the not-conjugated Ab were $5.47 \pm 0.23$ and $5.78 \pm$ $0.19 \mu \mathrm{g} \mathrm{mL} \mathrm{m}^{-1}$, respectively. The measured $A b$ concentrations demonstrate the high $A b$ bioconjugation yield (95\%) with the preparation methodology used. These values were then used to obtain the $A b$ concentration in terms of number of $A b$ per $\mathrm{mL}$ : a mean value of $2.20 \times 10^{16}$ molecules of $A b \mathrm{~mL}^{-1}$ was found in the purified $A b-A u N C$ bioconjugate solution. Quantitation was investigated by comparing the instrumental response to gels spiked with inorganic Au or Ab-AuNCs and showed that both provided a similar response and calibration curve, which is surprising because Ab-AuNCs have been reported to have an enhanced interaction with lasers. Interestingly the authors did not report using the metal content of the MT being measured, in this case $\mathrm{Zn}$, as an internal standard, either because the metal content of the MT is too low, or the metal was lost during the complex sample preparation method. The samples were formalin-fixed and paraffin-embedded (FFPE) following conventional protocols, prior to LA-ICP-MS analyses using eye tissue sections of 5$\mu \mathrm{m}$ thickness from the FFPE blocks that were placed in microscope slides. The samples were deparaffinised using xylene and ethanol prior to analysis and it is interesting to consider how this might have affected the distribution of the target analyte in the tissue. When measuring macromolecular species in post-mortem samples it is critical to maintain their original confirmation and structure, particularly when using an antibody tagging method for measurement, because any change in confirmation of the target protein could result in it not being recognised by the antibody. State-of-the-art instrumentation using very small laser spots, ultrafast ablation cells, and simultaneous ICP-MS detection systems, such as ICP-TOFMS, would provide high-resolution quantitative images of protein distribution in biological samples, but would also require more control of tissue slide preparation, so that the tissue was still representative of the original sample.

\subsection{Measurement of metalloproteins}

A review of the analytical platforms used in the study of metal speciation in neurodegenerative disease contained 109 references to studies performed between 1988 and 2017, effectively comparing the results found with older analytical approaches to those determined more recently using the conventional speciation approach of chromatography coupled to inorganic MS (ICP-MS, ICP-MS/MS and ICP-SF-MS), but also in this particular field, the use of molecular MS (ES-MS/MS, 
MALD-TOF-MS and FT-ICR-MS) which is widely used to provide species identification ${ }^{209}$. A range of neurological diseases, from mild cognitive impairment to amyotrophic lateral sclerosis, Alzheimer's disease and Parkinson's disease have been investigated in relation to the effect of metal(loid)s and speciation. This is an area of metal speciation where species stability and sample contamination are difficult to mitigate against because of the nature of the CSF sampling procedure, which requires a lumbar puncture necessitating the use of stainless steel needles and being an invasive clinical procedure makes it difficult to implement the complex steps needed to maintain, for instance, the oxidation state of a redox sensitive element. During the analytical step QC and QA are of paramount importance because of the difficulty in obtaining the precious CSF samples, which are often of small volume. Thankfully the review makes note of the studies which use adequate QC/QA approaches as part of their experimental design. Analytically the review shows that the less stable, non-covalently and loosely-bound species, such as Mn-transferrin should be assayed using gentle separation methods, such as GE, SEC, PAGE (with LA analysis) and Ultra-Filtration (UF), whereas more aggressive methods such as IE and RP can be used for covalently bound species, such as selenoprotein $\mathrm{P}$. The corollary of this is that the gentle separation methods are often of lower resolving power. Initially the paper deals with the low molecular mass (LMM) binding of $\mathrm{Cu}, \mathrm{Zn}$ and Fe and in most studies on CSF it seems that the LMM species dominate, principally because the HMM species are not able to penetrate the blood-brain barrier so easily. The review then covers studies involving speciation analysis of the known neurotoxic metal(loid)s Al, As, Mn, $\mathrm{Hg}$ and Se. The review concludes by making the point that the potential of speciation is still not fully recognised in the neurological field and that biologists and physicians often implement outdated analytical techniques and do not necessarily undertake the most appropriate degree of method validation prior to the study and can also be remiss in using the correct QC/QA procedures during the analysis of the valuable samples collected during a study.

Two different electrophoretic separation approaches coupled to ICP-MS have been reported, one using weak AE followed by column GE and the other capillary isoelectric focusing (cIEF) both being used for the separation of metalloproteins. To improve the resolution of 1D GE Yan et al ${ }^{210}$ have incorporated a semi-preparative weak AE (HiPrep 16/10 DEAE FF, GE Healthcare) gradient separation using Tris- $\mathrm{HCl}\left(20 \mathrm{mmol} \mathrm{L}^{-1}\right) \mathrm{pH} 7.4$ to the same buffer containing $\mathrm{NaCl}\left(1.0 \mathrm{mmol} \mathrm{L}^{-1}\right)$ over $35 \mathrm{~min}$, prior to a column GE separation coupled to ICP-MS. The GE apparatus consisted of a modified quartz glass tube $(10 \times 2.2 \mathrm{~mm}$ i.d.). The upper and lower buffer chambers were filled with the running buffer ( $25 \mathrm{mmol} \mathrm{L}^{-1}$ Tris, $192 \mathrm{mmol} \mathrm{L}^{-1}$ glycine, SDS, $\mathrm{pH}$ 8.3), while the elution buffer (50 
$\mathrm{mmol} \mathrm{L}^{-1} \mathrm{NH}_{4} \mathrm{NO}_{3}$ ) was introduced by a self-designed 3D printed eluent drainage device for transport of the separated and eluted analytes. A porous polypropylene filter and dialysis membrane was place at the bottom end of the tube to filter the elution buffer. After separation the fractions from the GE column were split into two parts by a T-piece connected to a peristaltic pump via Teflon tubing $(0.25 \mathrm{~mm}$ i.d.). One side was connected to the nebuliser of the ICP-MS, and the other to a fraction collector to retain samples for further analysis. The separation was carried out as a twostep procedure: $200 \mathrm{~V}$ for $30 \mathrm{~min}$, and then $800 \mathrm{~V}$ for an additional $100 \mathrm{~min}$. In order to decrease the heat generated in the system with the increase of the voltage, the whole system was run in a cooling tank. Protein samples $\left(10 \mu \mathrm{L}, 0.1 \mathrm{mg} \mathrm{mL}^{-1}\right)$ were mixed 1:1 (v/v) with sample buffer $(0.06$ mol L-1 Tris buffer, $25 \%$ glycerol, 2\% SDS) and then loaded onto the stacking gel using a small syringe with a Teflon tube attached. The separation power of the system was demonstrated by analysis of 6 proteins with MWs ranging from 14 to $77 \mathrm{kDa}$, which were labelled prior to separation by iodination of the histidine and tyrosine residues on each, which made the molecules detectable by ICP-MS. The applicability of the methodology as a strategy for metallomic type studies was illustrated by the qualitative analysis of metalloprotein expression in E. coli. In another study using electrophoretic separation the determination of the binding constant between transferrin and Th, and the conformational changes of the protein upon complexation with the actinides Th and $\mathrm{Pu}$ have been investigated by both $\mathrm{CE}$ and CIEF coupled to ICP-MS ${ }^{211}$. The study was aimed at understanding the distribution and kinetics of $\mathrm{Pu}$ when interacting with biological systems, but because of its high radioactivity, Th which has a similar atomic radius, was used as a proxy to understand the interaction with transferrin, an important Fe-transport metalloprotein. The very similar size-to-charge ratio between $\mathrm{Fe}^{3+}$ and $\mathrm{Pu}^{4+}$ means that in the event of an uncontrolled release resulting in human exposure, the fate of this actinide can be understood more fully if methods for the determination of serum transferrin are developed. The CE system used required a tailor-made capillary cartridge support designed for using an external detector, in this case a single quadrupole ICP-MS instrument. Both pieces of apparatus were coupled by a commercial interface using a parallel path Mira Mist CE micro-nebuliser specially designed for CE. A make-up liquid containing $\mathrm{HNO}_{3}(2 \% \mathrm{v} / \mathrm{v})$ and ethanol $(10 \% \mathrm{v} / \mathrm{v})$ was introduced by means of a syringe pump at a nominal flow rate of $8 \mu \mathrm{L} \mathrm{min}^{-1}$ to improve the signal stability by decreasing the surface tension of the eluent and providing the required flow rate for the nebuliser. Separations were performed at $+7 \mathrm{kV}, 25^{\circ} \mathrm{C}$ and a constant pressure of 1.2 psi to avoid capillary clogging. For the cIEF separation procedure, the capillary was filled with a carrier solution using a high pressure rinse mode ( 25 psi) for 15 min. Then 
a voltage of $20 \mathrm{kV}$ was applied for $45 \mathrm{~min}$ to focus the ampholytes and samples by placing the cathode in an $\mathrm{NH}_{4} \mathrm{OH}$ solution and the anode in a phosphoric acid solution. Once the focusing step was completed, the capillary was coupled with the ICP-MS and a make-up liquid $\left(\mathrm{NH}_{4} \mathrm{OH} 200 \mathrm{mmol}\right.$ $\mathrm{L}^{-1}$ ) was used. The coupling to the ICP-MS made chemical elution impossible, so the necessary $\mathrm{pH}$ gradient was achieved by using a voltage of $20 \mathrm{kV}$ and a 1 psi pressure applied for $60 \mathrm{~min}$. The capillaries required conditioning prior to use and then significant rinsing between samples, which made the approach only suitable for a specific application rather than routine analysis.

Recently reported methods for the speciation of $\mathrm{Cd}$-containing proteins found in fish and plant samples have used two distinctively different and unusual sample preparation and separation approaches for their measurement and in one have gone further by preparing a facsimile of the $\mathrm{Cd}$ binding protein using routine molecular biological methods. Yu et al. ${ }^{212}$ have developed a LA-ICPMS method for the investigation of Cd-binding proteins in rice plants (Oryza sativa), an important endeavour as this plant species can bioaccumulate this toxic element and it has been identified as a causative agent in bone disease in areas where it has been enriched in the soil. The proteins involved in the management of $\mathrm{Cd}$ within plants and animals are distinctly different, but similar in the respect that both classes contain cysteine residues, which are able to bind metals. This study used immobilised metal affinity chromatography (IMAC) which relies on the proteins of interest binding to metal ions that are immobilised on a solid support, in this case iminodiacetic acid. The chelating stationary phase used was prepared by treating a Ni-IDA resin with $0.1 \mathrm{~mol} \mathrm{~L}^{-1}$ EDTA solution, followed by soaking in $0.05 \mathrm{mmol} \mathrm{L}^{-1} \mathrm{Cd}\left(\mathrm{NO}_{3}\right)_{2}$ solution. Free $\mathrm{Cd}^{2+}$ was then removed by continuous washing with DI water to generate a Cd-IDA resin that was then packed into a column $(10 \times 1.5 \mathrm{~cm}$ i.d.). This was used to isolate the $\mathrm{Cd}$ binding proteins from an extract of different parts of the rice plant. Once identified using molecular MS, recombinant protein methods were used to encode the isolated proteins of interest for further analysis and testing in terms of their $\mathrm{Cd}$ binding properties. The presence of MT in fish has long been a useful environmental biomarker of the response to environmental contamination by heavy elements such as $\mathrm{Cd}^{213}$. In this study $\mathrm{Cd}$ saturation of the protein was used with a Protein-Pak DEAE-5PW $(75 \times 7.5 \mathrm{~mm}$ i.d., $10 \mu \mathrm{m}) \mathrm{AE}$ column coupled to single quadrupole ICP-MS to measure the two main isoforms of MT (MT-I and MT-II) commonly found in organisms responding to excess $\mathrm{Cd}$. Using a single quadrupole instrument it was not possible to achieve a suitable sensitivity for the measurement of these proteins via $\mathrm{S}$, so $\mathrm{Cd}$ saturation was used to increase the sensitivity of the method. If triple quadrupole instrumentation were available, the authors would have been able to measure the proteins via $S$ 
calibration. to reduce carbon deposition on the ICP-MS cones, the chromatographic separation used a $\mathrm{NH}_{3}-\mathrm{NH}_{4} \mathrm{Cl} \mathrm{pH} 8.6$ buffer as the eluent instead of Tris- $\mathrm{HCl}$. The chloride concentration was found to be a key factor to the separation of MT-I and MT-II. The limits of detection were $0.7 \mu \mathrm{g} \mathrm{g}^{-1}$ for MT-I and $1.0 \mu \mathrm{g} \mathrm{g}^{-1}$ for MT-II, with recoveries ranging from 96 to $104 \%$ for MT-I and 85 to $90 \%$ for MT-II in different fish tissues.

\subsection{Metallodrug Speciation}

Methods for the elucidation of the binding of metallodrugs to proteins and metalloproteins are an important area of research in the fields of drug development, human environmental exposure and metal homeostasis, and new applications in this area are welcome additions to the literature. The serum-binding properties of two anticancer drugs, plecstatin-1, an organoruthenium compound and its isosteric osmium analogue, have been investigated using SEC coupled to ICP-MS 214 . The measurements were carried out using an inert HPLC system and a UPLC Protein BEH column (4.6 $\mathrm{mm} \times 150 \mathrm{~mm}, 1.7 \mu \mathrm{m}$ i.d., pore size $1-80 \mathrm{kDa}$ ) hyphenated to a ICP-MS/MS instrument, operated in reaction cell mode with addition of $\mathrm{O}_{2}$ as the reaction gas. The two metal containing centres, $\mathrm{Ru}$ and Os were monitored on-mass, whereas $\mathrm{S}$ and Fe were observed as the oxide form. The SEC method was developed to look at the interaction of Ru and Os containing cancer therapeutics with ferritin, albumin and transferrin with masses of 65,80 and $474 \mathrm{kDa}$, respectively. A number of macromolecules including ferritin $\left(2.8 \mu \mathrm{mol} \mathrm{L}^{-1}, 440 \mathrm{kDa}\right)$, albumin $(1 \mu \mathrm{mol} \mathrm{L}-1,66 \mathrm{kDa})$, ovalbumin $(1 \mu \mathrm{mol} \mathrm{L}-1,43 \mathrm{kDa})$, and L-methionine $\left(1.6 \mu \mathrm{mol} \mathrm{L} \mathrm{L}^{-1}, 149 \mathrm{Da}\right)$ were used as mass calibration markers of the column. The major Ru peak observed had a retention time of $228 \mathrm{~s}$ and corresponded to the fraction containing both albumin and transferrin, while the minor peak at $204 \mathrm{~s}$ was close to the dead time indicated by immunoglobulin-bound $\mathrm{Ru}$. The area ratio of the two peaks was 3:1 in favour of the albumin/transferrin fraction, with a deviation of $\pm 2 \%$ among biological replicates. The method was applied to the qualitative analysis of the candidate chemotherapy agents in a tumour bearing mouse model and also by spiking into human serum. An assessment of 4 different approaches to the high-throughput screening of the interaction of metallodrugs with serum proteins has been undertaken 215 . The study assessed the analytical figures of merit of centrifugal ultrafiltration followed by FI-ICP-MS, turbulent flow chromatography and 2 different SEC approaches, one using UHPLC for the first time. The protein binding of two candidate $\mathrm{Pt}^{\mathrm{IV}}$-containing drugs, one with a maleimide moiety designed to bind covalently to the cysteine residues of serum proteins via maleimide-thiol coupling reaction and a second containing a succinimide moiety lacking 
this functionality, were investigated using foetal calf serum as the source of the proteins. The UHPLC-SEC-ICP-MS approach used columns newly available on the market, specifically an SEC column (4.6 $150 \mathrm{~mm}, 125 \mathrm{~A}, 1.7 \mu \mathrm{m}$ i.d.) using high pore-volume ethylene-bridged hybrid particles, with a diol-bonded surface which offers an increase of $\sim 75 \%$ in pore volume, whilst maintaining the mechanical rigidity required for use with high pressure. This approach gave excellent peak shape and resolution between the serum proteins as showed by the chromatogram for foetal calf serum using detection of ${ }^{32} \mathrm{~S}^{16} \mathrm{O}$. This approach was by far the best of those tested, giving quantitative metallodrug recoveries and LOD values of $0.1 \mu \mathrm{g} \mathrm{\textrm {L } ^ { - 1 }}$ as Pt. The poorest approach was the use of centrifugal ultrafiltration using Amicon Ultra $0.5 \mathrm{~mL}$ cellulose membrane filters with a $10 \mathrm{kDa}$ molecular weight cut-off. In this approach the sample is fractionated into a protein rich high molar mass fraction (HMF) and a filtrate which constitutes the low molar mass fraction (LMF). The established procedure is to analyse the total Pt content of the sample prior to fractionation, followed by the determination of the Pt content of the filtrate. Due to practical reasons, the HMF is derived from the difference of the two obtained Pt amounts provided that the mass balance of the procedure is complete. The recovery of the free drug from diluted drug standards was poor being $<10 \%$ for one drug and $<60 \%$ for the second, depending on the preconditioning solution used. The LOD values were lower by a factor of 10 compared to the SEC strategy. Although it is a straightforward method, the often encountered poor recoveries of the metal-based drugs and the lack of clear identification of the products being measured deemed this approach less than adequate.

The development and use of CE coupled to ICP-MS has always been limited by the difficulties in interfacing the two methods, due to the low flow rate in CE and the high uptake rate of the nebuliser, the small sample volumes used, which put high demands on detector sensitivity and the requirement to maintain the electrical circuit required for efficient separations. The group of Hartinger has been instrumental in the study of metallodrugs and have development an improved CE coaxial sheath-flow interface (CFSI) for use in the study of the properties and mode of action of various metal containing drugs using ICP-MS detection ${ }^{216}$. Modification of a commercially available CFSI using a simple PTFE-based end-cap improved the analytical performance and sensitivity compared to a commercially available coupling device. The design of the spray chamber end-cap incorporated carrier gas delivery through the sprayer and allowed grounding of the electrical circuit, as well as providing a connection for the required make-up gas. Using the separation of the Pt containing anticancer drug cisplatin (100 $\mu \mathrm{mol} \mathrm{L}^{-1}$ in $\mathrm{NaCl}$ solution) as an example, they optimised the main sample introduction parameters including: capillary positioning within the sprayer; the 
sheath liquid flow rate and the carrier gas flow rate. In comparison to a commercially available CEI100 MCN interface (CETAC, Technologies, USA) it performed well and although giving broader and smaller peaks the S/N ratio was improved (702 compared to 80 ) which afforded an LOD of 2.1 compared to $4.6 \mu \mathrm{mol} \mathrm{L}{ }^{-1}$ for the $\mathrm{CEI}-100$. The authors also reported that their design was less prone to clogging, which allowed for greater sample throughput, which is often required in pharmacokinetic studies. The CFSI was successfully used to develop a metallomic approach to the rapid screening of metallodrugs to determine their metabolites and how they interact with serum proteins ${ }^{217}$. By coating the CE capillary with poly(vinyl pyrrolidone) to prevent protein-capillary surface interactions, which can block the capillary, it was possible to improve the resolution of adducts of cisplatin and RAPTA-C, containing Pt and RU respectively, with albumin and transferrin. Detection by UV was used to optimise the separation, prior to quantification of the adducts using ICP-MS with a Co containing compound, tris(acetylacetonato)cobalt(III), as internal standard. Identification of the adducts was confirmed using CE coupled to a Bruker microTOF-Q II ES-MS instrument. A third study by the group, once again used CE-ICP-MS with coupling using the CSFI, but this time to explore the lipophilicity and biological activity of Ru-anticancer drugs using microemulsion electrokinetic chromatography (MEEKC) ${ }^{218}$. This micelle-based separation method uses a phosphate buffer with addition of SDS, 1-butanol and heptane, with sonication to produce microemulsion oil droplets, which act as a stationary phase. As a result, additional analyte separation is achieved due to different partitioning between the aqueous or surfactant aggregate phase. This approach can separate neutral species, such as the widely used Pt-based anticancer agents cisplatin, carboplatin and oxaliplatin, which would otherwise not be amenable to CE.

\section{$5 \quad$ Abbreviations used in this update}

\begin{tabular}{|l|l|}
\hline$A B$ & arsenobetaine \\
\hline Ab-AuNCs & antibody-conjugated gold nanoclusters \\
\hline$A C$ & arsenocholine \\
\hline AEC & anion exchange chromatography \\
\hline AFS & atomic fluorescence spectrometry \\
\hline API & active pharmaceutical ingredient \\
\hline ASE & accelerated solvent extraction \\
\hline ASU & Atomic Spectrometry Update \\
\hline BDE & brominated diphenyl ether \\
\hline CE & capillary electrophoresis \\
\hline
\end{tabular}




\begin{tabular}{|c|c|}
\hline $\mathrm{ClC}$ & compound independent calibration \\
\hline ClEF & capillary isoelectric focusing \\
\hline CPE & cloud point extraction \\
\hline CRM & certified reference material \\
\hline CSF & cerebral spinal fluid \\
\hline CV & cold vapour \\
\hline Cys & cysteine \\
\hline CZE & capillary zone electrophoresis \\
\hline DBT & dibutyltin \\
\hline DDTP & diethyl- \\
\hline DIT & dithiophosphoric acid \\
\hline DMA & dimethylarsenic \\
\hline DMDTA $^{v}$ & dimethyldithioarsinic acid \\
\hline DMMTA & dimethylmonothioarsinic acid \\
\hline DMMTA $^{V}$ & dimethylmonothiolated arsinic acid \\
\hline DSPME & dispersive solid phase microextraction \\
\hline DTPA & diethylenetriaminepentaacetic acid \\
\hline DTT & dithiothreitol \\
\hline EDTA & ethylenediaminetetraacetic acid \\
\hline EDX & energy dispersive X-ray \\
\hline EPA & environmental protection agency \\
\hline ERM & European Reference Material \\
\hline ES & electrospray \\
\hline ETAAS & electrothermal atomic absorption spectrometry \\
\hline EtHg & ethylmercury \\
\hline ETV & electrothermal vaporisation \\
\hline FAAS & flame atomic absorption spectrometry \\
\hline $\mathrm{FI}$ & flow injection \\
\hline FT & Fourier transform \\
\hline GC & gas chromatography \\
\hline GE & gel electrophoresis \\
\hline GFAAS & graphite furnace atomic absorption spectrometry \\
\hline GPx & gluthatione peroxidase \\
\hline GST & gutathione-S-transferase \\
\hline HEP & heparin sepharose \\
\hline HEPES & 4-(2-hydroxyethyl)piperazine-1-ethanesulfonic acid \\
\hline HERFD & high-energy fluorescence detection \\
\hline HG & hydride generation \\
\hline HPLC & high performance liquid chromatography \\
\hline HR & high resolution \\
\hline
\end{tabular}




\begin{tabular}{|c|c|}
\hline IAEA & International Atomic Energy Agency \\
\hline IC & ion chromatography \\
\hline ICP-MS & inductively coupled plasma mass spectrometry \\
\hline ICP-OES & inductively coupled plasma optical emission spectrometry \\
\hline ICR & ion cyclotron resonance \\
\hline ID & isotope dilution \\
\hline IDA & isotope dilution analysis \\
\hline IEF & isoelectric-focusing electrophoresis \\
\hline iHg & inorganic mercury \\
\hline IMAC & immobilised metal affinity chromatography \\
\hline INAA & Instrumental Neutron Activation Analysis \\
\hline iSe & inorganic selenium \\
\hline ISO & International Standards Organisation \\
\hline LA & laser ablation \\
\hline LC & liquid chromatography \\
\hline LLME & liquid-liquid microextraction \\
\hline LOD & limit of detection \\
\hline LOQ & limit of quantification \\
\hline LPME & liquid phase microextraction \\
\hline MAE & microwave assisted extraction \\
\hline MALDI & matrix-assisted laser desorption ionization \\
\hline MBT & monobutyltin \\
\hline MC & multicollector \\
\hline $\mathrm{MeHg}$ & methylmercury \\
\hline $\mathrm{MeOH}$ & methanol \\
\hline MeSeCys & methylselenocysteine \\
\hline MMA & monomethylarsenic \\
\hline MMMTA & monomethylmonothioarsonic acid \\
\hline MPS & sodium 3-mercapto-1-propysulfonate \\
\hline MS & mass spectrometry \\
\hline MT & metallothionein \\
\hline MWCNT & multiwalled carbon nanotubes \\
\hline NIST & National Institute of Standards and Technology \\
\hline NMIJ & National Measurement Institute of Japan \\
\hline NMR & nuclear magnetic resonance \\
\hline NP & nanoparticle \\
\hline NRCC & National Research Council of Canada \\
\hline ODMIM & 1-octyl-3-methylimidazolium chloride \\
\hline Org-Hg & organo mercury \\
\hline PBDE & polybrominated diphenyl ether \\
\hline
\end{tabular}

Page 85 of 96 


\begin{tabular}{|c|c|}
\hline PCR & polymerase chain reaction \\
\hline PEEK & polyetheretherketone \\
\hline PET & polyethyleneterephthalate \\
\hline PHE & phenylalanine \\
\hline $\mathrm{PhHg}$ & phenylmercury \\
\hline PM & particulate material \\
\hline PTFE & Polytetrafluoroethylene \\
\hline PTV & programmed temperature vaporisation \\
\hline PVP & Polyvinylpyrrolidone \\
\hline Pyr & pyrolysis \\
\hline Q & quadrupole \\
\hline QA & quality assurance \\
\hline QC & quality control \\
\hline REE & rare earth element \\
\hline RIXS & resonant inelastic X-ray scattering \\
\hline RM & reference material \\
\hline RP & reverse phase \\
\hline SDBS & sodium dodecylbenzene sulfonate \\
\hline SDS & sodium dodecyl sulfate \\
\hline SDVB & styrenedivinylbenzene \\
\hline SEC & size exclusion chromatography \\
\hline SeCys & selenocysteine \\
\hline SeCys2 & selenocystine \\
\hline Se-Cyst & selenocysteine \\
\hline SelAl & selenoalbumin \\
\hline SelP & selenoprotein \\
\hline SEM & scanning electron microscopy \\
\hline SeMet & selenomethionein \\
\hline SeSug & selenosugar \\
\hline SF & sector field \\
\hline SIMS & secondary ion mass spectrometry \\
\hline Sp & single particle \\
\hline SPE & solid phase extraction \\
\hline SPME & solid phase microextraction \\
\hline SRM & standard reference material \\
\hline SR-XANES & synchrotron radiation $\mathrm{X}$-ray absorption near edge structure \\
\hline ssIDMS & species specific isotope dilution mass spectrometry \\
\hline sulDA & species unspecific isotope dilution analysis \\
\hline SXRF & synchrotron XRF microscopy \\
\hline TBAH & tetrabutylammonium hydroxide \\
\hline
\end{tabular}

Page 86 of 96 


\begin{tabular}{|l|l|}
\hline TBT & tributyltin \\
\hline TEM & transmission electron microscopy \\
\hline THg & total mercury \\
\hline THI & thiomersal \\
\hline TLC & thin layer chromatography \\
\hline TMAH & tetramethylammonium hydroxide \\
\hline TMAO & trimethylarsine oxide \\
\hline TMSe & trimethylselenonium \\
\hline TOF & time of flight \\
\hline Tris & tris(hydroxymethyl)aminomethane \\
\hline TSA & 2-thiosalicylic acid \\
\hline TXRF & total reflection X-ray fluorescence \\
\hline UAE & ultrasound assisted extraction \\
\hline UF & ultrafiltration \\
\hline UHPLC & ultra high performance liquid chromatography \\
\hline UV & ultraviolet \\
\hline WDXRF & wavelength dispersive X-ray fluorescence \\
\hline XANES & X-ray absorption near-edge structure \\
\hline XRD & X-ray fluorescence \\
\hline XRF & \\
\hline
\end{tabular}

\section{References}

1 R. Clough, C. F. Harrington, S. J. Hill, Y. Madrid and J. F. Tyson, J. Anal. At. Spectrom., 2018, 33(7), 1103-1149.

2 O. T. Butler, W. R. L. Cairns, J. M. Cook, C. M. Davidson and R. Mertz-Kraus, J. Anal. At. Spectrom., 2018, 33(1), 8-56.

3 A. Taylor, N. Barlow, M. P. Day, S. Hill, N. Martin and M. Patriarca, J. Anal. At. Spectrom., 2018, 33(3), 338-382.

4 E. H. Evans, J. Pisonero, C. M. M. Smith and R. N. Taylor, J. Anal. At. Spectrom., 2018, 33(5), 684-705.

5 C. Vanhoof, J. R. Bacon, A. T. Ellis, L. Vincze and P. Wobrauschek, J. Anal. At. Spectrom., 2018, 33(9), 1413-1431.

6 S. Carter, R. Clough, A. Fisher, B. Gibson, B. Russell and J. Waack, J. Anal. At. Spectrom., 2018, 33(11), 1802-1848.

7 M. A. Z. Arruda, Metallomics The Science of Biometals, Vol. 1055, 2018.

8 W. Maret, in Metallomics: The Science of Biometals, Vol. 1055, ed. M. A. Z. Arruda, 2018, pp. $1-20$. 
A. Sussulini and R. A. Hauser-Davis, in Metallomics: The Science of Biometals, Vol. 1055, ed. M. A. Z. Arruda, 2018, pp. 21-37.

V. L. Dressler, E. I. Muller and D. Pozebon, in Metallomics: The Science of Biometals, Vol. 1055, ed. M. A. Z. Arruda, 2018, pp. 139-181.

11 Y. F. Li, J. T. Zhao, Y. X. Gao, C. Y. Chen and Z. F. Chai, in Metallomics: The Science of Biometals, Vol. 1055, ed. M. A. Z. Arruda, 2018, pp. 213-243.

12 J. R. de Jesus, L. F. da Costa, E. L. Lehmann, R. M. Galazzi, K. C. Madrid and M. A. Z. Arruda, in Metallomics: The Science of Biometals, Vol. 1055, ed. M. A. Z. Arruda, 2018, pp. 183-211.

13 J. Feldmann, K. Bluemlein, E. M. Krupp, M. Mueller and B. A. Wood, in Metallomics: The Science of Biometals, Vol. 1055, ed. M. A. Z. Arruda, 2018, pp. 67-100.

14 C. P. Braga, J. Adamec and P. D. Padilha, in Metallomics: The Science of Biometals, Vol. 1055, ed. M. A. Z. Arruda, 2018, pp. 101-110.

15 G. Rodriguez-Moro, S. Ramirez-Acosta, A. Arias-Borrego, T. Garcia-Barrera and J. L. GomezAriza, in Metallomics: The Science of Biometals, Vol. 1055, ed. M. A. Z. Arruda, 2018, pp. 3966.

M. Montes-Bayon and J. Bettmer, in Metallomics: The Science of Biometals, Vol. 1055, ed. M. A. Z. Arruda, 2018, pp. 111-137.

17 J. Jimenez-Lamana, J. Szpunar and R. Lobinski, in Metallomics: The Science of Biometals, Vol. 1055, ed. M. A. Z. Arruda, 2018, pp. 245-270.

18 D. P. Bishop, D. J. Hare, D. Clases and P. A. Doble, Trac-Trends in Analytical Chemistry, 2018, 104, 11-21.

19 B. Klencsar, S. W. Li, L. Balcaen and F. Vanhaecke, Trac-Trends in Analytical Chemistry, 2018, 104, 118-134.

20 J. Feldmann, A. Raab and E. M. Krupp, Anal. Bioanal. Chem., 2018, 410(3), 661-667.

21 D. F. Anagnostopoulos, Spectrochim. Acta, Part B, 2018, 148, 83-91.

22 M. R. Beccia, P. L. Solari, M. Monfort, C. Moulin and C. Den Auwer, New J. Chem., 2018, 42(10), 7582-7591.

23 J. I. Pacold, A. B. Altman, K. B. Knight, K. S. Holliday, M. J. Kristo, S. G. Minasian, T. Tyliszczak, C. H. Booth and D. K. Shuh, Analyst, 2018, 143(6), 1349-1357.

24 Z. R. Zou, Y. J. Deng, J. Hu, X. M. Jiang and X. D. Hou, Anal. Chim. Acta, 2018, 1019, 25-37.

25 F. J. Xu, J. Hu, J. Y. Zhang, X. D. Hou and X. M. Jiang, Applied Spectroscopy Reviews, 2018, 53(2-4), 333-348.

26 I. Karadjova, I. Dakova, T. Yordanova and P. Vasileva, J. Anal. At. Spectrom., 2016, 31(10), 1949-1973.

27 D. Clases, M. Sperling and U. Karst, Trac-Trends in Analytical Chemistry, 2018, 104, 135-147.

28 S. G. Sama, C. Barrere-Mangote, B. Bouyssiere, P. Giusti and R. Lobinski, Trac-Trends in Analytical Chemistry, 2018, 104, 69-76.

29 B. Meermann and V. Nischwitz, J. Anal. At. Spectrom., 2018, 33(9).

30 I. Lanekoff and J. Laskin, in Advances in Chromatography, Vol 54, Vol. 54, ed. E. Grushka, N. Grinberg, 2018, pp. 43-72.

31 E. Vassileva, S. Azemard and P. Mandjukov, Accreditation and Quality Assurance, 2018, 23(1), 29-37.

32 W. A. Maher, F. Krikowa, S. D. Foster, M. J. Ellwood and W. W. Bennett, J. Anal. At. Spectrom., 2018, 33(5), 706-712.

Page 88 of 96 
A. Maratta, B. Carrizo, V. L. Bazan, G. Villafane, L. D. Martinez and P. Pacheco, J. Anal. At. Spectrom., 2018, 33(12), 2195-2202.

W. J. Guo, Z. Y. Fu, H. Wang, F. H. Song, F. C. Wu and J. P. Giesy, Microchem. J., 2018, 137, 181-189.

L. Ye, S. X. Qiu, X. H. Li, Y. X. Jiang and C. Y. Jing, Sci. Total Environ., 2018, 640, 1-8.

Z. J. Wu, J. Cheng, X. J. Guo, C. G. Ding, X. Jin, Q. D. Ren, M. Zheng, L. Wang and W. J. Zhao, Toxicology, 2018, 408, 46-53.

M. Rubio, M. F. Mera, C. A. Perez and F. C. Vicentin, X-Ray Spectrom., 2018, 47(2), 171-175.

J. Werner, T. Grzeskowiak, A. Zgola-Grzeskowiak and E. Stanisz, Trac-Trends in Analytical Chemistry, 2018, 105, 121-136.

J. C. Fei, T. Wang, Y. Y. Zhou, Z. X. Wang, X. B. Min, Y. Ke, W. Y. Hu and L. Y. Chai, Chemosphere, 2018, 207, 665-675.

41 Q. Q. Liu, X. F. Lu, H. Y. Peng, A. Popowich, J. Tao, J. S. Uppal, X. W. Yan, D. Boe and X. C. Le, Trac-Trends in Analytical Chemistry, 2018, 104, 171-182.

I. Herath, M. Vithanage, S. Seneweera and J. Bundschuh, Environ. Int., 2018, 115, 370-386. H. Lee, Y. T. Kim, S. Jeong and H. O. Yoon, Jove-Journal of Visualized Experiments, 2018(133). S. A. Rabb, M. D. Le and L. L. Yu, Microchem. J., 2018, 143, 133-139.

H. Y. Cheng, L. H. Shen, J. H. Liu, Z. G. Xu and Y. C. Wang, J. Sep. Sci., 2018, 41(7), 1524-1531. J. R. Huang, P. Li, J. H. Wen, X. Hu, Y. J. Chen, D. H. Yin and H. Z. Lian, Spectrosc. Lett., 2018, 51(6), 252-256.

47 G. Gilmartin and D. Gingrich, J. Chromatogr. B, 2018, 1083, 20-27.

48 F. Pena-Pereira, L. Villar-Blanco, I. Lavilla and C. Bendicho, Anal. Chim. Acta, 2018, 1011, 110.

49 K. Marschner, S. Musil, I. Miksik and J. Dedina, Anal. Chim. Acta, 2018, 1008, 8-17.

50 E. Lukojko, E. Talik, A. Gagor and R. Sitko, Anal. Chim. Acta, 2018, 1008, 57-65.

51 C. K. Su and W. C. Chen, Microchimica Acta, 2018, 185(5).

52 A. Kana, Z. Klimsova and O. Mestek, Talanta, 2019, 192, 86-92.

53 F. Yang, S. W. Xie, C. Y. Wei and J. X. Liu, Spectrosc. Spectr. Anal., 2018, 38(6), 1884-1888.

54 C. Zaccone, D. Lobianco, G. Raber, V. D'Orazio, W. Shotyk, T. M. Miano and K. Francesconi, Sci. Total Environ., 2018, 621, 67-74.

55 S. Hong, S. D. Choi and J. S. Khim, Environ. Pollut., 2018, 237, 842-850.

56 K. Nan, M. He, B. B. Chen, Y. J. Chen and B. Hu, Talanta, 2018, 183, 48-54.

57 X. R. Guo, Y. G. Yin, Z. Q. Tan, J. F. Liu and G. B. Jiang, Acta Chim. Sinica, 2018, 76(5), 387-392.

58 F. Yang, S. W. Xie, C. Y. Wei, J. X. Liu, H. Z. Zhang, T. Chen and J. Zhang, Sci. Total Environ., 2018, 626, 77-86.

59 I. Allegretta, C. Porfido, M. Martin, E. Barberis, R. Terzano and M. Spagnuolo, Environ. Sci. Pollut. Res., 2018, 25(25), 25080-25090.

60 P. N. Gamaletsos, S. Kalatha, A. Godelitsas, M. Economou-Eliopoulos, J. Gottlicher and R. Steininger, J. Geochem. Explor., 2018, 194, 189-197.

61 L. Pierre, B. Marc, J. Amelie, R. Jean-Pascal, D. Manoj, M. Guillaume and C. Delphine, J. Anal. At. Spectrom., 2018, 33(12), 2070-2082. 
M. K. Ullrich, F. Gelman, Y. Zakon, L. Halicz, K. Knoller and B. Planer-Friedrich, Chem. Geol., 2018, 477, 92-99.

S. L. Zhao, Y. F. Duan, C. Chen, H. Wu, D. Y. Liu, M. Liu, J. H. Lu and X. B. Gu, Energy Fuels, 2018, 32(5), 6049-6055.

F. Yang, S. W. Xie, J. X. Liu, C. Y. Wei, H. Z. Zhang, T. Chen and J. Zhang, Chemosphere, 2018, 193, 777-784.

R. L. Chaney, C. E. Green and S. J. Lehotay, Anal. Bioanal. Chem., 2018, 410(22), 5703-5710.

Y. Wang, Y. Q. Li, K. Lv, X. L. Chen and X. Y. Yu, Spectrochim. Acta, Part B, 2018, 149, 197-202.

X. X. Wang, W. J. Sun, S. Zhang, H. Sharifan and X. M. Ma, Environ. Sci. Technol., 2018, 52(17), 10040-10047.

N. W. Sadiq and D. Beauchemin, Anal. Chem., 2017, 89(24), 13299-13304.

R. Guillod-Magnin, B. J. Bruschweiler, R. Aubert and M. Haldimann, Food Addit. Contam. Part A-Chem., 2018, 35(6), 1164-1178.

W. Maher, E. Duncan, H. Martin, P. Snell, F. Krikowa, R. Jagtap, S. Foster, T. Ezaz and M. J. Ellwood, Environ. Chem., 2018, 15(7), 387-402.

S. G. Lee, D. H. Kim, Y. S. Lee, S. Y. Cho, M. S. Chung, M. Cho, Y. Kang, H. Kim, D. Kim and K. W. Lee, J. Food Compost. Anal., 2018, 69, 25-32.

H. Rasheed, P. Kay, R. Slack and Y. Y. Gong, Sci. Total Environ., 2018, 634, 366-373.

M. B. Shakoor, I. Bibi, N. K. Niazi, M. Shahid, M. F. Nawaz, A. Farooqi, R. Naidu, M. M. Rahman, G. Murtaza and A. Luttge, Chemosphere, 2018, 199, 737-746.

F. Zhao, Y. M. Liu, X. Q. Zhang, R. Dong, W. J. Yu, Y. F. Liu, Z. M. Guo, X. M. Liang and J. H. Zhu, J. Chromatogr., 2018, 1573, 48-58.

75 Y. Gao, P. Baisch, N. Mirlean, F. M. R. da Silva, N. Van Larebeke, W. Baeyens and M. Leermakers, Chemosphere, 2018, 191, 89-96.

76 D. Guimaraes, A. A. Roberts, M. W. Tehrani, R. Huang, L. Smieska, A. R. Woll, S. Lin and P. J. Parsons, J. Anal. At. Spectrom., 2018, 33(10).

77 A. H. Petursdottir, J. R. de Jesus, H. Gunnlaugsdottir and J. Feldmann, J. Anal. At. Spectrom., 2018, 33(1), 102-110.

78 A. H. Petursdottir and H. Gunnlaugsdottir, Microchem. J., 2019, 144, 45-50.

79 L. Schmidt, J. A. Landero, D. L. Novo, F. A. Duarte, M. F. Mesko, J. A. Caruso and E. M. M. Flores, Food Chem., 2018, 255, 340-347.

80 S. Braeuer, J. Borovicka and W. Goessler, Anal. Bioanal. Chem., 2018, 410(9), 2283-2290.

81 S. Braeuer, J. Borovicka, T. Glasnov, G. G. de la Cruz, K. B. Jensen and W. Goessler, Talanta, 2018, 188, 107-110.

82 S. Y. Chen, B. A. Yuan, J. J. Xu, G. T. Chen, Q. H. Hu and L. Y. Zhao, Food Chem., 2018, 262, 134-141.

83 S. Y. Chen, J. J. Xu, G. T. Chen, Q. H. Hu and L. Y. Zhao, Anal. Lett., 2018, 51(13), 2141-2155.

84 L. X. Guo, G. W. Zhang, Q. Q. Li, X. M. Xu and J. H. Wang, Molecules, 2018, 23(11).

85 C. D. Quarles, P. Sullivan, M. P. Field, S. Smith and D. R. Wiederin, J. Anal. At. Spectrom., 2018, 33(5), 745-751.

86 C. B. Jiang, Y. M. Hsueh, G. L. Kuo, C. H. Hsu, J. H. Chang and L. C. Chien, Medicine, 2018, 97(43).

87 M. H. Nguyen, T. D. Pham, T. L. Nguyen, H. A. Vu, T. T. Ta, M. B. Tu, T. H. Y. Nguyen and D. B. 
Chu, J. Anal. Methods Chem., 2018.

88 F. Gonzalez-Martinez, D. Sanchez-Rodas, D. D. Caceres, M. F. Martinez, L. A. Quinones and

B. Johnson-Restrepo, Chemosphere, 2018, 212, 927-936.

B. W. Chen, F. L. Cao, X. F. Lu, S. W. Shen, J. Zhou and X. C. Le, Talanta, 2018, 184, 446-451.

90 P. Balakrishnan, A. Navas-Acien, K. Haack, D. Vaidya, J. G. Umans, L. G. Best, W. Goessler, K. A. Francesconi, N. Franceschini, K. E. North, S. A. Cole, V. S. Voruganti and M. O. Gribble, Toxicol. Appl. Pharmacol., 2018, 348, 123-129.

91 C. Y. Huang, Y. C. Lin, H. S. Shiue, W. J. Chen, C. T. Su, Y. S. Pu, P. L. Ao and Y. M. Hsueh, Toxicol. Lett., 2018, 295, 64-73.

92 Y. C. Lin, W. J. Chen, C. Y. Huang, H. S. Shiue, C. T. Su, P. L. Ao, Y. S. Pu and Y. M. Hsueh, Toxicol. Sci., 2018, 164(1), 328-338.

93 A. R. Gliga, K. Engstrom, M. Kippler, H. Skroder, S. Ahmed, M. Vahter, R. Raqib and K. Broberg, Arch. Toxicol., 2018, 92(8), 2487-2500.

94 J. De Loma, H. Skroder, R. Raqib, M. Vahter and K. Broberg, Toxicol. Appl. Pharmacol., 2018, 357, 80-87.

95 Y. Zhou, H. B. Wang, E. Tse, H. Y. Li and H. Z. Sun, Anal. Chem., 2018, 90(17), 10465-10471.

96 Y. M. Hsueh, W. J. Chen, Y. C. Lin, C. Y. Huang, H. S. Shiue, S. M. Yang, P. L. Ao, Y. S. Pu and C. T. Su, Toxicol. Appl. Pharmacol., 2018, 350, 11-20.

97 Y. X. Li, B. B. Chen, M. He and B. Hu, Talanta, 2018, 188, 210-217.

98 M. Ruiz-de-Cenzano, P. Cava-Montesinos, M. L. Cervera and M. de la Guardia, Int. J. Food Sci. Technol., 2017, 52(12), 2531-2537.

99 S. H. Son, W. B. Lee, D. Kim, Y. Lee and S. H. Nam, Food Chem., 2019, 270, 353-358.

100 R. Nogueira, E. A. Melo, J. L. C. Figueiredo, J. J. Santos and A. P. D. Neto, J. Braz. Chem. Soc., 2018, 29(8), 1593-1600.

101 S. Cui, C. K. Kim, K. S. Lee, H. S. Min and J. H. Lee, Microchem. J., 2018, 143, 16-20.

102 L. X. Guo, G. W. Zhang, J. T. Wang, Y. P. Zhong and Z. G. Huang, Molecules, 2018, 23(5).

103 L. Zhou, S. Wang, Q. X. Hao, L. P. Kang, C. Z. Kang, J. Yang, W. Z. Yang, J. Y. Jiang, L. Q. Huang and L. P. Guo, Chin. Med., 2018, 13.

104 T. Narukawa, T. Iwai and K. Chiba, Anal. Sci., 2018, 34(6), 687-691.

105 V. Vacchina, E. N. Epova, S. Berail, B. Medina, O. F. X. Donard and F. Seby, Food Additives \& Contaminants Part B-Surveillance, 2018, 11(4), 286-292.

106 S. Torres, L. D. Martinez and P. H. Pacheco, J. Food Compost. Anal., 2018, 66, 121-126.

107 R. F. Milani, E. L. de Paiva, L. I. Peron, M. A. Morgano and S. Cadore, Lwt-Food Science and Technology, 2018, 98, 606-612.

108 H. M. Yu, H. Du, L. Wu, R. L. Li, Q. Sun and X. D. Hou, Microchem. J., 2018, 141, 176-180.

109 M. R. Letsoalo, T. W. Godeto, T. Magadzu and A. A. Ambushe, Anal. Lett., 2018, 51(17), 27612775.

110 Y. Shi and A. Chatt, J. Radioanal. Nucl. Chem., 2018, 318(1), 785-795.

111 S. Z. Chen, S. P. Zhu and D. B. Lu, Spectrochim. Acta, Part B, 2018, 139, 70-74.

112 E. M. Hamilton, S. D. Young, E. H. Bailey and M. J. Watts, Food Chem., 2018, 250, 105-112.

113 F. Seby and V. Vacchina, Trac-Trends in Analytical Chemistry, 2018, 104, 54-68.

114 M. B. Arain, I. Ali, E. Yilmaz and M. Soylak, Trac-Trends in Analytical Chemistry, 2018, 103, 44-55.

Page 91 of 96 
115 A. Drincic, T. Zuliani, J. Scancar and R. Milacic, Sci. Total Environ., 2018, 637, 1286-1294.

116 K. Shigeta, A. Fujita, T. Nakazato and H. Tao, Anal. Sci., 2018, 34(8), 925-932.

117 A. A. Shaltout, M. Harfouche, S. I. Ahmed, M. Czyzycki and A. G. Karydas, Microchem. J., 2018, 137, 78-84.

118 K. Karas and M. Frankowski, Molecules, 2018, 23(11).

119 R. Pechancova, T. Pluhacek, J. Gallo and D. Milde, Talanta, 2018, 185, 370-377.

120 I. Aharchaou, J. S. Py, S. Cambier, J. L. Loizeau, G. Cornelis, P. Rousselle, E. Battaglia and D. A.

L. Vignati, Environ. Toxicol. Chem., 2018, 37(4), 983-992.

121 J. K. de Andrade, C. K. de Andrade, M. L. Felsner and V. E. dos Anjos, Talanta, 2019, 191, 94102.

122 A. Akhtar, T. G. Kazi, H. I. Afridi, M. Khan, M. Bilal and N. Khan, Journal of Industrial and Engineering Chemistry, 2018, 59, 320-327.

123 I. Lopez-Garcia, J. J. Marin-Hernandez and M. Hernandez-Cordoba, J. Anal. At. Spectrom., 2018, 33(9), 1529-1535.

124 E. Aksoy, S. G. Elci, A. N. Siyal and L. Elci, Acta Chimica Slovenica, 2018, 65(3), 512-520.

125 J. Malejko, N. Swierzewska, A. Bajguz and B. Godlewska-Zylkiewicz, Spectrochim. Acta, Part $B, 2018,142,1-7$.

126 Y. Yang, L. Luo, H. P. Li, Q. Wang, Z. G. Yang, Z. P. Qu and R. Ding, Talanta, 2018, 182, 156163.

127 J. Legat, M. Matczuk, A. R. Timerbaev and M. Jarosz, Anal. Bioanal. Chem., 2018, 410(3), 1151-1156.

128 A. Garcia-Figueroa, F. Pena-Pereira, I. Lavilla and C. Bendicho, Talanta, 2019, 193, 176-183.

129 C. L. Bromley, A. Raab, S. Parker-Nance, D. R. Beukes, M. Jaspars and M. T. Davies-Coleman, South African Journal of Chemistry-Suid-Afrikaanse Tydskrif Vir Chemie, 2018, 71, 111-117.

130 H. S. Doh and H. J. Park, J. Food Sci., 2018, 83(6), 1579-1587.

131 C. Zhang, X. Q. Li, Y. L. Chen, C. Wei, X. M. Li and Q. H. Zhang, J. Chromatogr., 2018, 1576, 120-130.

132 M. Bergant, R. Milacic and J. Scancar, J. Chromatogr., 2018, 1572, 112-118.

133 K. Y. Zheng, M. J. Dolan, P. J. Haferl, H. Badiei and K. Jorabchi, Anal. Chem., 2018, 90(3), 21482154.

134 J. Renpenning, A. Horst, M. Schmidt and M. Gehre, J. Anal. At. Spectrom., 2018, 33(2), 314321.

135 G. AlChoubassi, J. Aszyk, P. Pisarek, K. Bierla, L. Ouerdane, J. Szpunar and R. Lobinski, TracTrends in Analytical Chemistry, 2018, 104, 77-86.

136 D. M. Krauze, M. Grzelak, P. Wrobel, G. Veronesi, H. Castillo, L. Chmura, D. Adamek, R. Jach and M. Lankosz, J. Anal. At. Spectrom., 2018, 33(10), 1638-1644.

137 N. Dziuba, J. Hardy and P. A. Lindahl, Metallomics, 2018, 10(6), 802-817.

138 J. G. Fernandez, C. Sanchez-Gonzalez, J. Bettmer, J. Llopis, N. Jakubowski, U. Panne and M. Montes-Bayon, Anal. Chim. Acta, 2018, 1039, 24-30.

139 A. Alikhani, M. Eftekhari, M. Chamsaz and M. Gheibi, Journal of Food Measurement and Characterization, 2018, 12(1), 573-580.

140 R. A. Campos, P. R. Patricio, S. J. R. Vargas, L. H. M. Da Silva and M. C. Hespanhol, An. Acad. Bras. Cienc., 2018, 90(2), 1929-1944. 
141 Z. Gajdosechova, Z. Mester, J. Feldmann and E. M. Krupp, Trac-Trends in Analytical Chemistry, 2018, 104, 95-109.

142 J. Entwisle, D. Malinovsky, P. J. H. Dunn and H. Goenaga-Infante, J. Anal. At. Spectrom., 2018, 33(10), 1645-1654.

143 S. Bouchet, S. Berail and D. Amouroux, Anal. Chem., 2018, 90(13), 7809-7816.

144 H. Y. Cheng, X. P. Chen, L. H. Shen, Y. C. Wang, Z. G. Xu and J. H. Liu, J. Chromatogr., 2018, 1531, 104-111.

145 A. Londonio, P. E. Hasuoka, P. Pacheco, R. A. Gil and P. Smichowski, J. Anal. At. Spectrom., 2018, 33(10), 1737-1744.

146 A. C. Grijalba, P. Y. Quintas, E. F. Fiorentini and R. G. Wuilloud, J. Anal. At. Spectrom., 2018, 33(5), 822-834.

147 P. Strohmidel, M. Sperling and U. Karst, J. Trace Elem. Med Biol., 2018, 50, 100-104.

148 Q. Xu, Z. H. Wang, L. H. Jin, P. Liu, Y. Tian, S. X. Zhang and C. Q. Zhang, Anal. Methods, 2018, 10(18), 2144-2150.

149 Y. L. Zhang, M. Miro and S. D. Kolev, Talanta, 2018, 189, 220-224.

150 J. Teran-Baamonde, S. Bouchet, E. Tessier and D. Amouroux, J. Chromatogr., 2018, 1547, 7785.

151 X. S. Gao, J. Y. Dai, H. Y. Zhao, J. Zhu, L. Luo, R. Zhang, Z. Zhang and L. Li, RSC Adv., 2018, 8(33), 18364-18371.

152 O. Caylak, S. G. Elci, A. Hol, A. Akdogan, U. Divrikli and L. Elci, Food Chem., 2019, 274, 487493.

153 Q. He, X. K. Yu, Y. B. Li, H. J. He and J. Zhang, Microchem. J., 2018, 141, 148-154.

154 H. Liu, J. Y. Luo, T. Ding, S. Y. Gu, S. H. Yang and M. H. Yang, Biol. Trace Elem. Res., 2018, 186(2), 554-561.

155 M. W. Franco, L. A. Mendes, C. C. Windmoller, K. A. F. Moura, L. A. G. Oliveira and F. A. R. Barbosa, Water Air Soil Pollut., 2018, 229(4).

156 P. Coufalik, N. Meszarosova, K. Coufalikova, O. Zverina and J. Komarek, Microchem. J., 2018, 140, 8-13.

157 M. X. Bailon, A. S. David, Y. Park, E. Kim and Y. Hong, Environ. Monit. Assess., 2018, 190(5).

158 R. Akramipour, M. R. Golpayegani, S. Gheini and N. Fattahi, Talanta, 2018, 186, 17-23.

159 C. Wu, G. Q. Wu, Z. H. Wang, Z. J. Zhang, Y. Qian and L. Ju, Appl. Geochem., 2018, 89, 202209.

160 M. Senila, E. Covaci, O. Cadar, M. Ponta, M. Frentiu and T. Frentiu, Chemical Papers, 2018, 72(2), 441-448.

161 A. Sakanupongkul, R. Sananmuang, Y. Udnan, R. J. Ampiah-Bonney and W. C. Chaiyasith, Food Chem., 2019, 277, 496-503.

162 I. A. Pestana, W. R. Bastos, M. G. Almeida, M. H. Mussy and C. M. M. Souza, Chemosphere, 2019, 215, 758-765.

163 T. Narukawa, T. Iwai, K. Chiba and J. Feldmann, Anal. Sci., 2018, 34(11), 1329-1334.

164 J. R. Miranda-Andrades, S. Khan, C. A. T. Toloza, E. C. Romani, F. L. Freire and R. Q. Aucelio, Spectrochim. Acta, Part B, 2017, 138, 81-89.

165 L. A. Mendes, M. W. Franco, F. A. R. Barbosa, P. I. A. de Carvalho, J. C. de Lena and C. C. Windmoller, Anal. Methods, 2018, 10(1), 91-100. 
166 M. Liu, Z. Q. Gao, L. G. Chen, W. Zhao, Q. Lu, J. Yang, L. Ren and Z. C. Xu, Arch. Environ. Contam. Toxicol., 2018, 75(3), 495-501.

167 Y. Yang, Q. Tan, Y. Lin, Y. F. Tian, L. Wu, X. D. Hou and C. B. Zheng, Anal. Chem., 2018, 90(20), 11996-12003.

168 C. Willberger, S. Amayri and T. Reich, Electrophoresis, 2018, 39(23), 3013-3021.

169 P. A. Abramov, T. E. Romanova, V. V. Volchek, A. A. Mukhacheva, N. B. Kompankov and M. N. Sokolov, New Journal of Chemistry, 2018, 42(10), 7949-7955.

170 A. A. Shmakova, M. M. Akhmetova, V. V. Volchek, T. E. Romanova, I. Korolkov, D. G. Sheven, S. A. Adonin, P. A. Abramov and M. N. Sokolov, New J. Chem., 2018, 42(10), 7940-7948.

171 T. Yamamoto and A. Yukumoto, J. Anal. At. Spectrom., 2018, 33(4), 585-592.

172 R. K. Taggart, N. A. Rivera, C. Levard, J. P. Ambrosi, D. Borschneck, J. C. Hower and H. HsuKim, Environmental Science-Processes \& Impacts, 2018, 20(10), 1390-1403.

173 M. Y. Stuckman, C. L. Lopano and E. J. Granite, International Journal of Coal Geology, 2018, 195, 125-138.

174 K. L. LeBlanc, P. Kumkrong, P. H. J. Mercier and Z. Mester, Sci. Total Environ., 2018, 640, 16351651.

175 K. Bierla, S. Godin, R. Lobinski and J. Szpunar, Trac-Trends in Analytical Chemistry, 2018, 104, 87-94.

176 K. Bierla, R. Lobinski and J. Szpunar, Int. J. Mol. Sci., 2018, 19(2).

177 M. Kieliszek and S. Blazejak, Appl. Sci.-Basel, 2018, 8(11).

178 N. G. Turrini, N. Kroepfl, K. B. Jensen, T. C. Reiter, K. A. Francesconi, T. Schwerdtle, W. Kroutil and D. Kuehnelt, Metallomics, 2018, 10(10), 1532-1538.

179 W. Jin, C. Yoon, T. V. Johnston, S. Ku and G. E. Ji, Molecules, 2018, 23(11).

180 Y. Ogra, M. Shimizu, K. Takahashi and Y. Anan, Metallomics, 2018, 10(9), 1257-1263.

181 A. A. Krata, M. Wojciechowski, J. Karasinski and E. Bulska, Microchem. J., 2018, 143, 416-422.

182 Y. Fang, Y. Y. Zhang, M. Y. Wang, F. Pei, M. H. Xie, P. Li and Q. H. Hu, Food Funct., 2018, 9(8), 4493-4499.

183 Y. Jiang, A. F. El Mehdawi, Tripti, L. W. Lima, G. Stonehouse, S. C. Fakra, Y. G. Hu, H. Qi and E. A. H. Pilon-Smits, Frontiers in Plant Science, 2018, 9.

184 H. H. Gao, M. X. Chen, X. Q. Hu, S. S. Chai, M. L. Qin and Z. Y. Cao, J. Sep. Sci., 2018, 41(2), 432-439.

185 S. Bakirdere, M. Volkan and O. Y. Ataman, J. Food Compost. Anal., 2018, 71, 28-35.

186 Z. Cadkova, J. Szakova, J. Tremlova, O. Kopecky, O. Zila and P. Tlustos, Metallomics, 2018, 10(4), 579-586.

187 P. Heitland and H. D. Koster, Int. J. Hyg. Environ. Health, 2018, 221(3), 564-568.

188 S. Y. Lee and Y. N. Pak, Bull. Korean Chem. Soc., 2018, 39(8), 941-945.

189 Y. Liu, W. Zhang, J. T. Zhao, X. Y. Lin, J. M. Liu, L. W. Cui, Y. X. Gao, T. L. Zhang, B. Li and Y. F. Li, J. Trace Elem. Med Biol., 2018, 50, 589-595.

190 R. G. de Vega, M. Garcia, M. L. Fernandez-Sanchez, H. Gonzalez-Iglesias and A. Sanz-Medel, Metallomics, 2018, 10(1), 83-92.

191 Z. Touat-Hamici, A. L. Bulteau, J. Bianga, H. Jean-Jacques, J. Szpunar, R. Lobinski and L. Chavatte, Biochimica Et Biophysica Acta-General Subjects, 2018, 1862(11), 2493-2505.

192 T. Hu, L. P. Liu, S. Z. Chen, W. L. Wu, C. G. Xiang and Y. B. Guo, Anal. Lett., 2018, 51(14), 2316- 
2330.

193 Y. J. Zou, F. Du, H. J. Zhang and Q. X. Hu, Emirates Journal of Food and Agriculture, 2018, 30(8), 704-708.

194 J. Moreda-Pineiro, J. Sanchez-Pinero, A. Manana-Lopez, I. Turnes-Carou, E. AlonsoRodriguez, P. Lopez-Mahia and S. Muniategui-Lorenzo, Food Res. Int., 2018, 111, 621-630.

195 X. Q. Lu, Z. S. He, Z. Q. Lin, Y. Y. Zhu, L. X. Yuan, Y. Liu and X. B. Yin, Nutrients, 2018, 10(3).

196 B. Michalke and I. Vinkovic-Vrcek, J. Chromatogr., 2018, 1572, 162-171.

197 J. Gruszka, E. Zambrzycka-Szelewa, J. S. Kulpa and B. Godlewska-Zylkiewicz, J. Anal. At. Spectrom., 2018, 33(12), 2133-2142.

198 E. Novakova, J. Smolejova, T. Polozijova-Resslerova and J. Hranicek, Spectrochim. Acta, Part $B, 2018,149,294-299$.

199 Y. L. Jia, T. F. Xiao, J. L. Sun, F. Yang and P. C. Baveye, Sci. Total Environ., 2018, 630, 146-153.

200 W. T. Chen, S. J. Jiang and A. C. Sahayam, Microchem. J., 2018, 141, 104-109.

201 Y. Yao, F. Y. Zhang, M. Y. Wang, F. Liu, W. F. Liu, X. W. Li, D. D. Qin, X. H. Geng, X. X. Huang and P. Zhang, Environ. Exp. Bot., 2018, 155, 387-393.

202 M. Truskolaska and K. Jankowski, Int. J. Environ. Anal. Chem., 2018, 98(4), 295-307.

203 W. W. Bennett, E. Lombi, E. D. Burton, S. G. Johnston, P. Kappen, D. L. Howard and D. E. Canfield, J. Anal. At. Spectrom., 2018, 33(10), 1689-1699.

204 Naeemullah, M. Tuzen and T. G. Kazi, Journal of Industrial and Engineering Chemistry, 2018, 57, 188-192.

205 L. Cid-Barrio, F. Calderon-Celis, P. Abasolo-Linares, M. L. Fernandez-Sanchez, J. M. CostaFernandez, J. R. Encinar and A. Sanz-Meder, Trac-Trends in Analytical Chemistry, 2018, 104, 148-159.

206 A. F. Asensio, T. Iglesias, A. Cotarelo, M. Espina, E. Blanco-Gonzalez, L. M. Sierra and M. Montes-Bayon, Anal. Chim. Acta, 2018, 1023, 64-73.

207 B. Lajin and W. Goessler, Anal. Bioanal. Chem., 2018, 410(26), 6787-6793.

208 M. Cruz-Alonso, B. Fernandez, M. Garcia, H. Gonzalez-Iglesias and R. Pereiro, Anal. Chem., 2018, 90(20), 12145-12151.

209 B. Michalke, D. Willkommen, E. Drobyshev and N. Solovyev, Trac-Trends in Analytical Chemistry, 2018, 104, 160-170.

210 X. T. Yan, B. He, D. Y. Wang, L. G. Hu, L. H. Liu, C. Y. Liao and G. B. Jiang, Talanta, 2018, 184, 404-410.

211 F. Brulfert and J. Aupiais, Dalton Trans., 2018, 47(30), 9994-10001.

212 X. Yu, S. Wei, Y. X. Yang, Z. D. Ding, Q. Wang, J. T. Zhao, X. Q. Liu, X. Y. Chu, J. Tian, N. F. Wu and Y. L. Fan, Int. J. Biol. Macromol., 2018, 119, 597-603.

213 S. Li, Z. G. Yang, J. F. Cao, B. Qiu and H. P. Li, Chromatographia, 2018, 81(6), 881-889.

214 M. H. M. Klose, A. Schoberl, P. Heffeter, W. Berger, C. G. Hartinger, G. Koellensperger, S. M. Meier-Menches and B. K. Keppler, Monatsh. Chem., 2018, 149(10), 1719-1726.

215 L. Galvez, S. Theiner, M. Grabarics, C. R. Kowol, B. K. Keppler, S. Hann and G. Koellensperger, Anal. Bioanal. Chem., 2018, 410(27), 7211-7220.

216 H. U. Holtkamp, S. J. Morrow, M. Kubanik and C. G. Hartinger, J. Chromatogr., 2018, 1561, 76-82.

217 H. U. Holtkamp, S. Movassaghi, S. J. Morrow, M. Kubanik and C. G. Hartinger, Metallomics, 
2018, 10(3), 455-462.

218 K. Giringer, H. U. Holtkamp, S. Movassaghi, W. D. J. Tremlett, N. Y. S. Lam, M. Kubanik and C. G. Hartinger, Electrophoresis, 2018, 39(9-10), 1201-1207. 